Aus der Abteilung Psychiatrie und Psychotherapie

Prof. Dr. med. P. Falkai

im Zentrum Psychosoziale Medizin

der Medizinischen Fakultät der Universität Göttingen

\title{
Wechselwirkungen psychoemotionaler, neuroendokriner, immunologischer und dermatologischer Faktoren bei Patienten mit atopischer Dermatitis
}

\author{
INAUGURAL-DISSERTATION \\ zur Erlangung des Doktorgrades \\ der Medizinischen Fakultät \\ der Georg-August-Universität zu Göttingen
}

vorgelegt von

Carsten Schmidt

aus

Hildesheim

Göttingen 2006 
Dekan: Prof. Dr. med. C. Frömmel

I. Berichterstatter: Prof. Dr. rer. nat. Dr. med. habil. G. Hüther

II. Berichterstatter/in:

III. Berichterstatterlin:

Tag der mündlichen Prüfung: 


\section{Inhaltsverzeichnis}

1.

1.1

1.2

1.2.1

1.2 .2

1.2 .3

1.2.4

1.2 .5

1.2.6

1.2.7

1.3

2.

\section{Allgemeine Einleitung} 1

Beschreibung des Krankheitsbildes ..........................4

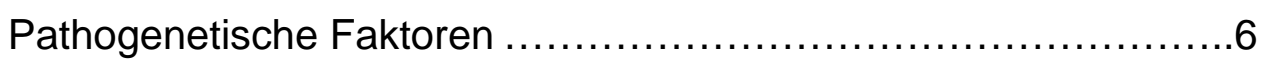

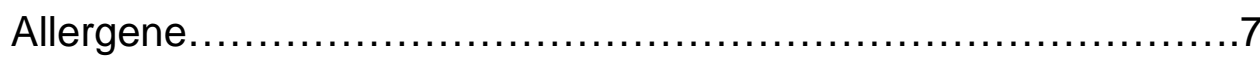

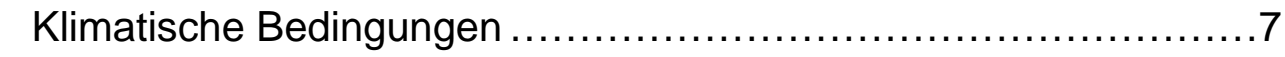

Funktionelle Hautveränderungen............................. 8

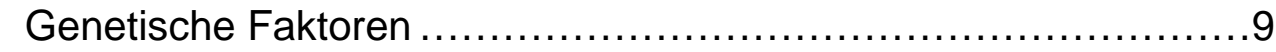

Immunologische Einflussfaktoren .......................... 11

Juckreiz und Kratzverhalten..................................

Psychoemotionale und neurovegetative Faktoren................18

Ziele der Arbeit - Arbeitsmodell - Fragestellung

Material und Methoden...........................................24

Die integrative naturalistische Einzelfallstudie $\ldots \ldots \ldots \ldots \ldots \ldots \ldots 24$

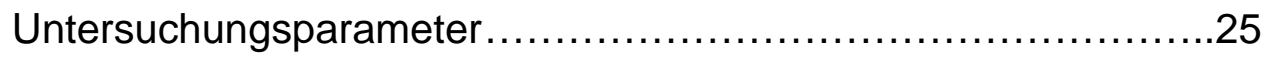

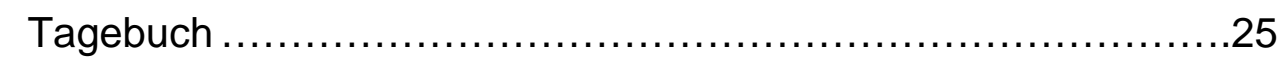

Fragebögen zur Erfassung der Persönlichkeit ..................25

Neuroendokrine und immunologische Parameter .................28

Laboranalytik - Bestimmungsverfahren .......................29

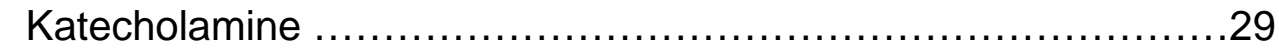

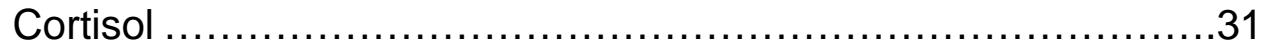

Neopterin und Kreatinin ....................................33

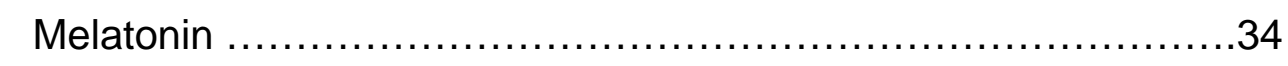

Auswertungsmethoden ..................................... 34

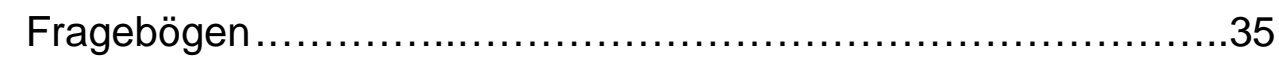

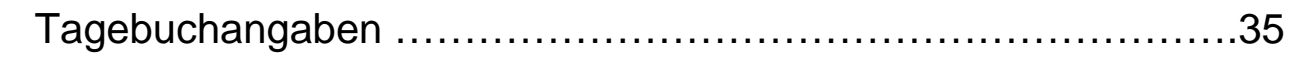

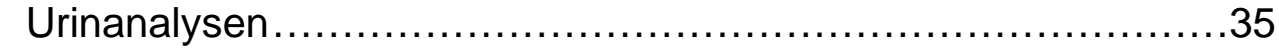

Mathematische Auswertungsverfahren - Allgemeines,

Zeitreihenanalyse, Kreuzkorrelationsanalyse 
3.

3.1.1 Darstellung des Hautzustandes und besonderer Ereignisse

3.1.2 Darstellung der statistischen Analysen der Residualzeitreihen

3.1.3 Darstellung der Ergebnisse der bivariaten

Kreuzkorrelationsanalyse nach Pearson 46

3.1.4 Darstellung und Beschreibung ausgewählter Zusammenhänge ...49

4. Patient AD04 - Allgemeine Beschreibung .51

Darstellung des Hautzustandes und besonderer Ereignisse .53 Darstellung der statistischen Analysen der Residual-Zeitreihen....55 Darstellung der Ergebnisse der bivariaten Kreuzkorrelationsanalyse nach Pearson 58 Darstellung und Beschreibung ausgewählter Zusammenhänge ...61 Ergebniszusammenfassung 63

Diskussion .65

Methodik, Vorgehensweise, Auswertungsverfahren .65 Zusammenhang zwischen Hautzustand und psychoemotionaler Befindlichkeit Zusammenhang zwischen Hautzustand und neuroendokrinen Faktoren Zusammenhang zwischen Hautzustand und Katecholaminen ....72 Zusammenhang zwischen Hautzustand und Cortisol .77 Zusammenhang zwischen Hautzustand und Immunsystem .......79 Zusammenhang zwischen Hautzustand und Melatonin ............82 Wechselwirkungen zwischen anderen Einflussfaktoren ............83 Schlussfolgerungen und Ausblick

.

Zusammenfassung .86

.

Anhang - ARIMA-Modelle, Tagebuch. .88

.




\section{Abkürzungsverzeichnis}

AAEDS: $\quad$ Allergic atopic eczema / dermatitis syndrome

AEDS: $\quad$ Atopic eczema / dermatitis syndrome

ACTH: $\quad$ Adrenocorticotrophes Hormon

APZ: $\quad$ Antigen-präsentierende Zellen

CGRP: $\quad$ Calcitonin gene related peptide

CLA: $\quad$ Cutaneous lymphozyte antigen

COX: Cyclooxygenase

$\mathrm{CRH}: \quad$ Corticotropin releasing hormone

DZ: Dendritische Zelle

GM-CSF: Granulozyte/macrophage-colony stimulating factor

HHNR: Hypothalamus-Hypophysen-Nebennierenrinde

HPLC: $\quad$ High pressure liquid chromatography

IFN- $\gamma: \quad$ Interferon- $\gamma$

Ig: Immunglobulin

IL: Interleukin

MDC: $\quad$ Macrophage-derived chemokine

MSH: Melanozyten stimulierendes Hormon

NAAEDS: Non allergic atopic eczema / dermatitis syndrome

NGF: $\quad$ Nerve growth factor

NNR: Nebennierenrinde

NOS: $\quad$ Nitritoxidsynthase

PAF: $\quad$ Platelet activating factor

PGE: $\quad$ Prostaglandin E

PNS: $\quad$ Peripheres Nervensystem

POMC: $\quad$ Pro-opiomelanocortin

RANTES: Regulation on activation, normal T cell expressed and secreted

SAM: $\quad$ Sympatho-adrenomedullär

SCD: $\quad$ Soluble cluster of differentiation

SCORAD: Scoring atopic dermatitis

SP: $\quad$ Substanz $P$

TARC: $\quad$ Thymus and activation regulated chemokine

TH: $\quad$ T-Helferzelle

TNF: $\quad$ Tumornekrosefaktor

VIP: $\quad$ Vasoaktives intestinales Peptid

ZNS: $\quad$ Zentrales Nervensystem 


\section{Allgemeine Einleitung}

Die atopische Dermatitis stellt eine chronische bzw. chronisch-rezidivierende Hautkrankheit dar, die zumeist mit einem ausgeprägten Juckreiz einhergeht. Die Erstmanifestation und der weitere Verlauf werden durch verschiedene Faktoren bestimmt, die auf noch ungeklärte Art und Weise mosaikartig zusammenwirken (Eichenfield 2004).

Dass bei der atopischen Dermatitis u. a. auch ein nervlicher bzw. seelischer Einfluss vorliegen könnte, kommt bereits 1891 in der damals von Brocq und Jaquet verwendeten Bezeichnung Neurodermitis zum Ausdruck (Buhk und Muthny 1997). Ontogenetisch betrachtet entwickeln sich sowohl das periphere und zentrale Nervensystem als auch die Haut aus dem ektodermalen Keimblatt (Benninghoff 1994a, S. 104-106), so dass eine unmittelbare wechselseitige Beeinflussung gut vorstellbar ist.

Der Begriff „atopische Dermatitis“ wurde 1933 von Wise und Sulzberger eingeführt (Leung 1991). Das Wort atopisch stammt aus dem griechischen und bedeutet „ungewöhnlich“, „seltsam“, „merkwürdig“, was als Hinweis auf die vielen merkwürdig unterschiedlichen Erscheinungsformen und Lokalisationen der atopischen Erkrankungen und deren assoziatives Auftreten zu verstehen ist. So gehören zum Formenkreis der atopischen Erkrankungen neben der atopischen Dermatitis außerdem die allergische Konjunktivitis, die Rhinitis allergica, das exogen-allergische Asthma bronchiale, die allergische Enteritis sowie die akute allergische Urtikaria. Die Besonderheit, dass es offenbar zu einer Verlagerung des pathologischen Prozesses von der Haut hin zu Organen der oberen und unteren Atemwege sowie des Verdauungstraktes kommen kann, beschrieb Ernest Besnier bereits 1892 (Ballmer-Weber 1998).

Im Laufe der Zeit sind viele Synonyme für die Krankheit entstanden, wie atopisches Ekzem, endogenes Ekzem, Neurodermitis atopica, Neurodermitis diffusa, konstitutionelles Ekzem, Prurigo Besnier, Sulzberger-Garbe-Syndrom, Ekzema flexuarum oder anlagebedingtes Ekzem (Braun-Falco 1995, S. 448). In der inter- 
nationalen dermatologischen Nomenklatur hat sich mittlerweile der Begriff Atopic eczema / dermatitis Syndrome (AEDS) durchgesetzt, wobei zwischen einem allergischen AEDS (AAEDS) und einem nichtallergischen AEDS (NAAEDS) unterschieden wird (Johansson et al. 2001). Das NAAEDS kann im Rahmen des atopic march in das AAEDS übergehen (Fölster-Holst et al. 2006). Unter atopic march versteht man die sequentielle Beteiligung weiterer Organe an der Erkrankung während der Kindheit. Dieser Nomenklatur entsprechend werden nachfolgend nur noch die Abkürzungen AEDS, AAEDS und NAAEDS verwendet.

Seit Jahren besteht die wissenschaftliche Erkenntnis (Ong und Leung 2002, Leung et al. 2004), dass dem AEDS eine genetische Disposition zugrunde liegt, sich die Krankheit selbst allerdings erst infolge von vielfältigen Wechselwirkungen zwischen endogenen und exogenen Faktoren, nach Überschreiten von individuellen Schwellenwerten in jeweils ganz unterschiedlichen Ausprägungsformen entwickelt.

Als bedeutsame Faktoren im Rahmen dieser multifaktoriellen Genese werden neben der genetischen Disposition Veränderungen in der humoralen und zellulären Immunantwort, funktionelle Hautveränderungen, neurovegetative Einflüsse, Allergien gegen Nahrungsbestandteile oder Umweltfaktoren, autoimmunologische Reaktionen, klimatische Einflüsse, Infektionen, chemische und physikalische Hautirritationen, psychisch emotionale Belastungssituationen, besondere Ausprägungen der Persönlichkeitsstruktur, Juckreiz und Kratzverhalten angenommen bzw. identifiziert (Biedermann und Röcken 2001).

Eine Sonderstellung kommt dabei der Allergie-Diathese zu. In Abhängigkeit davon wird zwischen den zwei genannten Formen des AEDS differenziert. Die extrinsische Variante (AAEDS 70-80 \% der Fälle) ist durch hohe Serum-IgE-Spiegel charakterisiert und wird durch Aero- und/oder Nahrungsmittelallergene getriggert. Außerdem findet sich häufig ein positiver Prick-Test (kutaner Allergentest). Die intrinsische Variante (NAAEDS 20-30\% der Fälle), bei der das klinische Bild identisch ausgebildet sein kann, stellt eine nicht IgE-assoziierte Dermatitis dar und 
es besteht keine oder nur eine geringe spezifisch nachweisbare Empfindlichkeit gegenüber Umwelt- oder Nahrungsmittelbestandteilen (Schmid-Grendelmeier et al. 2001). Inwieweit das NAAEDS jedoch wirklich eine eigene Entität darstellt, ist derzeit noch umstritten (Novembre et al. 2001, Fölster-Holst et al. 2006).

Im Rahmen dieser Arbeit soll versucht werden, den komplexen Einfluss von psychischen, neuroendokrinologischen und immunologischen Faktoren auf den Verlauf des AEDS bei Erwachsenen zu erfassen. Hierzu wurden zwei integrative Einzelfallstudien mit erwachsenen Patienten durchgeführt, die an der intrinsischen Variante (NAAEDS) erkrankt sind. So konnte ein unberechenbarer Einfluss von allergisch bedingten Hautreaktionen im Studienverlauf weitestgehend ausgeschlossen werden.

Nachfolgend wird zunächst ein Überblick über das Krankheitsbild, die Ätiologie und Pathogenese gegeben und es wird die Fragestellung dieser Arbeit beschrieben.

Anschließend werden die eingesetzten Methoden vorgestellt. Ein Schwerpunkt liegt dabei in der Beschreibung des Einzelfallstudiendesigns sowie der Datenauswertung mit zeitreihenanalytischen Methoden (ARIMA-Verfahren).

Im Ergebnis- und Auswertungsteil folgt die Darstellung und Betrachtung der gefundenen Zusammenhänge zwischen den untersuchten Parametern, die anschlieBend im Literaturzusammenhang kritisch diskutiert werden.

Abschließend finden sich die Zusammenfassung, das Literaturverzeichnis sowie im Anhang Angaben zu ARIMA-Modellen und dem verwendeten Tagebuch. 


\subsection{Beschreibung des Krankheitsbildes}

Die Prävalenz beträgt etwa $10-20 \%$ bei Kindern und etwa 1-3\% bei Erwachsenen (Leung et al. 2004, Grize et al. 2006). Sie hat sich in westlichen industrialisierten Ländern in den vergangenen 30 Jahren verdoppelt bis verdreifacht, wohingegen sich in Ländern mit mehr ursprünglicher Landschaft bzw. vorwiegend landwirtschaftlicher Kultur eine deutlich niedrigere Prävalenz findet (Leung et al. 2004). Es besteht ein altersabhängiger Einfluss auf die Erkrankung (Ballmer-Weber 1998, Schmid-Grendelmeier et al. 2001, Wüthrich und Schmid-Grendelmeier 2003). Sie entwickelt sich in etwa 80-90\% der Fälle bis zum fünften Lebensjahr und bildet sich in ca. 50\% der Fälle bis zur Pubertät wieder zurück. In ca. 40-60\% der Fälle bleibt die Erkrankung jedoch auch im Erwachsenenalter bestehen. Selten entwickelt sie sich erst im Erwachsenenalter.

Des Weiteren besteht eine unterschiedliche Inzidenz, Alters- und Geschlechterverteilung beim NAAEDS im Vergleich zum AAEDS. So nimmt das NAAEDS bei Kindern an Häufigkeit zu, entwickelt sich aber im Durchschnitt erst in einem etwas späteren Lebensalter und betrifft mehr Frauen als Männer (Werfel und Kapp 1999, Schäfer et al. 2000, Werner et al. 2002).

Das AEDS geht typischerweise mit intensivem Juckreiz einher. Daneben besteht oft eine trockene Haut und relativ typische Morphologie und Verteilung. So finden sich bei Erwachsenen typischerweise Vertiefungen der Handlinien, Lichenifikationen und ein Befall der Extremitätenbeugen. In ca. 30-60\% besteht eine positive Eigen- bzw. Familienanamnese hinsichtlich atopischer Erkrankungen. Charakteristisch sind nach Hanifin und Rajka (1980) des Weiteren paradoxe Gefäßreaktionen, verminderte Schweißsekretion, Sebostase sowie weißer Dermographismus. Die Hauterscheinungen sind in Morphe und Lokalisation abhängig vom jeweiligen Krankheitsstadium im Lebensverlauf (Kissling und Wüthrich 1994, Beltrani 1999). Die nachfolgende dermatologische bzw. histologische Beschreibung der Hautsymptomatik des AEDS findet sich bei Leung (2000), Schubert C (2002) und Leung und Bieber (2003). 
Das Akutstadium ist gekennzeichnet durch intensiv juckende, papulöse Pusteln über geröteter Haut assoziiert mit ausgedehnten Erosionen und Exkoriationen und seröser Exsudation. Im subakuten Stadium herrschen Rötungen, Exkoriationen und schuppende Hautareale vor. Im chronischen Stadium findet sich verdickte Haut mit vergröberter Hautfelderung und fibrotischen Pappeln. Dem entsprechen immunhistologische Korrelate. Charakteristisch für die akute Entzündungsphase sind begrenzte interstitielle Ödeme und spärliche Infiltrationen von überwiegend T-Lymphozyten in der Epidermis. In der Dermis finden sich perivenöse Entzündungen mit überwiegender T-Zell-Infiltration sowie gelegentlicher MonozytenMakrophagen-Infiltration. In der chronischen Entzündungsphase findet sich eine gesteigerte Anzahl von Langerhanszellen und Mastzellen in der Epidermis, Makrophagen dominieren die dermalen Zellinfiltrate und es zeigt sich eine Zunahme der Infiltration von Eosinophilen sowie eine Hypertrophie der Endothelzellen des oberflächlichen und tiefen Venenplexus. Alle drei Stadien (akut, subakut, chronisch) können beim AEDS gleichzeitig auftreten.

Der Schweregrad der Erkrankung kann mittels SCORAD (SCORing Atopic Dermatitis)-Index eingeschätzt werden (European Task Force on Atopic Dermatitis 1993, Gelmetti und Colonna 2004).

Wie bereits angedeutet, ist die Prävalenz des AEDS bis zum Schulanfang auch in der BRD in den letzten Jahrzehnten gestiegen und liegt zwischen 8-16\% (Schäfer et al. 2000). Die hohe Schwankungsbreite erklärt sich aus der Tatsache, dass das AEDS altersabhängig mit individuell unterschiedlichen Symptomen einhergeht, die zwischen Minimal- und Maximalausprägungen variieren, und keine einheitlichen, einfach anzuwendenden, validierten Diagnosekriterien für das AEDS existieren, die im Rahmen epidemiologischer Studien eingesetzt werden könnten.

Eine gute Orientierung für die Diagnosefindung stellen die bereits erwähnten Diagnosekriterien von Hanifin und Rajka (1980) dar, in denen verschiedene Symptome und anamnestische Besonderheiten des AEDS zusammengefasst sind. Die Diagnose basiert dabei auf der Präsenz von 4 Haupt- und 23 Nebenkriterien, von denen jeweils drei erfüllt sein müssen. Obwohl diese Kriterien bis heute nicht validiert sind, sind sie dennoch international anerkannt. Allerdings ist ihre Erhebung aufwendig und nicht für größere epidemiologische Studien geeignet. 
Als weiteres Diagnoseinstrument wurde 1994 von der United Kingdom Working Party (Williams et al. 1994a, b, c) ein neues einfacher zu handhabendes Muster von nur sechs Diagnosekriterien zusammengestellt und validiert. Dieses Diagnoseinstrument hat mit 96\% eine hohe Spezifität, allerdings schwankt die Sensitivität zwischen 10-85\%, in Abhängigkeit von Alter und genetischer Herkunft der Patienten, von Umweltfaktoren und dem medizinischen Versorgungssystem, in dem die Daten erhoben werden, so dass auch dieses Instrument nicht für den Einsatz in epidemiologischen Studien geeignet ist (Firooz et al 1999).

Die Angaben zur Prävalenz zeigen, wie groß der vom AEDS betroffene Anteil der Bevölkerung (ca. 3,2 Mio. Menschen) ist. Die jährlichen Kosten sind daher immens und liegen in der BRD zwischen 1,2 - 3,5 Mrd. Euro jährlich (Ehlken et al. 2005). Umso wichtiger ist eine gründliche Diagnostik, auch möglicher psychischer Komorbiditäten sowie eine individuell ausgerichtete wirksame Therapie zur Verlängerung der schubfreien Zeitintervalle sowie Vermeidung von schweren Schüben. Die Behandlungsmöglichkeiten bestehen sowohl in einer lokalen, ggf. auch systemischen Therapie der Haut mit z.B. UVA-Bestrahlung, rückfettenden Salben, Glukokortikoiden und immunmodulierend wirkenden Topika, als auch in einer Verhaltens- und Psychotherapie (Köhler und Niepoth 1988, Warschburger und Petermann 1996, Leung 1997, Ballmer-Weber 1998, Correale et al. 1999, Lange et al. 1999, Staughton 2001, Heratizadeh et al. 2003).

\subsection{Pathogenetische Faktoren}

Zunächst werden die pathogenetischen Faktoren im Einzelnen vorgestellt. Anschließend wird versucht, die bestehenden Erkenntnisse in Form eines pathogenetischen Netzwerkes im Zusammenhang darzustellen.

Da eine große Variabilität in der Ausprägung der Erkrankung innerhalb von Populationen mit ähnlicher genetischer Herkunft besteht, liegt die Vermutung nahe, dass insbesondere auch Umweltfaktoren einen großen Einfluss auf die Entwicklung des AEDS haben (Leung et al. 2004). 


\subsubsection{Allergene}

An erster Stelle der pathogenetischen Faktoren stehen deshalb Allergene. Sie führen insbesondere beim AAEDS immer wieder zu Exazerbationen, wenn der Erkrankte mit innen in Kontakt kommt, können aber auch einen Einfluss auf das NAAEDS haben (Fölster-Holst et al. 2006).

Als potentielle Allergene kommt ein breites Spektrum von Substanzen in Betracht (Sampson 1997, Leung 2000, Büchner 2001, Lever 2001, Fischer $S$ et al. 2003, Novak und Bieber 2004). Zu nennen sind v. a. Aeroallergene (Pollen, Hausstaub, Tierhaare, Duftstoffe), Chemikalien (z.B. Seifen), Textilien (insbes. Wolle), Nahrungsmittel (insbes. Ei, Milch, Fisch, Soja, Erdnuss und Weizen). Des Weiteren können hautbesiedelnde Bakterien (v. a. Staph. aureus) und Pilze (z.B. Pityrosporum ovale), aber auch körpereigene Proteine (z.B. Hom s 1 - Hom s 5) als allergene bzw. antigene Triggerfaktoren wirken (Morren et al. 1994, Valenta et al. 2000, Leung 2001, Heaton et al. 2003).

\subsubsection{Klimatische Bedingungen}

Klimatische Faktoren haben einen direkten und indirekten Einfluss auf die Haut (Braun-Falco et al. 1995, S. 459-460). So nimmt der Feuchtigkeitsgehalt der Haut in trockener Außen- bzw. Raumluft schnell ab. Ausgetrocknete Haut ist empfindlicher gegenüber physikalischen und chemischen Einflüssen. Ein eher indirekter Einfluss besteht hinsichtlich Pollenflug und Staubkonzentration in der Luft. Sehr warme oder kalte Luft oder abrupte Temperaturwechsel können ebenfalls zu einer Hautreizung führen (Bardana 2004). Dementsprechend ist ein gemäßigtes Raumklima mit ausreichender Luftfeuchtigkeit für den am AEDS Erkrankten am günstigsten. UV-Licht kann einen positiven Einfluss auf die Haut haben, weil es die Immunaktivität herabsetzt. Eine Verschlechterung der Krankheit tritt oft im Winterhalbjahr auf. 


\subsubsection{Funktionelle Hautveränderungen}

Funktionelle Hautveränderungen werden als mitverantwortlich für das Entstehen des AEDS angesehen.

Ursächlich hierfür könnte u. a. eine deutlich erhöhte Aktivität der SphingomyelinDeacylase sein, die insbesondere zu einem Verlust an Ceramiden führt (Imokawa 2001, Farwanah 2005, Segre 2006). Hierdurch kommt es vor allem zu einer Austrocknung der Haut infolge eines gesteigerten transepidermalen Wasserverlustes.

Daneben können aber auch erhöhte Glukokortikoidmengen, die infolge von Stress endogen gebildet wurden, die Integrität und Permeabilität der Haut im Stratum corneum negativ verändern. Die Folge ist eine abnehmende epidermale ZellProliferation und -differenzierung, eine abnehmende Dichte und Größe von Desmosomen im Stratum corneum und eine abnehmende Produktion und Sekretion von epidermalen Lipiden (Garg et al. 2001, Choi et al. 2005). Die gleichen Autoren erwähnen, dass auch Neuropeptide indirekt einen Einfluss auf die Hautintegrität haben können.

Daneben bestehen aber auch noch andere Einflüsse, wie z. B. eine starke Keimbesiedlung der Haut oder ungünstiges Waschverhalten, wodurch die schützende Barrierefunktion der Haut gestört werden kann (Horrobin 2000, Proksch et al. 2003, Segre 2006).

Infolge dieser Störung der physiologischen Hautbarriere besteht dann eine erhöhte Penetrierbarkeit für exogene Stoffe und chemische Substanzen, mit denen die Haut in Kontakt kommt. Verstärkt wird die Hautbarrierestörung zusätzlich durch die Entzündungsprozesse, die mit dem AEDS einhergehen sowie durch physikalische Hautirritationen wie z. B. Kratzen infolge von Juckreiz. 


\subsubsection{Genetische Faktoren}

Das genaue Ausmaß und die Auswirkungen des genetischen Einflusses beim AEDS sind derzeit noch weitgehend ungeklärt. Allerdings weisen epidemiologische Daten (Uehara und Kimura 1993, Coleman et al. 1997) eindeutig auf eine Beteiligung genetischer Faktoren hin. So erkranken ca. 30\% bzw. 70\% der Kinder am AEDS, wenn ein Elternteil bzw. beide Eltern betroffen sind. Ist nur ein Elternteil erkrankt, besteht ein höheres Erkrankungsrisiko für die Kinder, wenn die Mutter betroffen ist (Diepgen und Blettner 1996). In einer Zwillingsstudie (Larsen et al. 1986) bestand eine deutlich höhere Übereinstimmung bezüglich des Erkrankungsgrades zwischen homozygoten als zwischen heterozygoten Zwillingen mit $86 \%$ versus $21 \%$.

Mittlerweile sind mehrere Genloci identifiziert (siehe Tab. 1), die wahrscheinlich in einem bedeutsamen Zusammenhang zum AEDS stehen.

Viele Autoren (u.a. Forrest et al. 1999, Wollenberg und Bieber 2000, Cookson 2001, Cookson und Moffatt 2002, Reich et al. 2002, Heinzmann und Daser 2002, He et al. 2003, Leung und Bieber 2003, Bowcock und Cookson 2004, Morar et al. 2006) vertreten die Hypothese, dass Polymorphismen in bestimmten Genloci für die Prädisposition verantwortlich sind, der Phänotyp bzw. das Ausprägungsmuster hingegen durch andere Genloci in Interaktion mit weiteren endogenen und exogenen Faktoren bestimmt wird.

Hinweise zur Gewichtung des Einflusses von Genen und Umwelt auf atopische Erkrankungen ergeben sich $u$. a. aus einer Studie zu Asthma und Atopie, in der Palmer et al. (2000) gezeigt haben, dass genetische Dispositionen und Umwelteinflüsse jeweils einen Einfluss von ca. 50\% auf die IgE-Konzentration im Blutserum haben.

Folglich ist es höchst wahrscheinlich, dass beim AEDS eine polygenetische Veranlagung besteht, wobei die phänotypische Ausprägung in Abhängigkeit von 
Wechselwirkungen mit anderen endogenen Faktoren, aber insbesondere auch Umweltfaktoren sehr variabel zu sein scheint.

Die Kenntnisse über die (patho-)genetischen Muster, die beim AEDS wirksam sind, wachsen in den letzten Jahren genauso rasant wie die Kenntnisse über neue immunologische und neuroendokrine Zusammenhänge und müssen ständig aktualisiert werden. Vierteljährlich kamen in den letzten sechs Jahren in „MedlineRecherchen“ immer wieder neue Erkenntnisse über potentiell bedeutsame pathogenetisch wirksame Einflussfaktoren beim AEDS hinzu. Insgesamt finden sich zum Stichwort atopic dermatitis in „Medline“ über 12.000 Artikel. Daher können die in der vorliegenden Arbeit gemachten Angaben keinen Anspruch auf Vollständigkeit erheben und sie können auch nur in einem relativen Maßstab aktuell sein.

Tab.1: Genregionen, die wahrscheinlich mit atopischen Phänotypen assoziiert sind (nach Angaben von Wollenberg und Bieber 2000, Biedermann und Röcken 2001, Cookson 2001 sowie Morar et al. 2006)

\begin{tabular}{|c|c|c|}
\hline Genregionen & Genprodukte & Assoziierter Phänotyp \\
\hline Chromosom 2 & IL-1-Gen-Cluster & Hautimmunität \\
\hline Chromosom 5q31-33 & $\begin{array}{l}\text { Viele Zytokine incl. IL-4-Gen-Cluster, IL-5, IL- } \\
\text { 13, GC-Rezeptor, ß2-adreno-Rezeptor }\end{array}$ & $\begin{array}{l}\text { Prädisposition für AD, Gesamt-IgE, bron- } \\
\text { chiale Überreaktivität }\end{array}$ \\
\hline Chromosom 6p21.3 & $\begin{array}{l}\text { MHC-Komplex und viele immunassoziierte } \\
\text { Gene, z. B. TNF } \alpha\end{array}$ & Spezifisches IgE, Asthma \\
\hline Chromosom 10q11.2 & 5-Lipoxygenase & Asthma \\
\hline Chromosom 11q12-13 & ß-Kette des hochaffinen IgE-Rezeptors $\varepsilon$ & $\begin{array}{l}\text { Hohe Spiegel an Gesamt- und spezifi- } \\
\text { schem IgE, mögliche Autoallergieneigung }\end{array}$ \\
\hline Chromosom 12q15-q24.1 & $\begin{array}{l}\text { INF- } \gamma, \text { NOS1, Mastzell-growth factor, IGF1, } \\
\text { SCF }\end{array}$ & $\lg \mathrm{E}$, Atopie \\
\hline Chromosom 14q11 & $\begin{array}{l}\text { Mastzellchymase, T-Zell-Rezeptor- } \alpha \text {-Kette, } \\
\text { NFкB1 }\end{array}$ & $\begin{array}{l}\text { Beim AEDS überwiegen Mastzellen vom } \\
\text { Tryptase-Typ }\end{array}$ \\
\hline Chromosom 14q32 & Schwere Kette IgG & Atopie \\
\hline Chromosom 16q12.1 & $\alpha$-Kette des IL-4-Rezeptors & Gesamt IgE \\
\hline Chromosom 17q11 & RANTES & Atopische Dermatitis \\
\hline Chromosom 3q21 & Zytokine & Hautimmunität \\
\hline Chromosom 1q21 & Zytokine & Hautimmunität \\
\hline
\end{tabular}




\subsubsection{Immunologische Einflussfaktoren}

Da das Verständnis der immunologischen Vorgänge für die Pathogenese des AEDS von grundlegender Bedeutung ist, werden hierfür notwendige Vorkenntnisse an dieser Stelle einleitend vorangestellt. Die nachfolgend dargestellten Zusammenhänge physiologischer Immunprozesse wurden, insofern nicht anders vermerkt, dem Lehrbuch "Immunologie" von Janeway und Travers (2002, S. 1-93, 167-195, 317-451) entnommen.

Allergene werden von Antigen-Präsentierenden Zellen (APZ) der Haut (Langerhanszellen, dendritische Zellen, Makrophagen, B-Zellen, u. a.) mehr oder weniger spezifisch gebunden. Die Reaktion auf Allergene ist umso spezieller und potenter, je mehr hochaffine IgE-Rezeptoren auf den Antigen-präsentierenden Zellen ausgebildet sind.

APZ interagieren in der Haut und nach Auswandern in lymphatische Organe mit T-Zellen. Bei einer viralen Infektion erfolgt die Interaktion mit zytotoxischen T-Zellen und natürlichen Killerzellen, die die befallene Zelle töten. Bei einer bakteriellen Infektion erfolgt die Interaktion mit T-Helferzellen: Diese differenzieren sich aus einer Vorläuferzelle $\mathrm{TH}_{0}$ in Abhängigkeit von dem aktuell wirksamen „Zytokinmilieu" in zwei unterschiedliche Linien: $\mathrm{TH}_{1}$ - und $\mathrm{TH}_{2}$-Zellen. Unter dem Einfluss von IFN- $\gamma$, IL-12 und IL-18 entwickeln sich aus den Vorläuferzellen $\mathrm{TH}_{1}$-Zellen, wohingegen sich unter dem Einfluss von IL-4 und IL-10 aus den Vorläuferzellen $\mathrm{TH}_{2}$-Zellen entwickeln. Die genannten Zytokine werden u. a. von APZ und den T-Zellen selbst sezerniert. Im Weiteren erfolgt dann in Abhängigkeit vom Zytokinmilieu eine Aktivierung des zellulären Immunsystems sowie eine B-ZellAktivierung, wobei eine $\mathrm{TH}_{1}$-Antwort $\mathrm{u}$. a. zur Makrophagenaktivierung und eine $\mathrm{TH}_{2}$-Antwort u. a. zur IgE-Produktion führt. Physiologischerweise erfolgt im Rahmen einer Infektion zuerst eine $\mathrm{TH}_{1}$-Antwort, dann eine $\mathrm{TH}_{2}$-Antwort.

Die körpereigene spezifische Immunreaktion bildet sich erst langsam in den ersten Lebensjahren aus. Im Mutterleib und während der Stillphase dominieren $\mathrm{TH}_{2}$-geprägte Immunantworten. Nach der Geburt entwickelt sich infolge Exposition mit verschiedenen Umweltkeimen verstärkt eine $\mathrm{TH}_{1}$-geprägte Immunreaktion. Im weiteren Leben stehen beide in einem bestimmten Gleichgewicht miteinander. 
Eine Theorie (die sog. „Hygiene-Hypothese“) zur Entstehung des AEDS setzt genau hier an und geht davon aus, dass aufgrund übertriebener Hygiene, Impfungen, gehäufter Therapien mit Antibiotika und veränderter Essgewohnheiten sowie der damit verbundenen mangelnden bzw. im Spektrum veränderten Keimexposition diese Entwicklung in der frühen Kindheit ausbleibt (Novak und Bieber 2004). Infolgedessen persistiert eine $\mathrm{TH}_{1} / \mathrm{TH}_{2}$-Dysbalance (Böhm und Bauer 1997) und damit kommt es nach einer wie auch immer gearteten Aktivierung des kindlichen Immunsystems tendenziell zur „Manifestation“ einer zumindest initial eher $\mathrm{TH}_{2}$-dominierten Reaktion mit der Folge einer übermäßigen IgE-Produktion. Diese Theorie ist in sich durchaus schlüssig (Brehler und Luger 1999), sie lässt sich aber in epidemiologischen Studien nicht eindeutig belegen (Gibbs et al. 2004, Zutavern et al. 2005).

Dass veränderte Lebens- und Ernährungsgewohnheiten bei Müttern und Kindern zu einer gravierenden Verschiebung des Keimspektrums der sonst schützenden Darmflora führen können, zeigt eine finnische Studie (Kalliomaki et al. 2003). In dieser Studie konnte nachgewiesen werden, dass die Einnahme probiotischer Kulturen (Lactobacillus rhamnosus) von erkrankten Müttern und deren Kindern in wenigen Jahren eine signifikante Abnahme der Inzidenz des AEDS zur Folge hatte. Auch scheinen der Kontakt zu Tieren sowie frühe Atemwegsinfektionen Kinder mit einer Anlage zum AEDS vor einem stärkeren Ausbruch der Krankheit zu schützen (De Meer et al. 2005), ein Studienergebnis, welches die Hygiene-Theorie stützt. In diesem Kontext wird auch ein Mangel an der sekretorischen Komponente des IgA bei AEDS-Erkrankten (Lotti et al. 1995) postuliert. Das sekretorische IgA stellt eine Art „Schutzschild“ vor dem Eindringen von Antigenen durch die Schleimhaut des Magen-Darm-Traktes sowie der Luftwege dar. Ist dieser Schutzschild geschwächt, kann es verstärkt zu allergischen Reaktionen kommen.

Letztlich sind die immunologischen Besonderheiten bei der AD aber enorm vielfältig, in ihrer Fülle noch gar nicht vollständig erfasst (Leung 2000) und lassen sich selbstverständlich nicht auf eine einzelne Theorie zurückführen. Es besteht jedoch immer eine mehr oder weniger stark ausgeprägte Störung bezüglich der „T-Zell- 
Balance“ in der Immunantwort mit vielfältigen Auswirkungen. So wird die Expression von Genen der angeborenen Immunität auch von T-Zell-Zytokinen mit kontrolliert. Nachgewiesen werden konnte z.B. eine durch $\mathrm{TH}_{2}$-Zytokine mitbedingte verminderte Expression speziell von Human-ß-Defensin, iNOS und IL-8, wodurch eine pathologische Keimbesiedlung gefördert wird (Nomura et al. 2003).

Nachfolgend werden weitere, in verschiedenen Studien (Wüthrich 1999, Werfel und Kapp 1999, Akdis et al. 1999, Akdis et al. 2000, Higashi et al. 2001, SchmidGrendelmeier et al. 2001, Cooper und Stevens 2001, Ong und Leung 2002, Novak et al. 2002, Reich et al. 2002, Kang und Stevens 2003, Wüthrich und SchmidGrendelmeier 2003, Novak und Bieber 2004, Allam und Novak 2005 sowie Angelova-Fischer et al. 2006) beschriebene, immunologische Abläufe der beiden Subtypen des AEDS zusammenhängend aufgeführt.

Das AAEDS ist in der Akutphase (den ersten 24-48 Stunden) charakterisiert durch eine antigenspezifische Aktivierung spezifischer T-Zellen, denen die Antigene nach Bindung durch dendritische Zellen mittels z. T. hochaffiner IgE-Rezeptoren, Aufnahme und Prozessierung präsentiert worden waren. Als Antigene können hochmolekulare Aeroallergene (Pollen jeglicher Art, Hausstaub, Tierhaare), Autoantigene (z.B. Hom s 1 - Hom s 5) oder, wie bereits angedeutet, auch bakterielle (z.B. von Staphylococcus aureus), virale (z.B. von Herpes simplex) oder funguide Antigene (z.B. von Pityrosporum ovale) wirken.

Die aktivierten T-Zellen produzieren u. a. IL-4, aber v. a. hohe Mengen an IL-5 und IL-13. Dies entspricht phänotypisch einer $\mathrm{TH}_{2}$-dominierten Interaktionskaskade mit nachfolgender IgE-Produktion in aktivierten B-Lymphozyten, wodurch ein sich selbst verstärkender Kreislauf entsteht. Hochaffine IgE-Rezeptoren finden sich auch auf Monozyten, die hohe Mengen an $\mathrm{PEG}_{2}$ produzieren, wodurch es zu einer verstärkten IL-10-Produktion in den Monozyten kommen soll. IL-10 inhibiert die Entwicklung einer $\mathrm{TH}_{1}$-Antwort. Außerdem können Allergene über IgE-Rezeptoren auch Mastzellen und Basophile aktivieren, die ebenfalls IL-4 freisetzen und somit eine $\mathrm{TH}_{2}$-Antwort begünstigen.

Aufgrund der initial verminderten $\mathrm{TH}_{1}$-Antwort kommt es infolge mangelnder Aktivierung von zytotoxischen Zellen häufiger zu ernsteren bakteriellen und viralen 
Infektionen. Im Vordergrund stehen dabei Infektionen durch Staphylococcus aureus, der bei über 90\% der an AD Erkrankten die Haut besiedelt. Ebenfalls gehäuft treten Infektionen mit Herpes simplex oder Mollusca contagiosa auf. Zugleich können Proteine dieser Erreger als Trigger für eine lokale Exazerbation der Erkrankung fungieren.

Die aktivierten T-Zellen vermitteln außerdem durch Fas-Liganden eine Apoptose von Keratinozyten. So entsteht die für die Akutphase charakteristische Spongiose und es werden durch den Zelltod von Keratinozyten potenzielle Autoallergene freigesetzt.

Daneben werden von den aktivierten dendritischen Zellen und T-Zellen auch noch viele andere Chemokine produziert und sezerniert, wie z.B. IL-16, skin-homingreceptor, CLA und Eotaxin. Dementsprechend finden sich in der akuten Krankheitsphase bei vielen Patienten auch erhöhte Mengen an chemotaktisch wirksamen Botenstoffen im Blut. Dazu gehören neben den genannten, u. a. auch MDC, TARC, RANTES und SCD30 (Jahnz-Rozyk et al. 2005). Hierdurch werden weitere T-Zellen, aber auch verstärkt Eosinophile angelockt. Diese reichern sich in der betroffenen Haut an. Dort herrscht ein günstiges Milieu (erhöhte IL-5- und GMCSF-Konzentration, letzteres in Keratinozyten produziert), in dem das Überleben der Eosinophilen und T-Zellen verlängert und ihre Aktivität erhöht ist.

Eosinophile selbst produzieren, wie auch APZ, IL-12, aber auch die o. g. Zytokine IL-16 und RANTES. IL-12 wiederum fördert die Entwicklung einer $\mathrm{TH}_{1}$-Antwort, so dass es zu einer Verschiebung der $\mathrm{TH}_{1} / \mathrm{TH}_{2}$-Balance kommt und sich die gesamte Immunreaktion phänotypisch nun in die $\mathrm{TH}_{1}$ - Richtung verändert. $\mathrm{TH}_{1}$-Zellen produzieren INF- $\gamma$, welches zu einer verstärkten Makrophagenaktivierung und Neopterinfreisetzung aus diesen führt. Dies geschieht nach etwa 48-72 Stunden.

Beim AAEDS findet folglich ein fließender Übergang zwischen einer akuten $\mathrm{TH}_{2}$-dominierten und einer sich anschließenden chronischen $\mathrm{TH}_{1}$-dominierten Immunreaktion der Haut statt. 
Zum Teil andere, zum Teil ähnliche Konstellationen finden sich beim NAAEDS. Das Blutserum enthält in der akuten Phase weniger IL-4. Auch findet sich eine signifikant erniedrigte Expression des IL-4R auf Monozyten, eine niedrigere IL-13Produktion in T-Zellen sowie eine signifikant niedrigere Expression des hochaffinen IgE-Rezeptors auf dendritischen Zellen in betroffener Haut. Ähnlichkeiten bestehen bezüglich der eosinophilen Reaktion sowie der IL-5 Produktion von kutanen T-Zellen. Erhöht zu sein scheint jedoch die Menge an sezerniertem IL-5 in Blut-T-Lymphozyten. Wiederum keine Unterschiede sind bezüglich der Anzahl von Mastzellen in der Haut bei den beiden Formen des AEDS beschrieben. Die Entzündungsreaktion selbst verläuft ebenfalls ähnlich. In atopy patch tests konnte wider Erwarten sogar eine positive Reaktion auf Aeroallergene bei NAAEDSPatienten gefunden werden (Kerschenlohr et al. 2003, Fölster-Holst et al. 2006), weshalb, wie ja bereits in der Einleitung erwähnt, auch die eigene Entität des NAAEDS noch umstritten ist. Daneben wird bei beiden Formen des AEDS auch eine autoallergene Immunreaktion gegen humane Proteine, z.B. Hom S 1 - S 5, als mitverantwortlich für die Entstehung und die Chronifizierung diskutiert (Natter et al. 1998, Valenta et al. 2000).

Eine weitere Besonderheit des AEDS zeigt sich in einer überhöhten Aktivität der cAMP-PhosphodiesteraseIV. Diese bedingt einen erniedrigten cAMP-Spiegel mit weitreichenden Folgen, da der sonst vorhandene unspezifische Dämpfungseffekt von cAMP auf die Aktivität verschiedener Immunzellen nun entfällt. So führt die

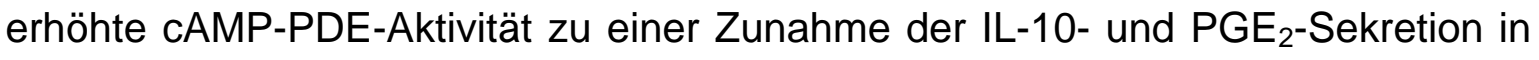
Monozyten, der IL-4-Produktion in T-Zellen und der IgE-Produktion in B-Zellen sowie zu einer erhöhten Freisetzung von Histamin und anderen Botenstoffen aus Mastzellen und Basophilen, was wiederum die $\mathrm{TH}_{1} / \mathrm{TH}_{2}$-Balance beeinflusst. Weitere Erkenntnisse liegen vor hinsichtlich einer Dysregulation der Apoptose von T-Zellen, Eosinophilen und Keratinozyten, deren Überleben verlängert bzw. verkürzt ist, mit ebenfalls pathogenetischen Auswirkungen (Akdis et al. 2001).

Wie bereits angedeutet, haben auch andere immunkompetente Zellen einen Einfluss auf den Entzündungsprozess. So sezernieren Mastzellen viele Zytokine, die 
die Aktivität anderer Immunzellen beeinflussen, Juckreiz auslösen oder die Neoangiogenese stimulieren (Greaves 2000, Alenius et al. 2002, Groneberg et al. 2005). Zur Mastzellaktivierung kommt es interessanterweise auch im Rahmen stressinduzierter Vorgänge (Esposito et al. 2001, Theoharides und Cochrane 2004). Verantwortlich dafür scheint eine $\mathrm{CRH}$-induzierte Endothel- und Mastzellaktivierung zu sein, in deren Folge es nach Freisetzung von NO und Histamin aus den genannten Zellen, z.B. zu Permeabilitätssteigerung von Hautgefäßen sowie proin-flammatorischen Effekten kommt (Theoharides et al. 1998, Singh et al. 1999, Crompton et al. 2003, O'Kane et al. 2006). Diese Interaktionen stellen ein bedeutsames Bindeglied zum Verständnis der Auswirkungen von psychischem Stress auf Hauterkrankungen dar.

\subsubsection{Juckreiz und Kratzverhalten}

Ein wesentliches Symptom des AEDS ist der Juckreiz und das daraus resultierende Kratzverhalten (Rühle 2000, Seite 47-73). Kratzen löst eine Immunreaktion aus, die zur Hautverschlechterung und gesteigertem Juckreiz führt (sog. „JuckKratz-Zirkel"). Im Laufe der Zeit kann es zu einer ganz unbewussten Konditionierung des Kratzverhaltens kommen, welches dann auch ohne vorherigen adäquaten Juckreiz in bestimmten, z.B. emotional belastenden Situationen auftritt und nachfolgend $\mathrm{zu}$ einer Hautverschlechterung führen kann. Eine Konditionierung wird auch beim Juckreiz angenommen (Scholz und Hermanns 1994). Aufgrund dieser bekannten und beschriebenen Zusammenhänge wird Patienten im Allgemeinen auch ein entsprechendes Verhaltenstraining empfohlen, welches darauf abzielt, sich möglichst wenig zu kratzen (Yosipovitch 2003). Dies ist therapeutisch äußerst sinnvoll, zumal das Spektrum potentieller Auslöser von Juckreiz beim AEDS sehr groß ist und der Juckreiz nur kognitiv kontrolliert werden kann (Beltrani 1999, Paus et al. 2006, Sonkoly et al. 2006). Auslösend wirken:

- Hauttrockenheit und Schwitzen, wobei diesbezüglich vermutet wird, dass eine

Dysfunktion mit verminderter Schweißsekretion vorliegt (Parkkinen et al. 1992),

- physikalische Hautirritationen durch Kleidung, Kratzen, Druckreiz, 
- klimatische Faktoren wie Hitze und Lufttrockenheit,

- die unter 1.1.2.1. genannten Allergene: Pollen, Hausstaubmilben, Tierhaare, Duftstoffe, andere Chemikalien (z.B. Seifen), Textilien (insbes. Wolle), Nahrungsmittel (z. B. Ei, Milch, Fisch, Soja, Erdnuss, Weizen, Bier, Gewürze),

- immunologische Reaktionen auf mikrobielle Besiedlung und Infektionen,

- hormonelle Einflüsse, z.B. im Menstruationszyklus,

- psychische Faktoren (Emotionen, Stress).

An der Perzeption, Weiterleitung, Wahrnehmung und anschließenden Reaktion auf einen Juckreiz sind viele verschiedene nervale Strukturen (spezialisierte chemonozitive Rezeptoren in der Haut, demyelinisierte C-Fasern, Neurone der dorsalen Hinterhörner des Rückmarkes, des Tractus spinothalamicus, der rostralen Medulla, des kaudalen Mittelhirnes, des ventralen posterioren Nucleus im Thalamus sowie des linken primären sensorischen Cortex) beteiligt (Schmelz 2001). Die initiale Rezeptorreizung erfolgt über verschiedene Transmitter über eine direkte und indirekte Rezeptorreizung, von denen Acetylcholin, SP, CGRP, VIP sowie Tryptase aus Mastzellen eine besondere Rolle spielen. Aber auch andere Substanzen wie z.B. Endorphine, Neurotrophin-4, Prostaglandien, Leukotriene und PAF können wichtige modulierende Funktionen (z.B. Senkung der Reizschwelle) haben. Des Weiteren können auch pH-Veränderungen in entzündlichen Bezirken die Juckreizperzeption beeinflussen. Histamin hingegen scheint nur einen geringeren Anteil an der Juckreizentstehung beim AEDS zu haben (Reitamo et al. 2001, Weisshaar und Gieler 2002, Ständer und Steinhoff 2002, Yosipovitch 2003). Letztlich ist die Entstehung und Empfindung des Juckreizes beim AEDS von vielen Einflussgrößen abhängig, wobei auch die zentralnervösen Verarbeitungsebenen eine bedeutsame Funktion haben. So kann auch Müdigkeit oder eine ängstlichdepressive Stimmungslage die Entstehung eines Juckreizes fördern bzw. dessen Wahrnehmung verstärken (Gupta et al.1994).

Kratzen ist immer kontraproduktiv, da es durch die mechanische Reizung direkt zur Hautverschlechterung führt. Insbesondere nächtliches Kratzen hat fatale Auswirkungen, da es in der Regel auch ein gehäuftes Aufwachen zur Folge hat. Dies 
bedingt eine erhöhte Tagesmüdigkeit und kann zu einer gereizten, ängstlich geprägten Stimmung sowie erhöhtem interpersonellen Stress führen (Ebata et al. 1999, Bardana 2004).

Der Juckreiz und das Kratzverhalten stellen somit ein Hauptsymptom und ein Hauptproblem beim AEDS dar. Sie haben erhebliche Auswirkungen auf die Lebensqualität und sind direkt und indirekt mit der psychischen Situation verknüpft.

\subsubsection{Psychoemotionale und neurovegetative Faktoren}

Die Metapher "Die Haut ist ein Spiegel der Seele“ beschreibt anschaulich, dass gerade bei Hauterkrankungen häufig eine psychische Komorbidität angetroffen wird. Aus psychodermatologischer Sicht gehört auch das AEDS zur Gruppe der multifaktoriell bedingten Dermatosen, deren Verlauf durch psychische Faktoren entscheidend beeinflusst werden kann (von Uexküll 1996, S. 1087-1091; Schneider und Gieler 2001; Korting 2003, Koblenzer 2005).

Immer wieder wird berichtet, dass psychische Einflüsse, wie negative Emotionen, schwierige Lebensereignisse und Stress zu einer Hautverschlechterung beim AEDS führen können (Buhk und Muthny 1997, Kodama et al. 1999, Tausk und Nousari 2001, Raap et al. 2003, Hashizume et al. 2005). Vermittelt werden psychische Effekte über zwei Wege: das Verhalten (Kratzverhalten, Allergenmeidung) sowie über neuroimmunoendokrine Interaktionen (Madden und Felten 1995, Besedovsky und Del Rey 1996, Slominski et al. 2000, Buske-Kirschbaum und Hellhammer 2003).

Die physiologische und anatomische Basis für diese Interaktionen stellen das $\mathrm{Hy}$ pothalamisch-hypophysäre-Nebennierenrinden-System (HHNR) und das Sympathisch-Adreno-Medulläre System (SAM) sowie das feine dreidimensionale Netzwerk aus demyelinisierten Nervenfasern, Gefäßen und den verschiedenen Zelltypen in der Haut dar (Metze 2001; Benninghoff 1994b, S. 803). Dabei erfolgt eine 
Informationsübertragung vom intensiv sympathisch innervierten Hautnervensystem sowohl direkt auf immunkompetente Zellen als auch auf Keratinozyten und Endothelzellen der Gefäße, wobei durch letztere der Blutfluss und die Durchlässigkeit für Immunzellen beeinflusst wird (Schulz et al. 1997, S. 224-253). Insbesondere Mastzellen scheinen sowohl beim AAEDS als auch beim NAAEDS in hoher Dichte und engem Kontakt zu Nervenfasern zu stehen (Järvikallio et al. 2003). Stressreaktionen des Organismus können bekanntermaßen verschiedenste Ursachen haben (Dienstbier 1989, O`Leary 1990). Neben physischen und psychischen Gründen bewirkt auch eine Aktivierung des Immunsystems, vermittelt v. a. durch die Zytokine IL-1, IL-6 und TNF $\alpha$, zeitlich versetzt eine zentralnervöse Stressreaktion (Birbaumer und Schmidt 1999, S. 52-61).

Letztlich erfolgt im Rahmen einer wie auch immer induzierten Stressreaktion eine wechselseitige zentralnervöse Aktivierung des SAM- und des HHNR-Systems über interaktiv kommunizierende CRHerge und noradrenerge Neurone im Hypothalamus, aber auch über Interaktionen auf hypophysärer Ebene (Rupprecht et al. 1995; O`Connor et al. 2000; Löffler und Petrides 2003, S.880). Karalis et al. (1991) konnten zeigen, dass $\mathrm{CRH}$ in vivo sowohl auto- als auch parakrine entzündungsfördernde Eigenschaften besitzt. ACTH, MSH, Cortisol, Noradrenalin und Adrenalin wirken in der Folge regulativ auf das Immunsystem zurück.

Adrenalin und Noradrenalin bewirken im Immunsystem kurzfristig eine typische „Notfallreaktion“, vermittelt überwiegend durch ß-adrenerge Rezeptoren auf den immunkompetenten Zellen: die Anzahl und Aktivität von natürlichen Killerzellen und zytotoxischen T-Zellen ist kurzzeitig (für 4-5 Stunden) erhöht und die Aktivität von $\mathrm{TH}_{1}$-Zellen, Makrophagen und $\mathrm{B}$-Zellen wird reduziert (Madden und Felten 1995, Dhabhar und McEwen 1999).

Es wird angenommen, dass es aufgrund unterschiedlicher ß-Rezeptorendichte auf $\mathrm{TH}_{1}$ - und $\mathrm{TH}_{2}$-Zellen (auf denen kaum ß-Rezeptoren vorhanden sind) zu einer stärkeren Suppression von $\mathrm{TH}_{1}$-Zellen kommt, weshalb sich die $\mathrm{TH}_{1} / \mathrm{TH}_{2}$-Balance in die $\mathrm{TH}_{2}$-Richtung verschiebt (Neumann 2003). Daneben wird seit langem vermutet, dass beim AEDS eine "Schwäche“ des ß-adrenergen-Rezeptors vorliege (Szentivanyi 1968 in Scholz et al. 1997, S. 319), was u. a. eine mangelnde Hem- 
mung der Proliferation und Aktivität von $\mathrm{TH}_{1}$-Helferzellen, Makrophagen und B-Zellen zur Folge hätte. Diese Vermutung konnte jedoch bisher noch nie eindeutig bestätigt werden. Somit ist der mögliche pathologische Einfluss veränderter ß-Rezeptor-Effekte beim AEDS derzeit noch nicht vollständig geklärt. Aber es bestehen Hinweise, dass es beim AEDS insbesondere zu einer verstärkten Reaktion des SAM infolge von Stress kommt. Seiffert et al. (2005) fanden erhöhte Herzfrequenzen während Stress- und Ruhephasen nach mentaler Belastung sowie eine erhöhte Ängstlichkeit, Depressivität und emotionale Erregbarkeit im Vergleich zu Gesunden. Andere noradrenerge Effekte zeigen sich in einer zunehmenden Migration von dendritischen Zellen nach psychologischem Stress (Saint-Mezard et al. 2003).

Die Effekte von Cortisol auf das Immunsystem sind ebenfalls vielfältig. Sie können grob unterteilt werden in vorbereitende, permissive und suppressive Effekte. Erstere werden vor allem über den Mineralokortikoidrezeptor, letztere vor allem über den Glukokortikoidrezeptor vermittelt. Die suppressiven Effekte erfolgen u. a. durch Hemmung der Prostaglandinsynthese, $\mathrm{COX}_{2}, \mathrm{NOS}_{2}$, IL-2, INF- $\gamma$ (Löffler und Petrides 2003, S. 885). Des Weiteren wird die Endotheladhäsion und die Diapedese von immunkompetenten Zellen beeinflusst und die Apoptose von Immunzellen gefördert (Sapolsky et al. 2000).

Ein wesentliches Effektorglied in dieser komplexen neuroendokrinoimmunologischen Interaktion sind wieder die T-Zellen. Dabei bewirken Cortisol und Katecholamine synergistisch eine Hemmung der $\mathrm{TH}_{1}$-Antwort und Verstärkung der $\mathrm{TH}_{2}$-Antwort, wobei dieser Effekt u. a. auch über eine Unterdrückung der IL-12Expression vermittelt wird (Marx et al. 1998, Elenkov und Chrousos 1999). Letztlich ist die Wirkung des HHNR- und SAM-Systems auf die $\mathrm{TH}_{1} / \mathrm{TH}_{2}$-Balance aber abhängig von der systemimmanenten Gesamtreaktion auf den jeweils vorherrschenden Stressor. So tritt entweder gar keine pathologische Reaktion des Systems auf oder aber es kommt zu pathologischen Folgen einer überschießenden Entzündungsreaktion vom $\mathrm{TH}_{2}$ - oder auch $\mathrm{TH}_{1}$-Typ (Chrousos 1995). 
Tab. 2: Cortisoleffekte auf das Immunsystem (modifiziert nach O`Connor et al. 2000, S. 326)

\begin{tabular}{|c|c|}
\hline Zelltyp / Gewebe & Effekt \\
\hline $\begin{array}{l}\text { Lymphozyten } \\
\text { (B-Zellen, T-Zellen, NK-Zellen) }\end{array}$ & $\begin{array}{ll}\text { - } & \text { Verringerung der Anzahl der im Blut zirkulierenden Zellen } \\
\text { - } & \text { Hemmung der Proliferation und Aktivität } \\
\text { - } & \text { Induktion der Apoptose } \\
\text { - } & \text { Hemmung der Produktion von IL-2, IL-3, IL-5, IL-6, IL-8, IFN- } \gamma \text {, } \\
\text { TNF, GM-CSF }\end{array}$ \\
\hline Monozyten / Makrophagen & $\begin{array}{ll}\text { - } & \text { Verringerung der Anzahl der im Blut zirkulierenden Zellen } \\
\text { - } & \text { Hemmung der Sekretion von IL-1, IL-6, TNF-a, MCAF } \\
\text { - } & \text { Verringerung der Synthese von Kollagenase, Elastase; } \\
& \text { Gewebe-Plasminogen-Aktivator }\end{array}$ \\
\hline Eosinophile Granulozyten & $\begin{array}{ll}\text { - } & \text { Verringerung der Anzahl der im Blut zirkulierenden Zellen } \\
\text { - } & \text { Reduktion des Überlebens } \\
\text { - } & \text { Reduktion der Endothel-Adhäsion }\end{array}$ \\
\hline Basophile Granulozyten & $\begin{array}{ll}\text { - } & \text { Verringerung der Anzahl der im Blut zirkulierenden Zellen } \\
\text { - } & \text { Reduktion der Endothel-Adhäsion }\end{array}$ \\
\hline Neutrophile Granulozyten & $\begin{array}{ll}\text { - } & \text { Erhöhung der Anzahl der im Blut zirkulierenden Zellen } \\
\text { - } & \text { Hemmung der Chemotaxis durch Hemmung von IL-1, IL-8 und } \\
& \text { Leukotrien } \mathrm{B}_{4} \\
\text { - } & \text { Reduktion der Endothel-Adhäsion }\end{array}$ \\
\hline Mastzellen & - $\quad$ Verhinderung der Mastzellproliferation (Expansion) \\
\hline $\begin{aligned} \text { HPA-Achse: } & \text { Hypothalamus } \\
& \text { Hypophyse }\end{aligned}$ & $\begin{array}{ll}\text { - } & \text { Hemmung der } \mathrm{CRH}-\text { Freisetzung } \\
\text { - } & \text { Hemmung der ACTH-Freisetzung }\end{array}$ \\
\hline Leber & - $\quad$ Induktion von Akut-Phase-Proteinen \\
\hline $\begin{array}{l}\text { Sonstige immunmodulatorische } \\
\text { Effekte }\end{array}$ & $\begin{array}{l}\text { - Hemmung der induzierbaren NO-Synthetase, } \\
\text { - Hemmung der } \mathrm{PLA}_{2} \text { und der induzierbaren } \mathrm{COX}_{2} \text { mit der Folge } \\
\text { einer verminderten Prostaglandinsynthese, } \\
\text { - } \quad \text { Modulation der Affinität von } \mathrm{B}_{2} \text {-adreno-Rezeptoren }\end{array}$ \\
\hline
\end{tabular}

Die systemimmanente Reaktion der HPA-Achse auf Stressreize kann auch von früheren Stresserfahrungen abhängen (Hüther 1996, Hüther et al. 1996, Pallanti et al. 2005). Als Schutz vor einer chronischen Aktivierung der HHNR-Achse durch andauernden Stress, kann es im Rahmen einer Anpassungsreaktion zur Herabregulation der ß-Glukokortikoidrezeptorexpression kommen, wodurch die hemmenden Effekte von Cortisol auf das Immunsystem abgeschwächt werden. Diese regulatorisch wirkenden hemmenden Effekte dienen einer Vermeidung von infektions-, autoimmun- oder allergisch bedingten entzündlichen Schäden, die durch ein chronisch ungezügelt aktiviertes Immunsystem entstehen können. 
Auch beim AEDS finden sich vermehrt Hinweise auf eine Hyporeaktivität der HHNR-Achse mit inadäquat niedrigen Cortisolanstiegen nach Stresseinfluss (Buske-Kirschbaum und Hellhammer 1999, Buske-Kirschbaum et al. 2001, BuskeKirschbaum et al. 2002a, b; Raap et al. 2003).

Neben dem bereits beschriebenen Einfluss von CRH auf Endothel- und Mastzellen wurden in der Haut von am AEDS Erkrankten eine Reihe von Neuropeptiden identifiziert, die an der neuroendokrinoimmunologischen Kommunikation maßgeblich beteiligt sind (O 'Sullivan et al. 1998). Die Neuropeptide SP, CGRP und VIP beeinflussen über ihre Rezeptoren die Aktivitätsmuster von APZ, T-Zellen, Makrophagen, Keratinozyten, Endothel- und Mastzellen, Basophilen, Haar- und Drüsenzellen (Scholzen et al. 1998). Sie wirken auch „vasoaktiv“ durch Steigerung der Gefäßpermeabilität und immunmodulierend im Sinne der Initiation einer Entzündungsreaktion, falls sie nicht schnell genug wieder von entsprechenden Enzymen wie z.B. der Neutralen Endopeptidase deaktiviert werden. Darüber hinaus können Neuropeptide wie SP direkt und auch indirekt über Histaminfreisetzung aus Mastzellen Juckreiz induzieren. Tovoda et al. (2002) fanden auch erhöhte Blutplasmakonzentrationen von NGF und SP in Abhängigkeit zur Krankheitsaktivität.

Des Weiteren existiert auch ein lokales CRH/POMC-System der Haut, dessen biologische Funktion im Schutz der Haut gegenüber lokalen Stressoren (v. a. UVStrahlung, Viren, Bakterien) liegt und eine immunologische Homöostase gewährleistet (Slominski et al. 2000). Daneben kann in der Haut Serotonin und wahrscheinlich auch Melatonin gebildet werden, welche ebenfalls zur Regulation der Hautfunktionen beitragen (Slominski et al. 2002).

All diese neurobiologischen Befunde zeigen, dass offenbar ein direkter "Draht“ zwischen Psyche und Haut besteht. Das Zusammenwirken von Psyche, Hormonund Immunsystem erfolgt durch ein psychoneuroimmunoendokrinologisches Netzwerk. Dieses Netzwerk wirkt systemisch im ganzen Organismus sowie auf Organebene in der Haut. 


\subsection{Ziele der Arbeit - Arbeitsmodell - Fragestellung}

Die zuvor dargestellten Zusammenhänge zeigen, dass beim AEDS von komplexen Interaktionen zwischen Genen, der Umwelt, dem ZNS und PNS, dem Immunsystem, den Emotionen und Verhaltensweisen sowie der Haut auszugehen ist und dass das Ergebnis dieser Wechselwirkungen den jeweiligen Hautzustand bestimmt. Der Faktor Stress kann dabei als einflussreiche Größe eine bedeutsame Rolle spielen. Auf der Grundlage der bisher bekannten Zusammenhänge und Wechselwirkungen wurde das nachfolgende schematische Modell abgeleitet:

Abb. 1

Psychophysiologisches Modell zum Zusammenwirken von emotionalen, neuroendokrinen, immunologischen und dermatologischen Faktoren

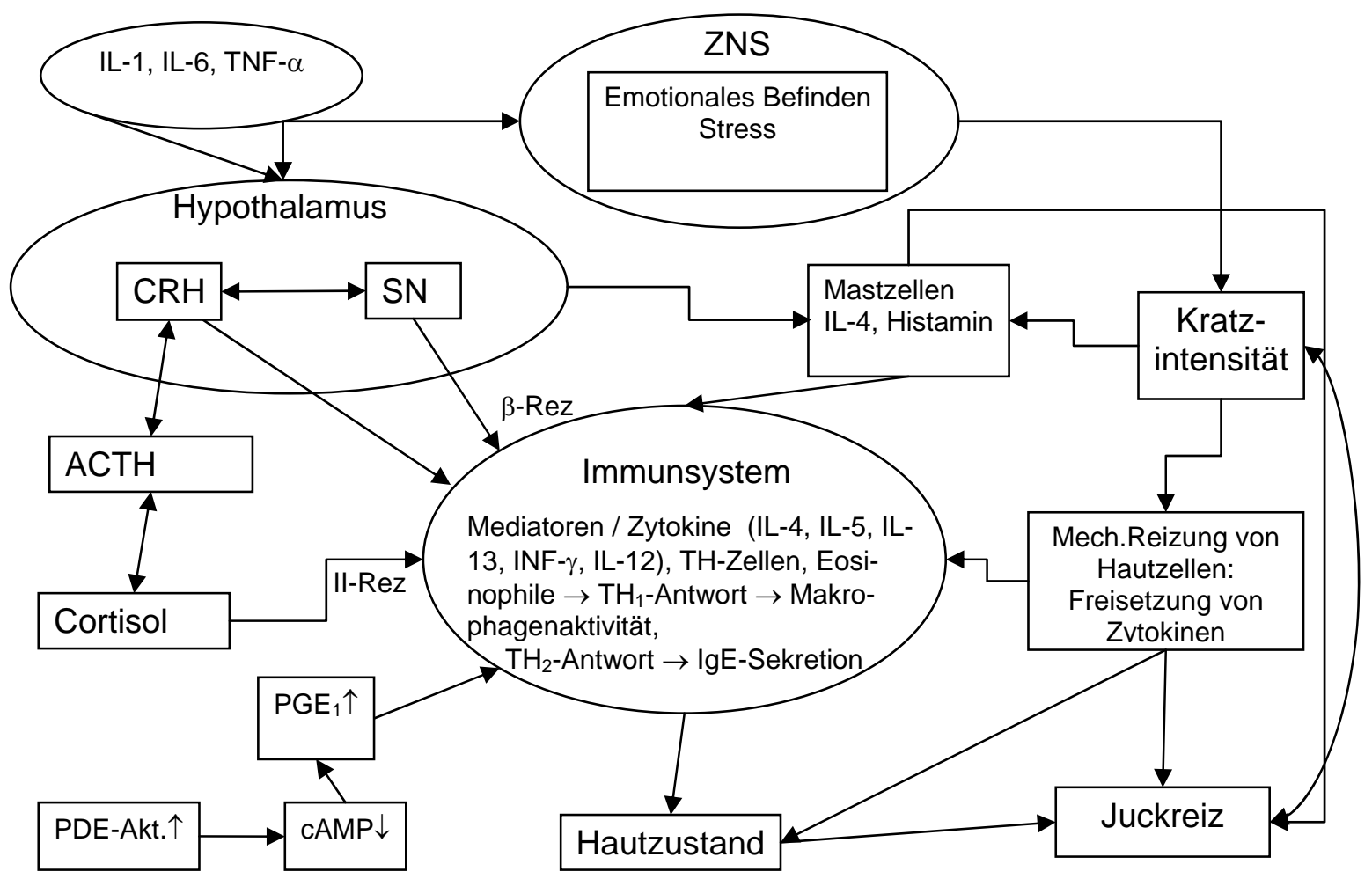

Aus dieser Zusammenstellung leiten sich zugleich auch die Fragestellungen ab, die in dieser Arbeit untersucht werden sollen:

1. Finden sich Zusammenhänge zwischen dem Hautzustand und dem Befinden ?

2. Finden sich Zusammenhänge zwischen dem Hautzustand und der Immunaktivität ?

3. Besteht ein "Juck-Kratz-Zirkel" und steht dieser in Beziehung zum Hautzustand?

4. Bestehen Zusammenhänge zwischen der Immunaktivität und dem Befinden ? 


\section{Material und Methoden}

Zunächst wird die Studienmethode besprochen, dann die Inhalte erläutert. Im Anschluss folgt die Beschreibung der einzelnen Parameter sowie der Analyse- und Auswertungsmethoden.

\subsection{Die integrative naturalistische Einzelfallstudie}

In dieser Studie sollen der Hautzustand, das emotionale Befinden, die Juckreizstärke und Kratzintensität sowie stressvolle Lebenssituationen erfasst und in Beziehung zueinander sowie in Beziehung zu biochemischen Indikatoren für Stress und die Immunaktivität gestellt werden, die täglich im Nachturin bestimmt wurden. Um allergisch und medikamentös bedingte Einflüsse auszuschließen, wurden nur Teilnehmer zugelassen, die nicht an einem AAEDS litten und zugleich keine Cortisontherapie vor oder während des Studienverlaufes durchführten.

Letztlich konnten nur ein Mann und eine Frau für die Studie ausgewählt werden. Beide leiden unter dem NAAEDS und waren ausreichend motiviert, über einen längeren Zeitraum gewissenhaft ein Tagebuch zu führen und ihren Nachturin zu sammeln. Von diesen beiden Probanden wurden über einen Zeitraum von 75 Tagen mittels strukturierter Tagebuchaufzeichnungen Angaben zum Hautzustand, der Juckreizstärke und Kratzintensität sowie zum Schlafverhalten und ihrem Befinden gemacht. Außerdem sammelten sie ihren Nachturin in einem Zeitfenster von 20.00 Uhr bis zum nächsten Morgen um 8.00 Uhr. Als biochemische Indikatoren wurden Neopterin, Adrenalin, Noradrenalin, Cortisol und Melatonin bestimmt. Im Rahmen des integrativen naturalistischen Einzelfallstudienkonzeptes sollte möglichst wenig in den normalen Tagesablauf der Studienteilnehmer durch somatische Untersuchungen, wie z.B. tägliche Blutabnahmen oder Hautarzttermine eingegriffen werden. Darum wurde auch auf eine tägliche Einschätzung des Hautzustandes mittels Scorad-Index verzichtet. Vielmehr wurde der Hautzustand von den beiden Probanden täglich subjektiv anhand einer Analogskala (0-100) hinsichtlich des Ausmaßes des Hautbefalls eingeschätzt. Auf diese Weise wurden auch die Stärke des Juckreizes und die Kratzintensität ermittelt. 


\section{$2.2 \quad$ Untersuchungsparameter}

Nachfolgend werden die Methoden zur Erfassung der Einflussgrößen vorgestellt.

\subsubsection{Tagebuch - Hautzustand, Befinden, Schlaf, Besonderheiten}

Die Teilnehmer wurden angehalten die Angaben im Tagebuch abends vor Beginn der nächtlichen Urinsammlung bzw. nach Abschluss derselben am kommenden Morgen zu machen.

Die Stärke des Hautbefalls wurde in einer visuellen Analogskala (nicht $=0 \mathrm{~mm}$ bis stark = $100 \mathrm{~mm}$ ) gesondert für die Körperregionen Gesicht, Hals, Hände, Arme, Rumpf und Beine erfasst und anschließend zu einem Gesamtwert (in mm) addiert. Ebenfalls über eine solche visuelle Analogskala wurde die Juckreiz- und Kratzintensität sowie die Intensität von beunruhigenden Gedanken erfasst.

Das aktuelle Befinden wurde über eine integrierte "Eigenschaftswörterliste" (EWL60 S) von Janke und Debus (1978) ermittelt. Dieses Instrument dient der mehrdimensionalen Erfassung des jeweils aktuellen Befindens und erlaubt das Erstellen von Befindlichkeitsprofilen. Sie eignet sich explizit für Wiederholungsuntersuchungen. Insgesamt werden dabei im Rahmen einer Selbstbeurteilung 60 Befindlichkeitsaspekte erhoben, die sechs Bereichen zugeordnet sind: Leistungsbezogene Aktivität, allgemeine Desaktivität, Extraversion / Introversion, allgemeines Wohlbefinden, emotionale Gereiztheit sowie Angst / Deprimiertheit. Außerdem wurde nach belastenden Tagesereignissen und besonderen körperlichen Anstrengungen gefragt. Des Weiteren wurden Fragen zum Schlafverhalten (Dauer, Unterbrechungen) und zur Schlafqualität und -erholsamkeit gestellt.

\subsubsection{Fragebögen zur Erfassung der Persönlichkeit}

Die nachfolgend genannten Fragebögen dienen zur testpsychologischen Untersuchung der beiden Studienteilnehmer. 
Fragebogen STAI (X1, X2): Das State Trait Anxiety Inventory (STAI) von Laux et al. (1981) setzt sich aus zwei Fragebögen zusammen. Die State-Angstskala (STAI-G Form X1) besteht aus 20 Feststellungen zum momentanen Befinden des Probanden. Den zeitlichen Bezugsrahmen der Skala X1 stellt somit die Situation der Testdurchführung dar. Die Beantwortung erfolgt auf einer vierstufigen Ratingskala mit den Intensitätsangaben „überhaupt nicht“ (1)“, „ein wenig “ (2), „ziemlich“ (3), „sehr“ (4). Die Trait-Angstskala (STAI-G Form X2) enthält ebenfalls 20 Items. Sie beziehen sich auf das situationsunabhängige Allgemeinbefinden. Die Beantwortung der Skala X2 ist weniger zeit- und situationsgebunden, da Angst als relativ stabiles Persönlichkeitsmerkmal erfasst werden soll. Die Beantwortung erfolgt auf einer vierstufigen Ratingskala mit Häufigkeitsangaben "fast nie" (1), „manchmal“ (2), „oft“ (3), „fast immer“ (4).

Fragebogen CES-D: Bei der deutschen Version der Center for Epidemiological Studies - Depressions Skala (CES-D) von Hautzinger (1988) handelt es sich um ein kurzes, einfach anzuwendendes Instrument zur Messung depressiver Stimmungen und Symptome. Das Verfahren umfasst insgesamt 20 Items, die typisch depressive Symptome mit Schwerpunkt auf den affektiven Komponenten beschreiben (gedrückte Stimmung, Schuldgefühle, Wertlosigkeit, Hoffnungslosigkeit, Antriebsmangel, Appetitverlust, Schlaflosigkeit). Die einzelnen Feststellungen können auf einer vierstufigen Skala hinsichtlich der Häufigkeit und der Dauer des Auftretens jedes Symptoms beurteilt werden. Bezugsrahmen für die Beantwortung der Items ist die vorausgegangene Woche.

Fragebogen AAS: Bei der Entwicklung der Adult Attachment State (AAS) von Collins und Read (1990) wurde versucht, den Bindungsstilen zugrunde liegende Strukturen zu identifizieren und durch die Formulierung geeigneter Selbstbeschreibungen erfassbar zu machen. Die resultierende AAS ist ein Bindungsfragebogen, der mit 18 Items die drei bindungstheoretisch als grundlegend erachteten Dimensionen Vertrauen, Nähe und Angst abdeckt. 
Fragebogen F-SOZU: Der Fragebogen zur Sozialen Unterstützung (F-SOZU) von Sommer und Fydrich (1989) ist ein Verfahren zur Erfassung des Konzeptes „Soziale Unterstützung“. Soziale Unterstützung wird charakterisiert durch das Ausmaß und Art der Hilfeleistung, die der Proband bei der Bewältigung von Lebensproblemen und Lebensbelastungen aus seiner natürlichen sozialen Umwelt erhält bzw. zu erhalten erwartet, wobei insbesondere der subjektiven Wahrnehmung von sozialer Unterstützung Bedeutung zukommt. Bei dem vorliegenden Verfahren stehen drei Aspekte sozialer Unterstützung im Vordergrund: emotionale Unterstützung, praktische Unterstützung sowie soziale Integration. Die Kurzform (F-SOZU K-22) besteht aus 22 Aussagen, die auf einer fünfstufigen Ratingskala von „trifft nicht zu“ bis „trifft genau zu“ zu beantworten sind.

Fragebogen SF-36: Der Fragebogen zum Gesundheitszustand „Short-Form-36 Health Survey" (SF-36) von Bullinger und Kirchberger (1998) ist ein krankheitsübergreifendes Messinstrument zur Erfassung der gesundheitsbezogenen Lebensqualität von Patienten. Der SF-36 erfasst 8 Dimensionen der gesundheitsbezogenen Lebensqualität oder subjektiven Gesundheit, die sich konzeptuell in die Bereiche „körperliche Gesundheit“ und „psychische Gesundheit“ einordnen lassen.

Fragebogen SOC: Der Fragebogen zum Kohärenzsinn (Sense of Coherence, SOC) von Antonovsky (1993) thematisiert verschiedene Bewältigungsformen gegenüber allgemeinen Stressoren. Der Fragebogen umfasst 29 als Fragen oder Statements formulierte Items, mit den die drei Dimensionen Verstehbarkeit („comprehensibility“), Machbarkeit („manageability“) und Bedeutsamkeit („meaningfulness") abgedeckt werden.

Fragebogen MNF: Der Marburger Neurodermitis Fragebogen (MNF) ist Bestandteil einer Batterie von Instrumenten, die von Stangier et al. (1996) als Fragebögen zur Bewältigung von Hautkrankheiten $(\mathrm{FBH})$ veröffentlicht wurden. Der MNF umfasst insgesamt 42 Items, die fünf faktorenanalytisch ermittelten Subskalen zugeordnet sind: (1) Stigmatisierung, (2) Leidensdruck, (3) allgemeine emotionale Belastung, (4) Einschränkung der Lebensqualität und (5) krankheitsbezogenes 
Problembewusstsein. Das Zutreffen der Aussagen ist auf fünfstufigen Ratingskalen von „1“ (überhaupt nicht) bis „5“ (sehr stark) einzuschätzen. Abschließend sind Fragen nach der Stärke verschiedener Einflussfaktoren (Veranlagung, Psychische Belastungen, Umweltfaktoren) sowie den zum Zeitpunkt der Befragung befallenen Körperteilen zu beantworten.

Fragebogen JKF: Der Juckreiz-Kognitions-Fragebogen (JFK), der ebenfalls Bestandteil der Fragebogenbatterie (FBH) von Stangier et al. (1996) ist, umfasst insgesamt 20 Items, die Kognitionen zum Juckreiz und zu dessen Bewältigung vorgeben. Die Items sind zwei faktorenanalytisch bestimmten Skalen (Katastrophisierung/Hilflosigkeit, Bewältigung) zugeordnet, die ungünstige (JKF-1) und günstige (JKF-2) Gedanken für die Bewältigung des Juckreizes enthalten. Auf einer fünfstufigen Antwortskala von „0“ (nie) bis "4“ (immer) ist anzugeben, wie häufig der entsprechende Gedanke auftritt, wenn der Juckreiz besteht.

Fragebogen FKV-LIS: Der Freiburger Fragebogen zur Krankheitsverarbeitung (FKV) von Muthny (1989) umfasst in seiner Kurzform (FKV-LIS) 35 Aussagen, die die Bereiche depressive Verarbeitung, aktives problemorientiertes Coping, Ablenkung und Selbstaufbau, Religiosität und Sinnsuche sowie Bagatellisierung und Wunschdenken abdecken. Damit erlaubt der FKV die Abbildung eines breiten Spektrums von Coping- und Krankheitsverarbeitungs-Modi.

\subsubsection{Neuroendokrine und immunologische Parameter}

Als biochemische Stressindikatoren wurden Adrenalin, Noradrenalin und Cortisol, sowie Neopterin als Indikator für die zelluläre Immunaktivität im Nachturin bestimmt. Außerdem wurde der Melatoninhalt im Nachturin gemessen, über dessen Bezug zum AEDS bisher kaum etwas bekannt ist. 


\section{$2.3 \quad$ Laboranalytik - Bestimmungsverfahren}

Nachfolgend werden alle angewandten Methoden zur Analytik der neuroendokrinen und immunologischen Parameter aus den Urinproben beschrieben.

\subsubsection{Katecholamine}

Vor der chromatographischen Trennung ist eine Isolierung der Katecholamine aus der komplexen biologischen Probenmatrix erforderlich. Die dabei am häufigsten angewendete Methode basiert auf der selektiven Adsorption der Katecholamine an Aluminiumoxid (Festphase) in basischem Milieu und wurde erstmals von Anton und Sayre (1962) beschrieben. Die Festphase wird gewaschen und anschließend werden die Katecholamine durch eine saure Pufferlösung wieder freigesetzt. In der vorliegenden Arbeit kam die von Smedes et al. (1982) entwickelte Flüssigextraktionsmethode zur Anwendung. Diese basiert auf der Komplexbildung der DiolGruppe der Katecholamine mit Diphenylborsäure und gleichzeitiger Kationenpaarbildung mit Tetraoctylammoniumbromid. Der entstandene Borat-Diol-Komplex kann in die organische Phase übergehen. Durch anschließendes Ausschütteln mit 0,08 M Essigsäure wird die Komplexbindung gelöst und die Katecholamine werden in der wässerigen Essigsäurephase angereichert. Die Flüssigextraktionsmethode besitzt die gleiche Spezifität wie die Aluminiumoxid-Adsorption, zeigt jedoch größere Wiederfindungsraten (95-100\%) und höhere Präzision (Bauch et al. 1986). Die Aufarbeitung von Urinproben kann mit der Flüssigextraktionsmethode leicht als Mikroansatz im Eppendorf-Reaktionsgefäß durchgeführt werden. Stark saure Urine müssen für die Extraktion ausreichend neutralisiert werden.

Probenaufbereitung: Zur Vorbereitung der Urinproben für die Extraktion wird die Probe für $5 \mathrm{~min}$ bei $2000 \mathrm{U} / \mathrm{min}$. zentrifugiert. Die anschließende Extraktion der Katecholamine wurde folgendermaßen durchgeführt: $25 \mu$ klare Urinprobe plus $10 \mu \mathrm{l}$ interner Standard (DHBA = Dihydroxybenzylamin; $5 \mathrm{ng}$ ) wurden in ein 1,5 ml Eppendorf-Reaktionsgefäß gegeben und mit $200 \mu \mathrm{NH}_{4} \mathrm{OH}-\mathrm{NH}_{4} \mathrm{Cl}-\mathrm{Puffer}(2 \mathrm{M}$; pH 8,5; enthält 0,2 \% Diphenylboric Acid 2-Amino-Ethyl Ester und 0,5\% EDTA) und $800 \mu$ l organischer Lösung (n-Heptan, mit 1\% Octanol und 0,25\% Tetraoctylammoniumbromid) versetzt. Die Proben wurden 2 min. von Hand geschüttelt und bei 
$1200 \times$ g für 5 min. zentrifugiert. $600 \mu \mathrm{l}$ des organischen Überstandes wurden abgenommen, in ein zweites $1,5 \mathrm{ml}$ Eppendorfgefäß gegeben und mit $300 \mu \mathrm{l}$ Octanol und $50 \mu \mathrm{l}$ 0,08 M Essigsäure versetzt. Nochmals wurde die Probe 2 min. geschüttelt und anschließend zentrifugiert. Von der unteren wässrigen Phase wurden $35 \mu \mathrm{l}$ mit einer Hamilton-Spritze entnommen und in ein Autosampler-Mikrogefäß überführt. $10 \mu \mathrm{l}$ Katecholamin-Extrakt wurden in das HPLC-System injiziert. Die Herstellung der Lösungen erfolgte nach Smedes et al. (1982).

Kalibrierung: Mit einer Verdünnungsreihe aus Katecholamin-Standardlösung wurde eine lineare Eichfunktion erstellt (0,3 bis $150 \mathrm{ng} / \mathrm{ml})$ und aus dem Vergleich der Peakflächen von Standardsubstanz und Probe die Katecholamin-Konzentration ermittelt (Chromatographie-Software: Gynkosoft). Die Wiederfindung des zugesetzten internen Standards DHBA schwankte zwischen 80 und 100\%. Alle Meßergebnisse wurden auf 100\% DHBA normiert.

Kontrolle und Präzision: Ein Kontroll-Urin mit der mittleren Konzentration von $43,16 \mathrm{ng} / \mathrm{ml}$ für Noradrenalin und $5,19 \mathrm{ng} / \mathrm{ml}$ für Adrenalin wurde bei jeder Probenaufarbeitung mit gemessen. Der Messfehler (Variationskoeffizient) für $n=23$ Kontroll-Urine betrug für Noradrenalin, Adrenalin und den internen Standard DHBA 2,28\%, 3,14\% und 2,19\%.

Die anschließende Auftrennung der extrahierten Proben erfolgte mittels HPLC (high pressure liquid chromatography) mit anschließender amperometrischer Detektion. Das HPLC-System bestand aus einem Entgasungsgerät (GT 103), einer Präzisionspumpe (M 480), einem kühlbaren Injektionsautomat (GINA 160), einem Peltier-Säulenthermostat (STH-585), und einem amperometrischen Detektor (EP 30). Alle Geräte entstammen der Fa. Gynkotek in Germering. Für die amperometrische Detektion wurde mit Hilfe einer Standard-Potentialreihe ein optimales Arbeitspotential von $550 \mathrm{mV}$ ermittelt.

Die Trennung erfolgte über eine Reversed-Phase-C18-Säule (Nucleosil, $3 \mu \mathrm{m}$, $120 \times 3 \mathrm{~mm}$ ), die über Fa. Sepserv (Berlin) bezogen wurde. Als Elutionsmittel wurde ein Citrat-Puffer folgender Zusammensetzung verwendet: $25 \mathrm{mM}$ Citrat; $50 \mathrm{mM}$ Di-Natriumhydrogenphosphat; 0,270 mM EDTA und 2,75 mM Octansulfonsäure (Ionenpaar-Reagenz). Der pH-Wert betrug 4,9. Der Puffer enthielt 8\% Methanol. 
Die Trennung wurde bei einer Temperatur von $30^{\circ} \mathrm{C}$ und einer Flußrate von $500 \mu \mathrm{l} / \mathrm{min}$. durchgeführt (der Druck entsprach ca. 160 bar).

Verwendete Materialien und Chemikalien: Citronensäure-Monohydrat, Natriumdihydrogenphosphat, Titriplex III, Methanol, Essigsäure (Fa. Merck, Darmstadt); 1-Octane-sulfonic acid, Tetraoctylammoniumbromid, 1-Octanol, n-Heptane, DiphenylboricAcid2-Amino-Ethyl-Ester, (-)-Arterenol ((-)-Norepinephrine), (-)-Epinephrine, Dihydroxybenzylamine (Fa. Sigma, Deisenhofen)

\subsubsection{Cortisol}

Zur Bestimmung von freiem Cortisol aus Urinproben wurde ein Radio-ImmunoAssay (RIA) eingesetzt (Doering et al. 2001). Das Meßprinzip beruht auf einer Konkurrenzreaktion von Proben-Cortisol und radioaktiv markiertem Cortisol um die Bindung an den Cortisol-Antikörper (aus Kaninchen gewonnen). Zu jeder Probe mit unbekannter Konzentration an Cortisol wird eine konstante Menge radioaktiv markiertes Cortisol zugegeben. Bei hoher Cortisol-Konzentration in der Probe wird sich wenig radioaktives Cortisol an den Antikörper binden, während bei niedrigerer Cortisol-Konzentration in der Probe entsprechend mehr Radioaktivität am Antikörper meßbar ist (Konkurrenzreaktion). Bevor die Radioaktivität gemessen werden kann, muß in herkömmlichen RIA's noch die ungebundene Radioaktivität durch einen Extraktionsschritt (meist mit Aktiv-Kohle) entfernt werden. Bei den Tritiummarkierten $\left({ }^{3} \mathrm{H}\right)$ Substanzen, wie in unserem RIA der Fall, wird die Radioaktivität nicht direkt gemessen, sondern über den Zusatz einer fluoreszierenden Flüssigkeit (z.B. Lumagel) wird durch die ß-Strahlung diese Flüssigkeit zur Fluoreszenz angeregt, und die entstehenden Lichtblitze werden in einer photosensitiven Meßzelle des „Counters“ gezählt. Die ß-Strahlung ist zu schwach um durch die Wände der Reaktionsgefäße zu dringen und beeinflusst somit die direkte Messung nicht. Zur Cortisolbestimmung in der vorliegenden Studie wurde eine modifizierte Version dieses „klassischen“ RIA's, der sogenannte SP-RIA (szintillisation proximity radio immuno assay) eingesetzt. Durch die Verwendung so genannter Fluoromikrospheren ist kein „Lumagel“ mehr erforderlich. Fluoromicrospheren sind kleine Kü- 
gelchen, die an der Oberfläche mit einem Antikörper gegen den verwendeten Cortisol-Antikörper beschichtet sind und die im Inneren aus einer Festsubstanz bestehen, die durch ß-Strahlung zur Fluoreszenz angeregt werden kann. Diese Fluoromikrospheren-Suspension wird gleich zu Beginn des Assays zu gleichen Teilen allen Proben hinzugegeben. Nur die an die Cortisol-Antikörper gebundene Radioaktivität (nicht die frei umherschwimmende) kann die Kügelchen zum fluoreszieren bringen, weil hierfür der direkte Kontakt der Radioaktivität mit den Kügelchen nötig ist, der über die Bindung mit dem Oberflächen-Antikörper gegen Kaninchen hergestellt wird.

Probenaufbereitung: Die Urinproben müssen $5 \mathrm{~min}$. bei $2000 \mathrm{U} / \mathrm{min}$. zentrifugiert werden. $50 \mu \mathrm{l}$ des klaren Urins wurden in ein Eppendorfgefäß überführt, und mit $1 \mathrm{ml}$ RIA-Puffer gemischt. $2 \times 100 \mu \mathrm{l}$ wurden in den RIA eingesetzt. Hinweis: Mit diesem Versuchsansatz wird nur die freie Fraktion des Cortisols im Urin bestimmt. Zusammensetzung des RIA-Puffers: $0,05 \mathrm{M}$ Tris- $\mathrm{HCl}, 0,1 \mathrm{M} \mathrm{NaCl}, 0,1 \%$ Gelatine, $0,1 \%$ Natriumazid. Die Gelatine wurde unter leichtem Erwärmen (ca. $50^{\circ} \mathrm{C}$ ) gelöst. Mit $\mathrm{HCl}$ wurde der $\mathrm{pH}-$ Wert auf 8,0 eingestellt.

Eichkurve: Zur Quantifizierung der Cortisol-Konzentration wurde über eine Verdünngsreihe von Cortisolstandard (7,5pg bis $1000 \mathrm{pg} / 100 \mu \mathrm{l})$ eine Eichkurve erstellt, die typischerweise einen sigmoiden Verlauf zeigte. Durch das Mitführen von Aliquots einer Kontrollprobe kann die Abweichung der Analysenergebnisse innerhalb des RIA's (Intraassay-Variation) und die Abweichung mehrerer RIA's untereinander (Interassay-Variation) ermittelt werden. Für den verwendeten RIA lagen beide Variationskoeffizienten unter $10 \%$.

Chemikalien und Reagenzien: Cortisol-Antikörper (Wirt: Kaninchen) (Fa. Biogenesis, Poole, UK), Tritium markiertes Cortisol, Szintillization proximity reagent (Anti-Rabbit) (Fa. Amersham-Buchler, Braunschweig); Tris- $\mathrm{HCl}, \mathrm{NaCl}, \mathrm{HCl}$, Ethanol 99\% (Fa. Merck, Darmstadt); Gelatine (Bovine), Natriumazid (Fa. Sigma, Deisenhofen). 


\subsubsection{Neopterin und Kreatinin}

Die verwendete Bestimmungsmethode von Neopterin (Tetrahydrobiopterin) aus dem Nachturin geht auf Hausen et al. (1982) zurück und erfolgt mittels HPLC. Sie wurde auf eine moderne, hochauflösende Mikromethode optimiert. Durch die Verwendung von zwei hintereinander angeordneten Detektoren kann gleichzeitig Neopterin mit Fluoreszenz und Kreatinin mit UV detektiert werden.

Probenaufbereitung: Die Urinproben müssen $5 \mathrm{~min}$. bei 2000U/min. zentrifugiert werden. Der klare Überstand wurde 1:250 mit HPLC-Puffer (siehe unten) verdünnt. $10 \mu \mathrm{l}$ wurden chromatographiert.

Chromatographische Bedingungen: Die Auftrennung der Probe erfolgte über eine

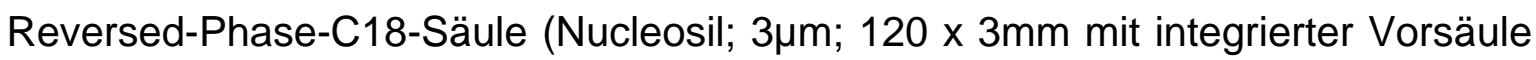
gleichen Trennmaterials; Fa. Knauer, Berlin) bei $30^{\circ} \mathrm{C}$ und $0,6 \mathrm{ml} / \mathrm{min}$ Fluss.

HPLC-System: siehe Katecholamine (ohne elektrochemischen Detektor). Die Detektion der Substanzen wurde durch die Reihenschaltung eines Fluoreszenzdetektors (RF 2000; Fa. Dionex) und eines UV-Vis Detektors (UV-VIS 160; Fa. Gynkotek) erreicht. Neopterin wurde fluorometrisch bestimmt (Anregungswellenlänge: $353 \mathrm{~nm}$; Abstrahlungswellenlänge: $438 \mathrm{~nm}$ ). Für Kreatinin wurde die Absorption bei $235 \mathrm{~nm}$ gemessen. Als HPLC-Puffer wurde ein $15 \mathrm{mM}$ Kaliumphosphatpuffer pH 6,6 eingesetzt.

Kalibrierung: Mit einer Verdünnungsreihe aus Neopterin und KreatininStandardlösung wurde eine lineare Eichfunktion erstellt $(0,03 \mathrm{mM}$ bis $30 \mathrm{mM}$ für Kreatinin; 3,16 nM bis 3,16 $\mu \mathrm{M}$ für Neopterin) und aus dem Vergleich der Peakflächen von Standardsubstanz und Probe die Konzentrationen ermittelt (Chromatographie-Software: Fa. Gynkosoft)

Kontrolle und Präzision: Ein Kontroll-Urin mit der mittleren Konzentration von 8,24 mM Kreatinin und 1,166 $\mu \mathrm{M}$ Neopterin wurde bei jeder Probenaufarbeitung mitgemessen. Der Meßfehler (Variationskoeffizient) für $n=18$ Kontroll-Urine betrug für Kreatinin 1,26\% und für Neopterin 4,97\%.

Chemikalien und Reagenzien: Kaliumdihydrogenphosphat, di-Kaliumhydrogenphosphat (Fa. Merck, Darmstadt), Kreatinin, Neopterin (Fa. Sigma, Deisenhofen). 


\subsubsection{Melatonin}

Die Bestimmung von Melatonin erfolgte ebenfalls mit einem Radioimmunoassay (Lang et al. 1981). Für eine Einführung zum Meßprinzip wird auf die Anleitung zur Cortisol-Bestimmung verwiesen. In diesem RIA wird die freie Radioaktivität vor der Messung durch einen zusätzlichen Aktiv-Kohle-Extraktionsschritt entfernt. Die Zugabe von Fluoromicrospheren entfällt. Die Transformation der ß-Strahlung in Lichtsignale erfolgt durch die Zugabe einer Szintillisationsflüssigkeit (Lumagel).

Probenaufbereitung: $3 \mathrm{ml}$ Urin zentrifugieren (2000 U/min.; $5 \mathrm{~min}$.). Davon $2 \mathrm{ml}$ klaren Urin in ein („lösungsmittelfestes“) Falcon-Röhrchen pipettieren. $1 \mathrm{ml}$ Acetatpuffer $\left(\mathrm{pH} \mathrm{4,0)}\right.$ und $2 \mathrm{ml}$ Chloroform $1 \mathrm{~min}$. schütteln. $15 \mathrm{~min}$. bei $4^{\circ} \mathrm{C}$ ruhen lassen. 5 min. zentrifugieren (300 U/min.). Wässrige Oberphase so gut es geht abpipettieren und verwerfen. Zu der verbleibenden Chloroformphase $250 \mu \mathrm{l}$ 0,1 M $\mathrm{NaOH}$ zugeben, 1 min. über Kopf schütteln, 15 min. bei $4^{\circ} \mathrm{C}$ ruhen lassen. Dann erneut $5 \mathrm{~min}$. zentrifugieren (300 U/min.). 1,5 ml der Chloroformphase werden in der Vakuum-Zentrifuge (Heto-Vac, Fa. Hereus) bis zur Trocknung eingeengt. Für den RIA wurde der Rückstand mit 750 $\mathrm{Ml}$ RIA-Puffer (Zusammensetzung: siehe Anleitung für Cortisol) gelöst und $2 \times 300 \mu$ für eine Doppelbestimmung eingesetzt. Eichkurve: Zur Ermittlung der Melatonin-Konzentration wurde mit einem Melatoninstandard $(1,5 \mathrm{pg}-250 \mathrm{pg} / 300 \mu \mathrm{l})$ mittels Verdünngsreihe eine Eichkurve erstellt. Chemikalien und Reagenzien: Tritium-markiertes Melatonin und Melatonin-Antikörper (Fa. Guildhay Antisera, Guildford, UK), Tris- $\mathrm{HCl}, \mathrm{NaCl}, \mathrm{HCl}$, Essigsäure, Natriumhydroxid, Natriumacetat (Fa. Merck, Darmstadt); Gelantine (Bovine), Natriumazid, Aktivkohle, Dextran (Fa. Sigma, Deisenhofen).

\section{$2.4 \quad$ Auswertungsmethoden}

Nachfolgend werden die angewandten Auswertungsmethoden näher beschrieben, wobei insbesondere auf die mathematischen Auswertungsmethoden näher eingegangen wird. 


\subsubsection{Fragebögen}

Die unter 2.2.2. genannten Fragebögen dienen in erster Linie der näheren Beschreibung der Persönlichkeit. Diese erfolgt jeweils am Anfang der individuellen Ergebnisdarstellung.

\subsubsection{Tagebuchangaben}

Die Tagebuchangaben wurden tabellarisch transkribiert und als SPSS-Datendateien gespeichert. Als Einflussgrößen aus dem Tagebuch wurden aufgenommen: Hautzustand, Juckreizintensität, Kratzstärke, Gereiztheit, Ängstlichkeit, Aktivität, Desaktivität, Extravertiertheit, Introvertiertheit, Wohlbefinden, Grübelintensität, Schlafqualität und Schlaferholsamkeit.

\subsubsection{Urinanalysen}

Die Konzentrationsangaben aller bestimmten biochemischen Parameter wurden zwecks direkter Vergleichbarkeit auf Kreatinin in $\mathrm{mmol} / \mathrm{l}$ bezogen und ebenfalls in SPSS Datendateien erfasst. Bestimmt wurden die Konzentrationen von Adrenalin, Noradrenalin, Cortisol, Neopterin und Melatonin.

\subsubsection{Mathematische Auswertungsverfahren - Allgemeines, Zeitreihenanalyse, Kreuzkorrelationsanalyse}

Um zeitliche Beziehungen zwischen den verschiedenen biochemischen und psychologischen Variablen sowie dem Hautzustand zu erfassen, wurden pro Einzelfall die über jeweils 75 Tage erfassten Daten aller genannten 18 Einzelparameter zu entsprechend vielen Zeitreihen mit je 75 Messpunkten zusammengefasst. Jede Zeitreihe wurde einer Zeitreihenanalyse unterzogen, anschließend erfolgten Korrelationsanalysen der Zeitreihen. Die gesamte statistische Datenanalyse wurde mit dem Statistikprogramm SPSS Version 12.0 (Bühl und Zöfel 2005) durchgeführt. 
Zum grundlegenden Verständnis der Analyse von Zeitreihen sind einleitende Ausführungen notwendig, deren detaillierte mathematische Hintergründe jedoch nicht Thema dieser Arbeit sind. Für die vorliegende Arbeit sind vielmehr die daraus abgeleiteten konkret anwendbaren Verfahren von Interesse. Hierzu findet sich u. a. bei Bortz und Döring (2002) eine sehr gut verständliche und übersichtliche anwendungsorientierte Beschreibung der Methoden zur Zeitreihenanalyse. Ergänzende Informationen zu den entsprechenden mathematischen Grundlagen finden sich z. B. bei Schmitz et al. (1985) sowie Schlittgen und Streitberg (2001).

Beobachtete Zeitreihen stellen die Realisation eines stochastischen Prozesses dar. Dabei entspricht jeder Einzelwert der Zeitreihe der Realisation der jeweils beobachteten Zufallsvariable zum Zeitpunkt ( $\mathrm{t}$ ), so dass die Zeitreihe selbst letztlich eine Aneinanderreihung von Zufallsvariablen unbekannter Verteilung darstellt. Die Realisation einer gesamten Zeitreihe wird dabei als Überlagerung von drei Komponenten aufgefasst: einer Trendkomponente, zyklischen Schwankungen und einer Zufalls- oder Restkomponente. Es wird angenommen, dass jede Zeitreihe durch diese drei Komponenten „Vollständig“ erklärt und mathematisch beschrieben werden kann. Hierdurch wird zugleich auch die Grundproblematik bei der Auswertung von Zeitreihendaten deutlich, die Einzelwerte sind zumeist voneinander abhängig. Das bedeutet, dass ein bestimmter Messwert von den Vorhergehenden mitbestimmt wird. Dadurch entstehen im Allgemeinen charakteristische Regelmäßigkeiten im Zeitreihenverlauf. Diese Regelmäßigkeiten führen zu Autokorrelationen, deren Identifikation und Elimination als Voraussetzung für die weitere statistische Analyse der Zeitreihe gilt (Bortz und Döring 2002, S. 569). Noch bestehende Regelmäßigkeiten können Ursache von Scheinzusammenhängen sein.

Ein häufig angewandtes und etabliertes Verfahren zur Beschreibung der Regelmäßigkeiten von Zeitreihen wurde in der Ökonomie von Box und Jenkins (1976) entwickelt. Dieses Verfahren identifiziert und beschreibt die Regelmäßigkeiten einer Zeitreihe in Form eines sog. „ARIMA-Modells“, welches in mehreren Teilschritten in einem Prozess entwickelt wird. Die Bezeichnung „ARIMA“ steht für „Auto- 
Regressive-Integrated-Moving-Average“ und umschreibt somit die regelmäßigen Zeitreihenkomponenten.

Dabei entspricht die Auto-Regressive-Komponente (AR) einem Wachtumsprozeß, bei dem das System sich an den vorhergehenden Zuständen orientiert. Die vorangehenden Werte verlieren langsam an Einfluss. Ein AR-Prozess hat die Ordnung $p$, wenn die gewichtete Summe zurückliegender Werte eine optimale Vorhersage der Zeitreihenanteile gewährleistet.

Die Moving-Average-Komponente (MA) entspricht eher einem homöostatischen Modell, in dem die zufällige Auslenkung eines Prozesses von dem zugrunde liegenden Sollwert des Systems korrigiert wird. Das heißt, dass der jeweilige Messwert durch den „Fehlerwert“ davor liegender Zeitpunkte bestimmt wird. Der MAProzess hat die Ordnung q, wenn q zurückliegende Fehlerwerte zur Vorhersage der Zeitreihenanteile führen.

Die Integrative-Komponente (I) entspricht einer sog. stochastischen Drift im Niveau einer Zeitreihe oder anders ausgedrückt, einer zufälligen Alternation im Verlauf der Zeitreihe. Derartige Komponenten werden nach einer Autokorrelationsanalyse durch Differenzenbildung (Ordnung d) bestimmt und aus der Zeitreihe eliminiert. Diese wird dadurch stationär.

Dieser Schritt ist zugleich der erste auf dem Weg zur Identifikation des ARIMAProzesses, der die Zeitreihe beschreibt. Erst nach Erfüllung der Stationaritätsbedingung erfolgen die beiden vorgenannten AR- und MA-Prozesse. Dabei werden die Parameter $\mathrm{p}$ und $\mathrm{q}$ mittels Schätzverfahren (z.B. Unconditional Least Squares method) ermittelt. Entscheidend in diesem Verfahren ist immer wieder die abschließende Gütebewertung des auf diese Weise ermittelten ARIMA-Modells mit Hilfe verschiedener Statistiken anhand derer das ermittelte ARIMA-Modell entweder akzeptiert oder aber durch Wiederholung der beschriebenen Schritte weiter optimiert wird, solange bis das beste Modell gefunden wurde (siehe Anhang). 
Der gesamte ARIMA-Prozess (Modellidentifikation, Parameterschätzung Modellgüteüberprüfung) dient also zum einen der Erzeugung einer stationären Zeitreihe (Stationaritätsbedingung) mit gleicher mittlerer Höhe und gleicher Variabilität der Daten über die gesamte Zeitreihe hinweg und zum anderen dem Herausfiltern von autoregressiven Trends und rhythmischen Fluktuationen (Periodizität), die sich in der Zeitreihe befinden. Das entsprechende ARIMA-Modell beschreibt somit die jeweilige Originaldatenzeitreihe vollständig und überführt diese durch Elimination der identifizierten Anteile zugleich in eine sog. Residualzeitreihe, deren Einzeldaten wie ein weißes Rauschen (,white noise“) zufällig um die Nullinie herum verteilt sind. Aus den Originalzeitreihen werden durch diesen Prozess Bestandteile herausgefiltert, die in der nachfolgenden statistischen Analyse zum Auftreten von Scheinkorrelationen und somit auch zu Fehlinterpretationen führen könnten. Damit sind zugleich die Voraussetzungen erfüllt, die eine weitergehende statistische Analyse der Daten ermöglichen.

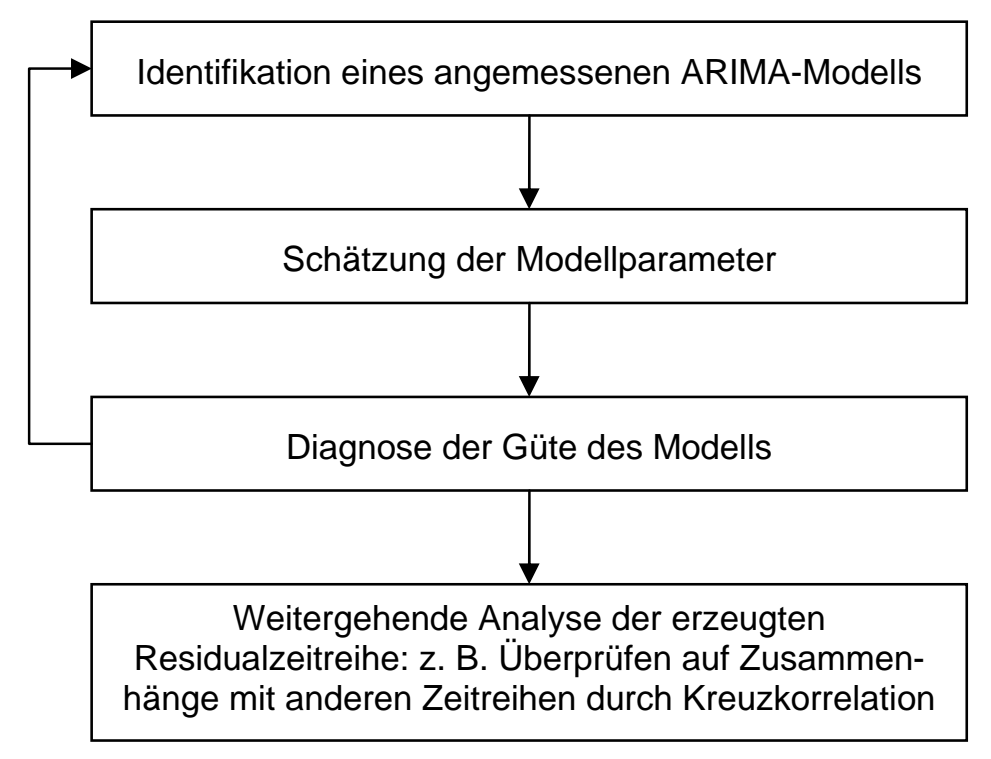

Abb. 2 Übersicht über das Vorgehen im Rahmen der Zeihenreihenanalyse nach Box und Jenkins (verändert nach Bortz und Döring 2002, S.569)

Diese bestand zunächst darin, die einzelnen Residualzeitreihen einer Kreuzkorrelationsanalyse zu unterziehen, um Hinweise auf das Vorliegen von Zusammenhängen zu erhalten. Diese Methode eignet sich insbesondere dann sehr gut zum Screening auf Zusammenhänge, wenn vorab keine eindeutigen Hypothesen dar- 
über vorliegen, welche Zeitreihe einer anderen vorangeht bzw. nachfolgt und/oder wenn eine wechselseitige Beeinflussung zwischen zwei Zeitreihen angenommen werden kann. Unter SPSS ist ein Signifikanzniveau $(\alpha)$ von 0,05 vorgegeben. Im nächsten Schritt wurden daher alle Residual-Zeitreihen mittels bivariater Korrelationsanalyse nach Pearson untersucht, um weitere möglicherweise bedeutsame Zusammenhänge bis zu einem Signifikanzniveau $(\alpha)$ von 0,1 zu erfassen.

Die abschließende Aufgabe bestand dann darin, die gefundenen Korrelationen in einen sinnvollen Zusammenhang zu stellen. Hierzu wurden die erhaltenen Ergebnisse in Übersichtsdiagrammen in Anlehnung an die Darstellungen (jedoch nicht in Anlehnung an die Methode!) bei Brosig und Brähler (2001) in Form vektorkodierter Pfeile dargestellt und es wurde versucht die ermittelten Einflussgrößen in einen pathogenetisch kausalen Zusammenhang zu stellen und so ein patientenspezifisches Wirkungsgefüge der Einflussfaktoren herauszuarbeiten.

\section{Ergebnisse und Auswertung}

Zunächst werden die Patienten vorgestellt, dann folgt eine Darstellung der Ergebnisse der statistischen Auswertung und anschließend die fallspezifische Gesamtbetrachtung des untersuchten Netzwerkes aus emotionalen, neuroendokrinen, immunologischen und Verhaltensfaktoren. Die kritische Bewertung der Ergebnisse findet in der Diskussion statt. Angaben zu den ARIMA-Modellen finden sich im Anhang.

\subsection{Patient AD02 - Allgemeine Beschreibung}

Die Patientin AD02 ist eine 25-jährige Medizinstudentin, die sich während der Studie in der Vorbereitungsphase auf das zweite Staatsexamen befand. Zum Ende 
der Studie legte sie zunächst das schriftliche und zwei Wochen später auch das mündliche Examen ab. Zum Praktischen Studienjahr wollte sie nach Würzburg gehen und dort mit ihrem Freund zusammenziehen, mit dem sie seit dreieinhalb Jahren eine „feste" partnerschaftliche Beziehung führt.

Die Patientin leidet seit ihrer Kindheit unter ekzematösen Hautveränderungen, vor allem an den Beugen, zeitweise auch im Gesicht. Bei ihr liegt die intrinsische Variante der atopischen Dermatitis vor. Der dermatologsiche Screeningtest auf häufige Atopieallergene sowie das Gesamt-IgE waren bei einer Untersuchung im Juli 2000 unauffällig. Der SCORAD wurde laut Befundbericht von Facharzt Dr. C. Gutgesell (im Jahr 2000 an der Dermatologischen Klinik der Georg-AugustUniversität Göttingen) am 12. Juli 2000 mit 19 Punkten bewertet.

Während des Studienzeitraumes bestand überwiegend eine geringe Krankheitsaktivität. Wenn sich ihre Haut verschlechtert, dann nicht übermäßig stark, aber doch deutlich. Sie kratzt sich des Öfteren unbemerkt, achtet ansonsten jedoch auf ihre Haut. Sie charakterisiert sich allerdings als jemanden, dem viele Dinge auch unter die Haut gehen können. Exogene Faktoren, die ihren Hautzustand mit beeinflussen, sind Klima und Schwitzen sowie körperliche Belastung, Aufregung/Stress im Privatbereich, Ernährung und Schlaf.

Die Patientin ist eine ausgeglichene Persönlichkeit mit vielfältigen sozialen Bindungen, die zufrieden ist mit ihrem Leben und ihre Erkrankung angenommen hat. $Z u$ ihren Eltern, die etwa $65 \mathrm{~km}$ entfernt leben, unterhält sie regelmäßigen Telefonkontakt, alle 6 Wochen besucht sie sie. Sie hat zwei Schwestern, die entfernter leben und die sie seltener sieht, zu denen aber ebenfalls ein regelmäßiger Telefonkontakt besteht. Am Studienort pflegt sie einen größeren Bekanntenkreis mit zwei besonders guten Freunden. Als Vertraute gibt sie ihren Partner und einen guten Freund an. Aus der Kindheit gibt sie keine besonderen Vorkommnisse an. 


\subsubsection{Darstellung des Hautzustandes und besonderer Ereignisse}

Der Hautzustand von AD02 ist in Abb. 3 (Originaldaten) und Abb. 4 (Residualdaten) dargestellt. Als Grundlage dienen, wie in Kapitel 2.2.1 beschrieben, die Tagebuchangaben zur Stärke des Hautbefalls in der Einheit Millimeter. Die mittels ARIMA-Verfahren erzeugten Residualdaten sind dimensionslos und schwanken in Form eines „white noise“ um die Nullinie.

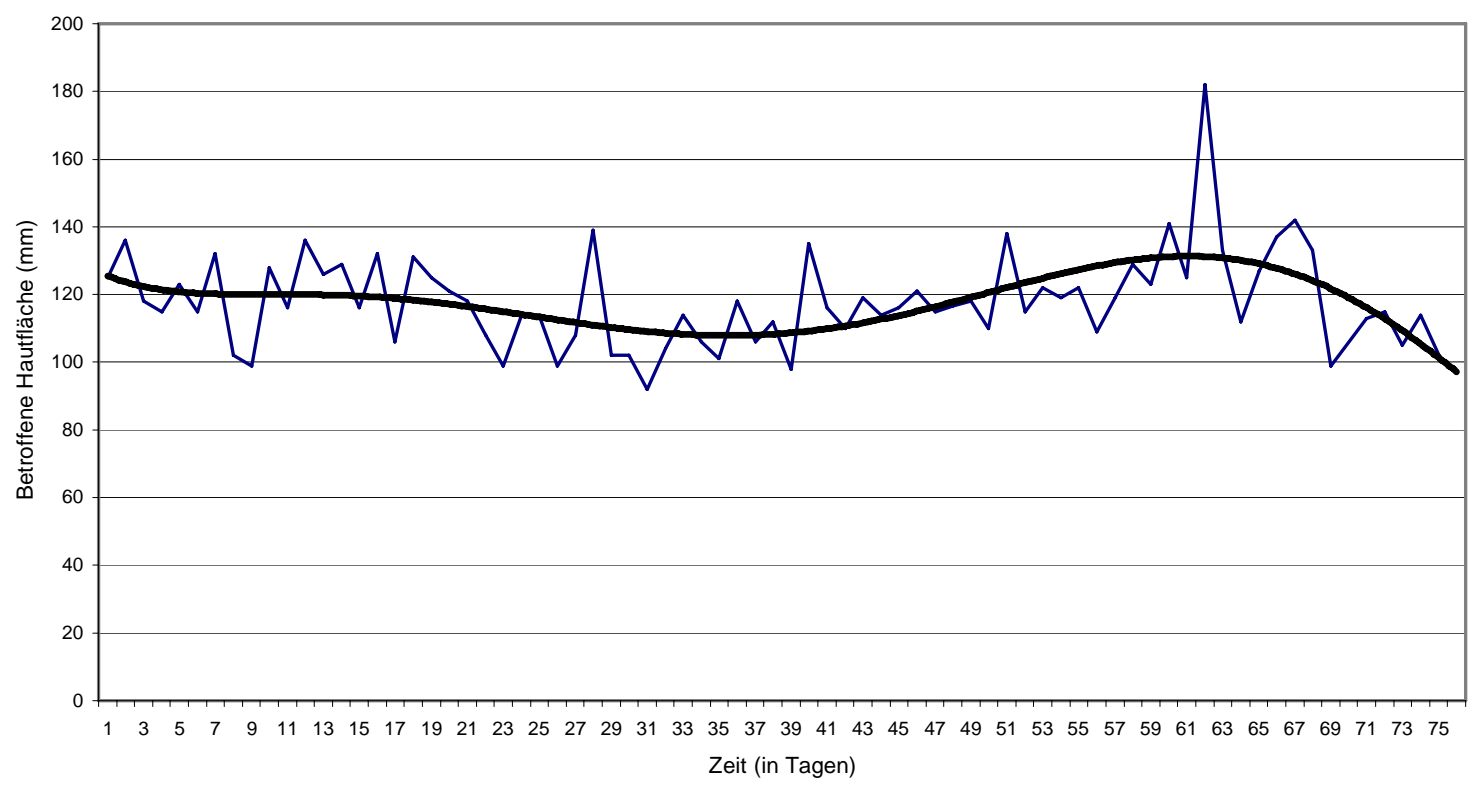

Abb. 3: Hautzustand (betroffene Hautfläche) von AD02 im Studienverlauf (Originaldaten)

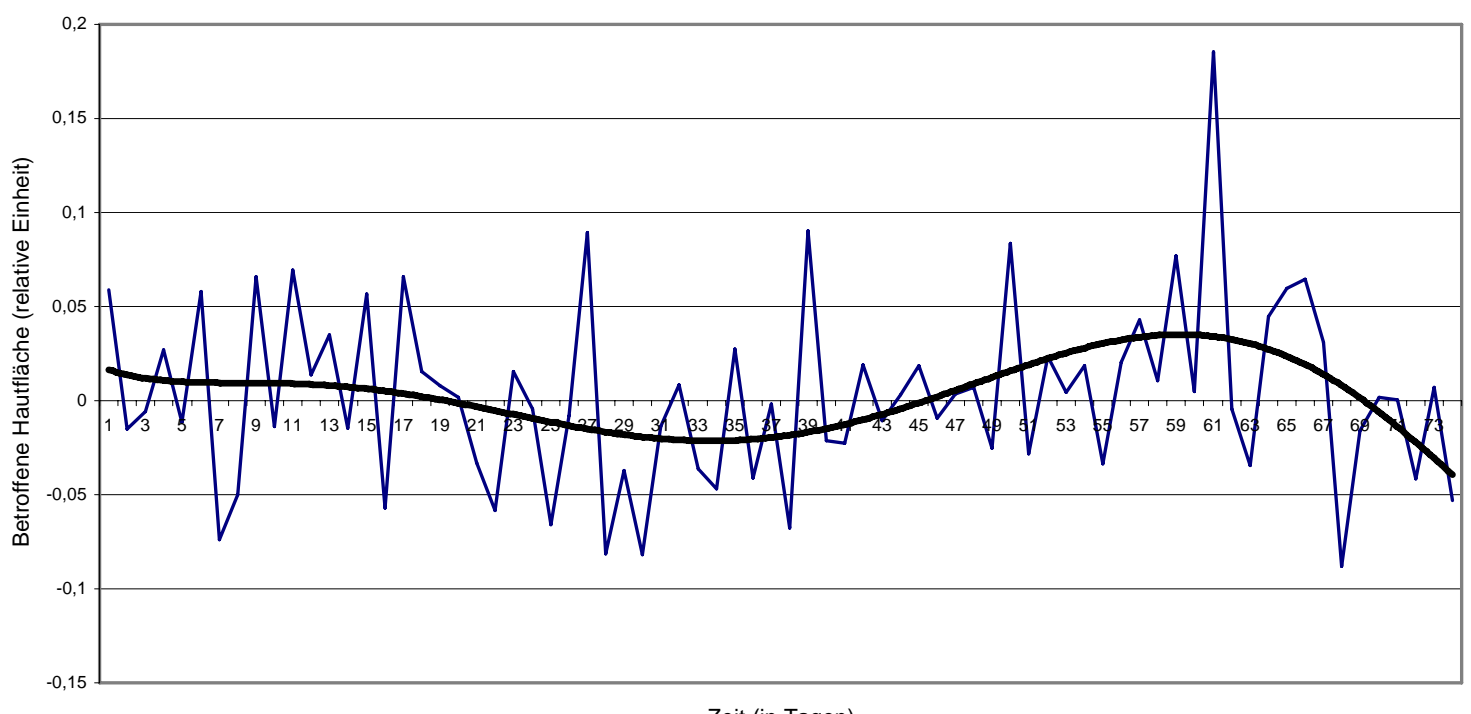

Zeit (in Tagen)

Abb. 4: Hautzustand (betroffene Hautfläche) von AD02 im Studienverlauf (Residualdaten) 
Es zeigt sich, dass das Ausmaß der betroffenen Hautfläche im gesamten Studienverlauf relativ konstant bleibt. Auffällige Veränderungen finden sich vor allem an einzelnen Tagen (z. B. zwischen Tag 39-41) sowie während der Endphase des Examens zwischen dem 57. und 67. Tag der Studie. Zum Studienende tritt wieder eine deutliche Besserung ein.

Von besonderem Interesse ist der Vergleich mit den Tagebuchangaben. Insbesondere bezüglich Hinweisen für das Vorliegen psychischer Belastungen in Phasen, in denen sich zugleich der Hautzustand verschlechtert.

Es folgt eine chronologische Übersicht von Tagebucheinträgen, die psychisch belastende Situationen beschreiben:

1. Tag 2-4 $\rightarrow$ Krankheit der Mutter (Verdacht auf Mamma-Karzinom).

2. Tag 32-34 $\rightarrow$ Grübeln bezüglich Umzug nach Würzburg, Zusammenziehen mit Freund.

3. Tag 39-41 $\rightarrow$ Ungewissheit bezüglich Wohnungskündigung ohne Zusage aus Würzburg.

4. Tag 55-67 $\rightarrow$ Erneute Sorgen wegen Umzug, Nachuntersuchung der Mutter, Examensstress.

Ob statistisch signifikante Zusammenhänge zwischen dem Auftreten psychisch belastender Situationen bzw. den damit einhergehenden Veränderungen des emotionalen Befindens und dem Hautzustand vorliegen, wie nach „oberflächlicher“ Betrachtung zu vermuten wäre, wurde mittels Kreuzkorrelationsanalyse bzw. bivariater Korrelationsanalyse der Residual-Datenreihen geprüft. Die Ergebnisse werden im nächsten Abschnitt vorgestellt. 


\subsubsection{Darstellung der statistischen Analysen der Residual-Zeitreihen}

Es folgt die graphische Darstellung der Kreuzkorrelationsanalysen der ResidualZeitreihen des Hautzustandes von AD02. Sie ermöglicht eine schnelle optische Durchsicht auf Zusammenhänge.

Abb. 5: Kreuzkorrelationsdiagramme des Hautzustandes von AD02 mit allen Faktoren ( a) Noradrenalin, b) Adrenalin,c) Cortisol, d) Neopterin. e) Juckreizstärke, f) Kratzintensität, g) Ängstlichkeit, h) Gereiztheit i) Desaktivität, j) Aktivität, k) Extravertiertheit, l) Introvertiertheit, m) Wohlbefinden, n) Melatonin, o) Schlafqualität, p) Schlaferholsamkeit)

Die Lag-Nummern geben die Anzahl der Tage an, um die die jeweilige Variable $\mathrm{x}$ gegenüber dem Hautzustand verschoben ist. Als Bezugszeitpunkt dient der Tag 0 (=Lag-Nummer 0). Zu lesen sind die Diagramme wie folgt: der Hautzustand korreliert mit der Variablen $\mathrm{x}$ zeitversetzt um y Tage. Negative Lag-Nummern weisen auf eine dem Hautzustand vorangehende Korrelation, positive Lag-Nummern auf eine dem Hautzustand nachfolgende Korrelation hin. In Klammern sind die jeweiligen ARIMA-Modelle aufgeführt. CC bedeutet Correlation coefficient (Korrelationskoeffizient)

a) Hautzustand $(100,000)$ - Noradrenalin $(001,000)$

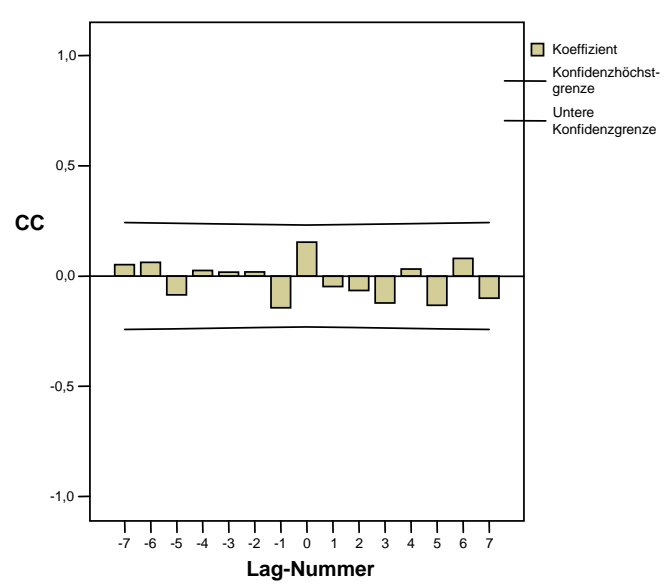

c) Hautgesamt $(100,000)$ - Cortisol $(100,100) 5$

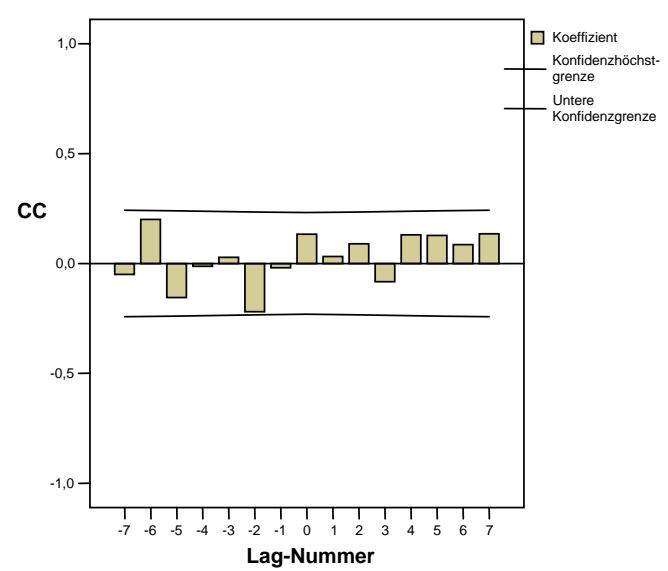

b) Hautzustand $(100,000)$ - Adrenalin $(100,000)$

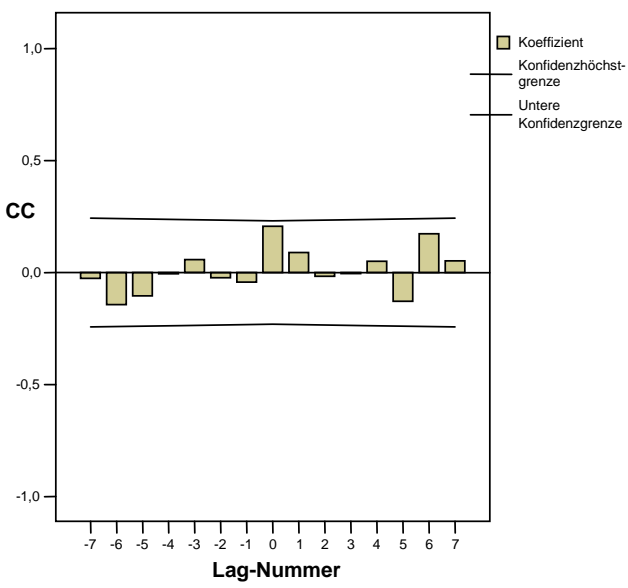

d) Hautzustand $(100,000)$ - Neopterin $(001,000)$

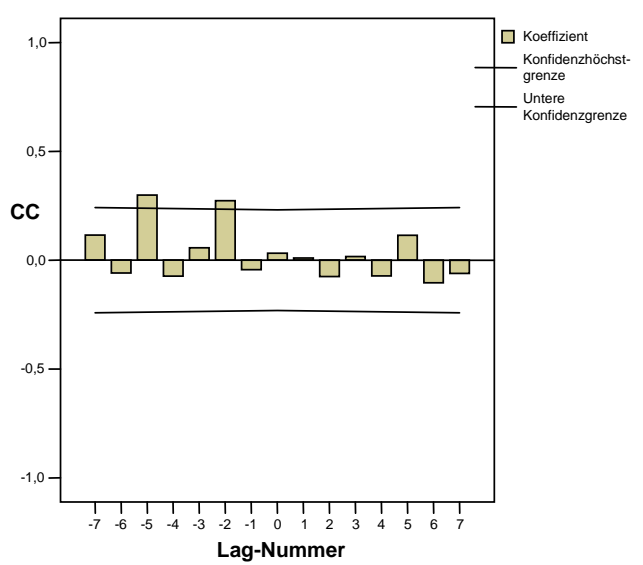


e) Hautgesamt $(100,000)$ - Juckreizstärke $(100,000)$

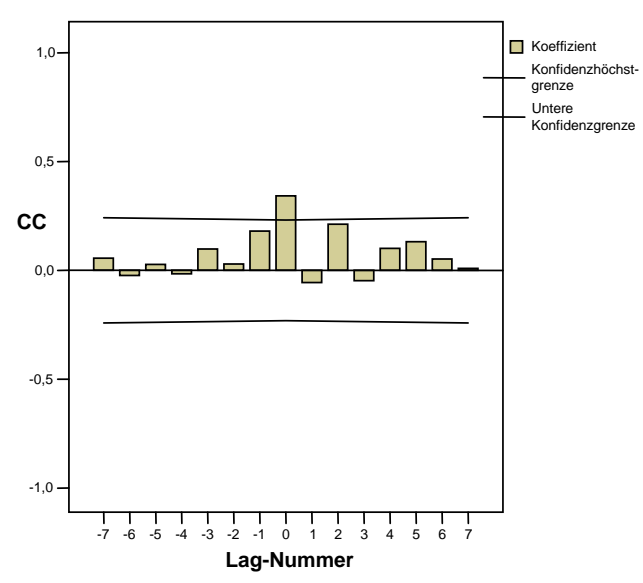

g) Hautzustand $(100,000)-m$ Ängstlichkeit $(011,000)$

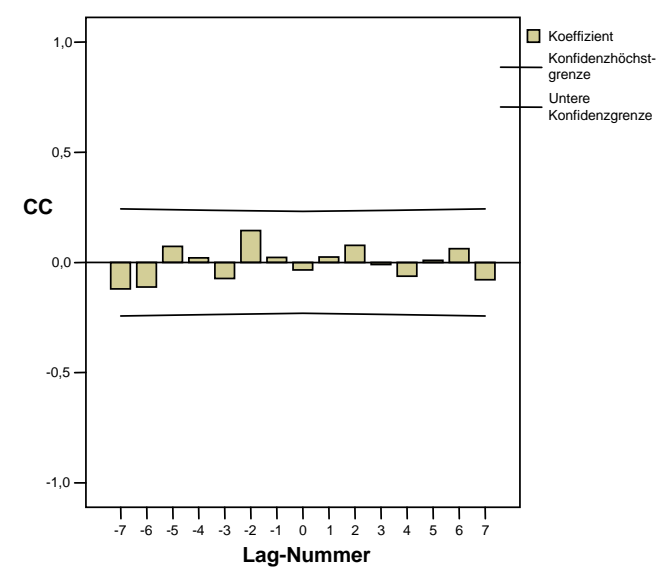

i) Hautzustand $(100,000)$ - Desaktivität $(011,011) 7$

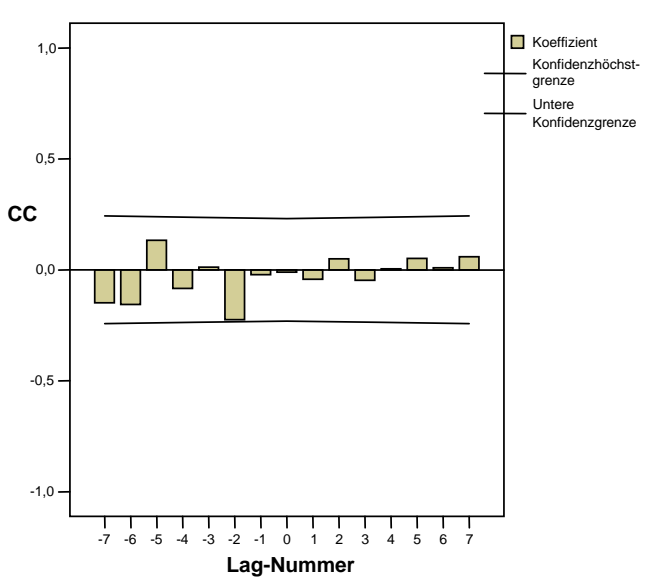

f) Hautzustand $(100,000)-m$ Kratzintensität $(100,000)$

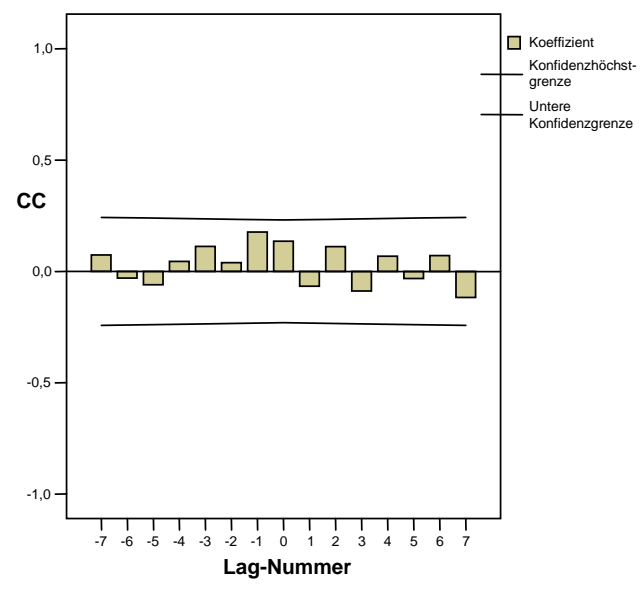

h) Hautzustand $(100,000)$ über Gereiztheit $(011,100) 3$

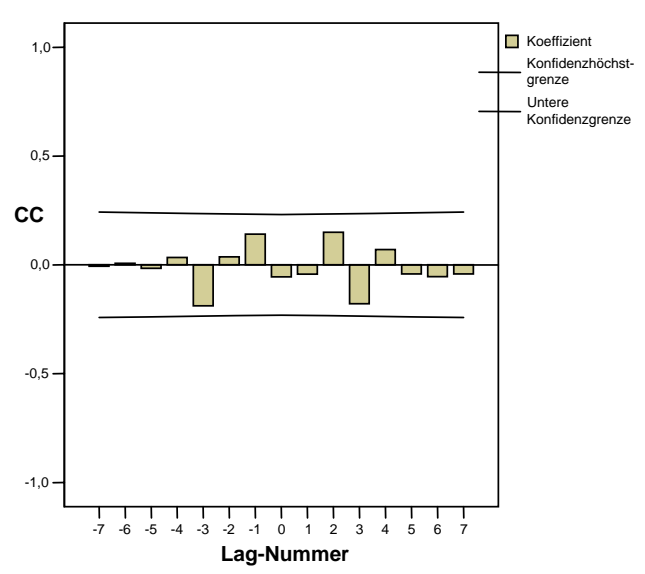

j) Hautzustand $(100,000)$ - Aktivität $(011,000)$

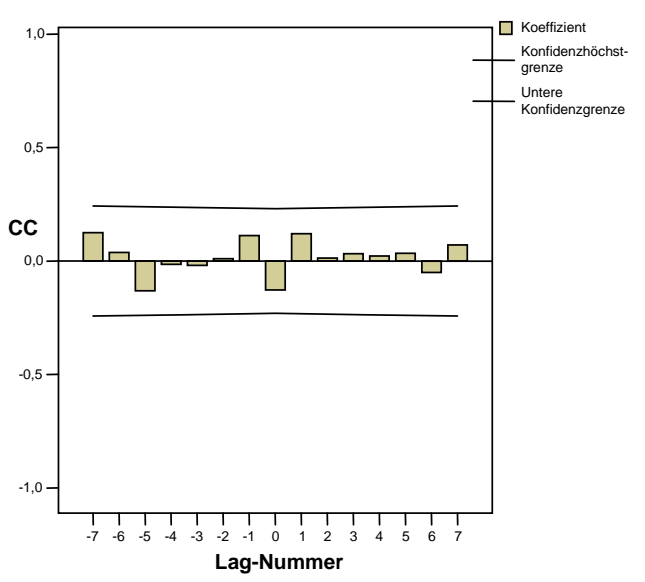


k) Hautzustand $(100,000)$ - Extravertiertheit $(011,100) 8$

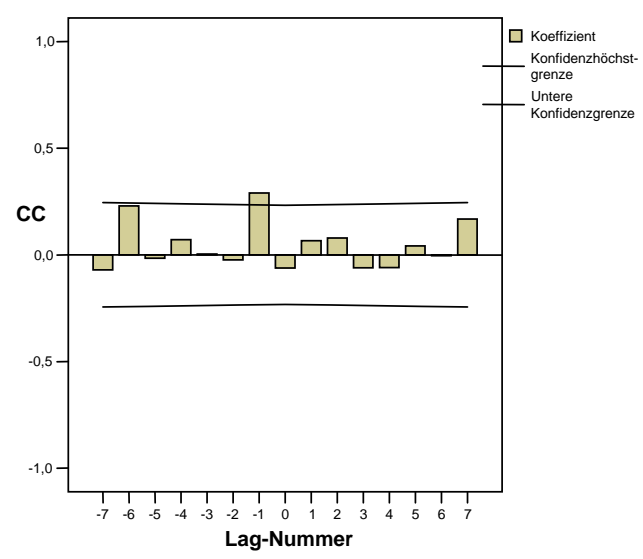

m) Hautzustand $(100,000)$ - Wohlbefinden $(111,000)$

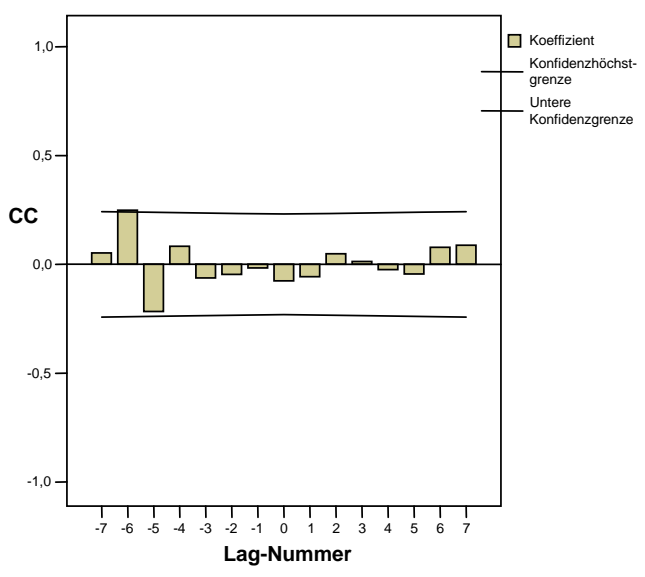

o) Hautzustand $(100,000)$ - Schlafqualität $(001,100) 3$

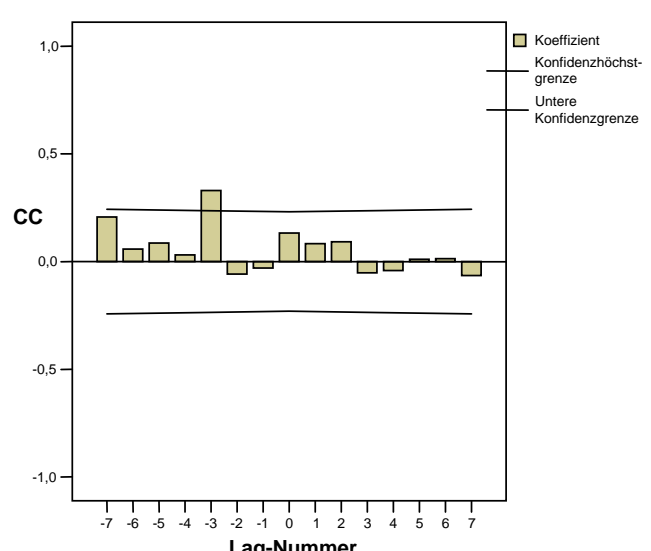

I) Hautzustand $(100,000)-m$ Introvertiertheit $(100,000)$

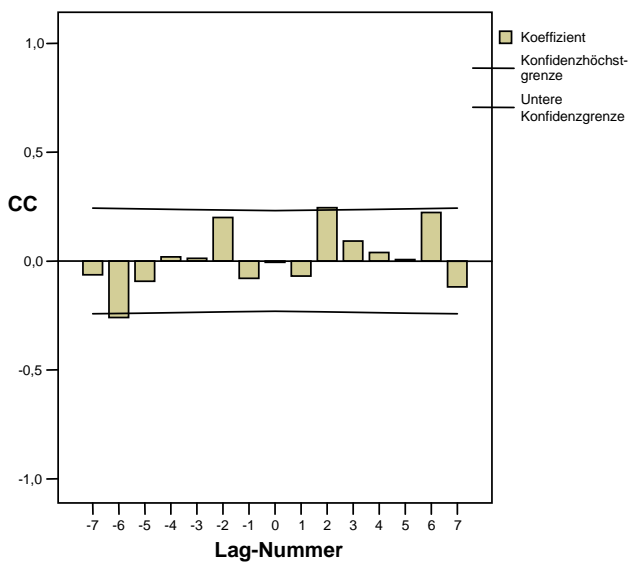

n) Hautzustand $(100,000)$ - Melatonin $(100,000)$

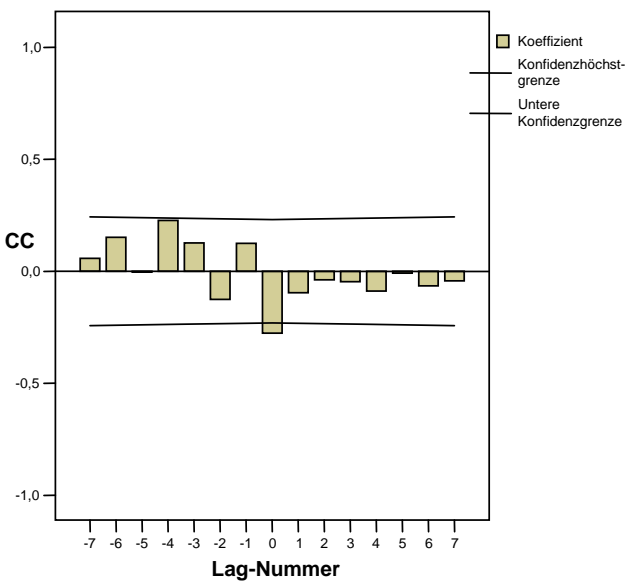

p) Hautzustand $(100,000)$ - Schlaferholsamkeit $(100,100) 6$

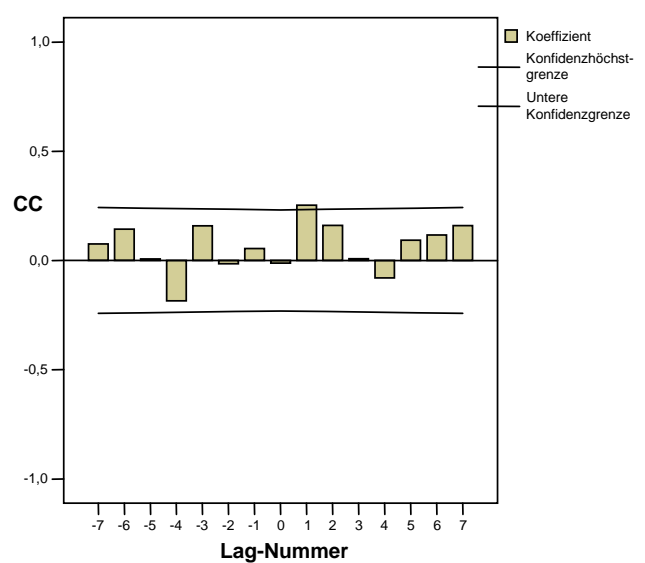




\subsubsection{Darstellung der Ergebnisse der bivariaten Kreuzkorrelations- analyse nach Pearson}

Um die Stärke der Zusammenhänge zwischen den einzelnen Faktoren genauer ermitteln zu können, wurden alle Residual-Zeitreihen mittels bivariater Korrelationsanalyse nach Pearson untersucht. Hierzu wurden die unabhängigen Variablen im Verhältnis zur jeweils abhängigen Variablen zeitlich um bis zu fünf Tagen zurück versetzt (timelag). Das heißt, dass ein bestimmter Zustand einer unabhängigen Variablen $x$ Tage später in Beziehung zum Zustand der abhängigen Variablen steht. Der Zustand der abhängigen Variablen folgt also dem Zustand der unabhängigen Variablen. Von Interesse waren Korrelationen bis zu einem Signifikanzniveau $(\alpha)$ von 0,1 . Dieses Vorgehen gewährleistet, dass bei ausreichender statistischer "Genauigkeit" möglichst viele Beziehungen zwischen den Zeitreihen erfasst werden, die in einem kausalen Zusammenhang zueinander stehen könnten.

Tab. 3: Ergebnisse der Kreuzkorrelationsanalysen nach Pearson aller Faktoren (3.1. - 3.18.) von AD02 Dargestellt sind die gefundenen Beziehungen der unabhängigen Variablen (Einflussfaktoren) zur jeweils abhängigen Variablen. Die Zahlen in Klammern geben die Zeitverschiebung (timelag) in Tagen in der Beziehung der unabhängigen Einflussfaktoren zur abhängigen Variable an. Des Weiteren sind die Korrelationskoeffizienten und das jeweilige Signifikanzniveau $(\alpha)$ = Signifikanz (2-seitig) aufgeführt.

3.1. Abhängige Variable Hautzustand

\begin{tabular}{|l|l|l|}
\hline $\begin{array}{l}\text { Unabhängige Einfluss- } \\
\text { faktoren (timelag) }\end{array}$ & $\begin{array}{l}\text { Korrelations- } \\
\text { koeffizient }\end{array}$ & $\begin{array}{l}\text { Signifikanz } \\
\text { (2-seitig) }\end{array}$ \\
\hline Melatonin (-4) & $+0,243$ & 0,041 \\
\hline Melatonin (0) & $-0,276$ & 0,016 \\
\hline Neopterin (-5) & $+0,315$ & 0,008 \\
\hline Neopterin (-2) & $+0,276$ & 0,018 \\
\hline Cortisol (-2) & $-0,226$ & 0,055 \\
\hline Juckreizstärke (0) & $+0,342$ & 0,003 \\
\hline Adrenalin (0) & $+0,207$ & 0,075 \\
\hline Desaktivität (-2) & $-0,231$ & 0,049 \\
\hline Extravertiertheit (-1) & $+0,229$ & 0,049 \\
\hline Introvertiertheit (-2) & $+0,202$ & 0,087 \\
\hline Schlafqualität (-3) & $+0,340$ & 0,003 \\
\hline Grübelintensität (-5) & $+0,398$ & 0,032 \\
\hline Wohlbefinden (-5) & $-0,227$ & 0,059 \\
\hline
\end{tabular}

\subsection{Abhängige Variable: Adrenalin}

\begin{tabular}{|l|l|l|}
\hline $\begin{array}{l}\text { Unabhängige Einfluss- } \\
\text { faktoren (timelag) }\end{array}$ & $\begin{array}{l}\text { Korrelations- } \\
\text { koeffizient }\end{array}$ & $\begin{array}{l}\text { Signifikanz } \\
\text { (2-seitig) }\end{array}$ \\
\hline Melatonin (0) & $-0,326$ & 0,004 \\
\hline Nordrenalin (0) & $+0,699$ & 0,000 \\
\hline Hautzustand (0) & $+0,207$ & 0,075 \\
\hline Juckreizstärke (-4) & $+0,273$ & 0,021 \\
\hline Juckreizstärke (-2) & $+0,264$ & 0,024 \\
\hline Kratzintensität (-2) & $+0,267$ & 0,022 \\
\hline Schlaferholsamkeit (-1) & $-0,202$ & 0,084 \\
\hline Ängstlichkeit (-1) & $+0,214$ & 0,068 \\
\hline Desaktivität (0) & $-0,228$ & 0,049 \\
\hline Extravertiertheit (-1) & $-0,202$ & 0,084 \\
\hline Wohlbefinden (-1) & $-0,215$ & 0,066 \\
\hline Grübelintensität (-5) & $+0,387$ & 0,038 \\
\hline
\end{tabular}

3.2. Abhängige Variable: Grübelintensität \begin{tabular}{|l|l|l|}
\hline Unabhängige Einfluss- & Korrelations- & Signifikanz \\
\hline
\end{tabular} \begin{tabular}{|l|l|l} 
faktoren (timelag) & koeffizient & (2-seitig)
\end{tabular} \begin{tabular}{l|l|l}
\hline Noradrenalin (-5) & $+0,456$ & 0,008 \\
\hline
\end{tabular}

\begin{tabular}{|l|l|l|}
\hline Noradrenalin (-1) & $+0,308$ & 0,076 \\
\hline
\end{tabular}

\begin{tabular}{|l|l|l} 
Neopterin $(-5)$ & $+0,360$ & 0,039
\end{tabular}

Neopterin (-1)

Hauzustand (-1)

Juckreizstärke (0)

Kratzintensität (0) Wohlbefinden (0)

$-\quad 0,471$

$+0,362$

$+0,317$

\begin{tabular}{l|l|}
$+0,317$ & 0,067 \\
$+0,282$ & 0,106 \\
\hline
\end{tabular}

\begin{tabular}{l|l|l}
\hline & $-0,290$ & 0,096 \\
\hline
\end{tabular}

\begin{tabular}{|l|l|l|}
\hline & & \\
\hline & & \\
\hline & & \\
\hline & & \\
\hline
\end{tabular}

3.4. Abhängige Variable: Noradrenalin

\begin{tabular}{|l|l|l|}
\hline $\begin{array}{l}\text { Unabhängige Einfluss- } \\
\text { faktoren (timelag) }\end{array}$ & $\begin{array}{l}\text { Korrelations- } \\
\text { koeffizient }\end{array}$ & $\begin{array}{l}\text { Signifikanz } \\
\text { (2-seitig) }\end{array}$ \\
\hline Melatonin (0) & $-0,208$ & 0,073 \\
\hline Adrenalin (-2) & $-0,200$ & 0,089 \\
\hline Adrenalin (0) & $+0,699$ & 0,000 \\
\hline Neopterin (-2) & $-0,233$ & 0,047 \\
\hline Desaktivität (0) & $-0,196$ & 0,092 \\
\hline Ängstlichkeit & $+0,190$ & 0,105 \\
\hline Schlaferholsamkeit (-1) & $-0,219$ & 0,060 \\
\hline Schlafqualität (-4) & $-0,196$ & 0,101 \\
\hline Aktivität (-5) & $+0,217$ & 0,072 \\
\hline Aktivität (-3) & $-0,195$ & 0,100 \\
\hline Wohlbefinden (-1) & $-0,205$ & 0,080 \\
\hline & & \\
\hline
\end{tabular}


3.5. Abhängige Variable: Neopterin

\begin{tabular}{|l|l|l|}
\hline $\begin{array}{l}\text { Unabhängige Einfluss- } \\
\text { faktoren (timelag) }\end{array}$ & $\begin{array}{l}\text { Korrelations- } \\
\text { koeffizient }\end{array}$ & $\begin{array}{l}\text { Signifikanz } \\
\text { (2-seitig) }\end{array}$ \\
\hline Ängstlichkeit (-3) & $+0,198$ & 0,095 \\
\hline Schlaferholsamkeit (-2) & $-0,251$ & 0,033 \\
\hline Melatonin (-2) & $+0,224$ & 0,057 \\
\hline Noradrenalin (-2) & $+0,202$ & 0,087 \\
\hline Noradrenalin (-1) & $+0,209$ & 0,073 \\
\hline Wohlbefinden (-3) & $-0,290$ & 0,014 \\
\hline Wohlbefinden (0) & $-0,324$ & 0,005 \\
\hline Desaktivität (-2) & $-0,213$ & 0,071 \\
\hline & & \\
\hline & & \\
\hline
\end{tabular}

3.7. Abhängige Variable: Juckreizstärke

\begin{tabular}{|l|l|l|}
\hline $\begin{array}{l}\text { Unabhängige Einfluss- } \\
\text { faktoren (timelag) }\end{array}$ & $\begin{array}{l}\text { Korrelations- } \\
\text { koeffizient }\end{array}$ & $\begin{array}{l}\text { Signifikanz } \\
\text { (2-seitig) }\end{array}$ \\
\hline Hautzustand (-2) & $+0,270$ & 0,021 \\
\hline Hautzustand (0) & $+0,342$ & 0,003 \\
\hline Grübelintensität (-5) & $+0,417$ & 0,024 \\
\hline Grübelintensität (-3) & $+0,357$ & 0,049 \\
\hline Grübelintensität (0) & $+0,317$ & 0,067 \\
\hline Cortisol (0) & $+0,253$ & 0,028 \\
\hline Adrenalin (-4) & $-0,213$ & 0,074 \\
\hline Kratzintensität (-3) & $+0,231$ & 0,050 \\
\hline Kratzintensität (0) & $+0,699$ & 0,000 \\
\hline Gereiztheit (-2) & $-0,205$ & 0,082 \\
\hline Extravertiertheit (-3) & $+0,205$ & 0,084 \\
\hline Extravertiertheit (0) & $+0,293$ & 0,011 \\
\hline Schlafqualität (-3) & $+0,195$ & 0,101 \\
\hline
\end{tabular}

3.9. Abhängige Variable: Gereiztheit

\begin{tabular}{|l|l|l|}
\hline $\begin{array}{l}\text { Unabhängige Einfluss- } \\
\text { faktoren (timelag) }\end{array}$ & $\begin{array}{l}\text { Korrelations- } \\
\text { koeffizient }\end{array}$ & $\begin{array}{l}\text { Signifikanz } \\
\text { (2-seitig) }\end{array}$ \\
\hline Ängstlichkeit (0) & $+0,420$ & 0,000 \\
\hline Desaktivität (0) & $-0,207$ & 0,075 \\
\hline Schlaferholsamkeit (-2) & $-0,242$ & 0,039 \\
\hline Schlaferholsamkeit (0) & $-0,224$ & 0,054 \\
\hline Cortisol (-2) & $+0,190$ & 0,108 \\
\hline Kratzintensität (-1) & $-0,278$ & 0,016 \\
\hline Wohlbefinden (0) & $-0,236$ & 0,042 \\
\hline Hautzustand (-3) & $-0,224$ & 0,056 \\
\hline & & \\
\hline
\end{tabular}

3.11. Abhängige Variable: Introvertiertheit

\begin{tabular}{|l|l|l|}
\hline $\begin{array}{l}\text { Unabhängige Einfluss- } \\
\text { faktoren (timelag) }\end{array}$ & $\begin{array}{l}\text { Korrelations- } \\
\text { koeffizient }\end{array}$ & $\begin{array}{l}\text { Signifikanz } \\
\text { (2-seitig) }\end{array}$ \\
\hline Schlaferholsamkeit (-2) & $-0,227$ & 0,054 \\
\hline Hautzustand (-2) & $+0,303$ & 0,009 \\
\hline Grübelintensität (-1) & $+0,315$ & 0,074 \\
\hline Melatonin (-2) & $-0,202$ & 0,086 \\
\hline Cortisol (-2) & $+0,251$ & 0,032 \\
\hline Juckreizstärke (-2) & $+0,252$ & 0,032 \\
\hline Kratzintensität (-1) & $-0,224$ & 0,055 \\
\hline Gereiztheit (-1) & $+0,203$ & 0,083 \\
\hline Ängstlichkeit (0) & $+0,256$ & 0,026 \\
\hline & & \\
\hline & & \\
\hline & &
\end{tabular}

3.6. Abhängige Variable: Cortisol

\begin{tabular}{|l|l|l|}
\hline $\begin{array}{l}\text { Unabhängige Einfluss- } \\
\text { faktoren (timelag) }\end{array}$ & $\begin{array}{l}\text { Korrelations- } \\
\text { koeffizient }\end{array}$ & $\begin{array}{l}\text { Signifikanz } \\
\text { (2-seitig) }\end{array}$ \\
\hline Juckreizstärke (0) & $+0,253$ & 0,028 \\
\hline Kratzintensität (0) & $+0,235$ & 0,043 \\
\hline Desaktivität (-5) & $+0,209$ & 0,082 \\
\hline Melatonin (-5) & $-0,269$ & 0,024 \\
\hline Melatonin (-3) & $-0,210$ & 0,076 \\
\hline Melatonin (-1) & $-0,240$ & 0,039 \\
\hline Melatonin (0) & $+0,195$ & 0,094 \\
\hline Adrenalin (-2) & $-0,197$ & 0,095 \\
\hline Neopterin (-3) & $-0,284$ & 0,016 \\
\hline Gereiztheit (-1) & $-0,195$ & 0,095 \\
\hline
\end{tabular}

3.8. Abhängige Variable: Kratzintensität

\begin{tabular}{|l|l|l|}
\hline $\begin{array}{l}\text { Unabhängige Einfluss- } \\
\text { faktoren (timelag) }\end{array}$ & $\begin{array}{l}\text { Korrelations- } \\
\text { koeffizient }\end{array}$ & $\begin{array}{l}\text { Signifikanz } \\
\text { (2-seitig) }\end{array}$ \\
\hline Juckreizstärke (0) & $+0,699$ & 0,000 \\
\hline Gereiztheit (-1) & $-0,230$ & 0,042 \\
\hline Noradrenalin (-2) & $+0,203$ & 0,085 \\
\hline Desaktivität(-5) & $-0,204$ & 0,090 \\
\hline Cortisol (0) & $+0,235$ & 0,043 \\
\hline Grübelintensität (0) & $+0,282$ & 0,106 \\
\hline & & \\
\hline & & \\
\hline & & \\
\hline & & \\
\hline & & \\
\hline & & \\
\hline & & \\
\hline
\end{tabular}

3.10. Abhängige Variable: Ängstlichkeit

\begin{tabular}{|c|c|c|}
\hline $\begin{array}{l}\text { Unabhängige Einfluss- } \\
\text { faktoren (timelag) }\end{array}$ & $\begin{array}{l}\text { Korrelations- } \\
\text { koeffizient }\end{array}$ & $\begin{array}{l}\text { Signifikanz } \\
\text { (2-seitig) }\end{array}$ \\
\hline Introvertiertheit (0) & $+0,256$ & 0,026 \\
\hline Wohlbefinden (0) & - 0,712 & 0,000 \\
\hline Extravertiertheit (0) & - 0,261 & 0,024 \\
\hline Schlaferholsamkeit (0) & - 0,236 & 0,042 \\
\hline Gereiztheit (-2) & $+0,200$ & 0,090 \\
\hline Gereiztheit (0) & $+0,420$ & 0,000 \\
\hline Neopterin (-2) & - 0,202 & 0,086 \\
\hline Neopterin (-1) & - 0,360 & 0,002 \\
\hline Aktiv & $-0,229$ & 0,048 \\
\hline
\end{tabular}

3.12. Abhängige Variable: Extravertiertheit

\begin{tabular}{|l|l|l|}
\hline $\begin{array}{l}\text { Unabhängige Einfluss- } \\
\text { faktoren (timelag) }\end{array}$ & $\begin{array}{l}\text { Korrelations- } \\
\text { koeffizient }\end{array}$ & $\begin{array}{l}\text { Signifikanz } \\
\text { (2-seitig) }\end{array}$ \\
\hline Neopterin (-1) & $+0,193$ & 0,099 \\
\hline Juckreizstärke (-4) & $-0,236$ & 0,048 \\
\hline Juckreizstärke (0) & $+0,293$ & 0,011 \\
\hline Ängstlichkeit (0) & $-0,261$ & 0,024 \\
\hline Desaktivität (-4) & $-0,269$ & 0,024 \\
\hline Desaktivität (-3) & $-0,213$ & 0,073 \\
\hline Desaktivität (0) & $-0,222$ & 0,055 \\
\hline Wohlbefinden (0) & $+0,459$ & 0,000 \\
\hline Aktivität (0) & $+0,430$ & 0,000 \\
\hline Schlaferholsamkeit (-4) & $+0,199$ & 0,096 \\
\hline Gereiztheit (-2) & $-0,195$ & 0,099 \\
\hline
\end{tabular}


3.13. Abhängige Variable: Desaktivität

\begin{tabular}{|l|l|l|}
\hline $\begin{array}{l}\text { Unabhängige Einfluss- } \\
\text { faktoren (timelag) }\end{array}$ & $\begin{array}{l}\text { Korrelations- } \\
\text { koeffizient }\end{array}$ & $\begin{array}{l}\text { Signifikanz } \\
\text { (2-seitig) }\end{array}$ \\
\hline Wohlbefinden (-1) & $+0,214$ & 0,067 \\
\hline Gereiztheit (0) & $-0,207$ & 0,075 \\
\hline Aktivität (-1) & $+0,373$ & 0,001 \\
\hline Aktivität (0) & $-0,303$ & 0,008 \\
\hline Extravertiertheit (-1) & $+0,339$ & 0,003 \\
\hline Extravertiertheit (0) & $-0,222$ & 0,055 \\
\hline Schlafqualität (-1) & $-0,256$ & 0,028 \\
\hline Neopterin (-3) & $-0,263$ & 0,026 \\
\hline Noradrenalin (-5) & $+0,317$ & 0,008 \\
\hline Noradrenalin (0) & $-0,196$ & 0,092 \\
\hline Adrenalin (-5) & $+0,342$ & 0,004 \\
\hline Adrenalin (-1) & $-0,199$ & 0,090 \\
\hline Adrenalin (0) & $-0,228$ & 0,049 \\
\hline Kratzintensität (-3) & $+0,198$ & 0,096 \\
\hline Grübelintensität (-5) & $-0,389$ & 0,037 \\
\hline
\end{tabular}

3.15. Abhängige Variable: Wohlbefinden

\begin{tabular}{|l|l|l|}
\hline $\begin{array}{l}\text { Unabhängige Einfluss- } \\
\text { faktoren (timelag) }\end{array}$ & $\begin{array}{l}\text { Korrelations- } \\
\text { koeffizient }\end{array}$ & $\begin{array}{l}\text { Signifikanz } \\
\text { (2-seitig) }\end{array}$ \\
\hline Aktivität (0) & $+0,405$ & 0,000 \\
\hline Extravertiertheit (0) & $+0,459$ & 0,000 \\
\hline Neopterin (-1) & $+0,348$ & 0,002 \\
\hline Neopterin (0) & $-0,342$ & 0,005 \\
\hline Gereiztheit (-2) & $-0,266$ & 0,023 \\
\hline Gereiztheit (0) & $-0,236$ & 0,042 \\
\hline Ängstlichkeit (0) & $-0,712$ & 0,000 \\
\hline Kratzintensität (-4) & $-0,203$ & 0,089 \\
\hline Grübelintensität (0) & $-0,290$ & 0,096 \\
\hline
\end{tabular}

3.17. Abhängige Variable: Schlafqualität

\begin{tabular}{|l|l|l|}
\hline $\begin{array}{l}\text { Unabhängige Einfluss- } \\
\text { faktoren (timelag) }\end{array}$ & $\begin{array}{l}\text { Korrelations- } \\
\text { koeffizient }\end{array}$ & $\begin{array}{l}\text { Signifikanz } \\
\text { (2-seitig) }\end{array}$ \\
\hline Grübelintensität (-5) & $+0,443$ & 0,016 \\
\hline Grübelintensität (-1) & $-0,290$ & 0,102 \\
\hline Schlaferholsamkeit (0) & $+0,554$ & 0,000 \\
\hline Juckreizstärke (0) & $+0,187$ & 0,108 \\
\hline Melatonin (-3) & $+0,221$ & 0,062 \\
\hline Melatonin (-1) & $+0,203$ & 0,083 \\
\hline Neopterin (-2) & $+0,234$ & 0,047 \\
\hline Gereiztheit (-3) & $+0,220$ & 0,063 \\
\hline Desaktivität (-5) & $-0,235$ & 0,050 \\
\hline & & \\
\hline & & \\
\hline & & \\
\hline & &
\end{tabular}

3.14. Abhängige Variable: Aktivität

\begin{tabular}{|c|c|c|}
\hline $\begin{array}{l}\text { Unabhängige Einfluss- } \\
\text { faktoren (timelag) }\end{array}$ & \begin{tabular}{|l|}
$\begin{array}{l}\text { Korrelations- } \\
\text { koeffizient }\end{array}$ \\
\end{tabular} & $\begin{array}{l}\text { Signifikanz } \\
\text { (2-seitig) }\end{array}$ \\
\hline Schlaferholsamkeit (-2) & $+0,226$ & 0,055 \\
\hline Melatonin (-1) & $-0,227$ & 0,052 \\
\hline Kratzintensität (-4) & - 0,248 & 0,037 \\
\hline Kratzintensität (-1) & $+0,224$ & 0,055 \\
\hline Ängstlichkeit (0) & $-0,229$ & 0,048 \\
\hline Desaktivität (0) & $-0,303$ & 0,008 \\
\hline Wohlbefinden (0) & $+0,405$ & 0,000 \\
\hline & & \\
\hline & & \\
\hline & & \\
\hline & & \\
\hline & & \\
\hline & & \\
\hline
\end{tabular}

3.16. Abhängige Variable: Melatonin

\begin{tabular}{|l|l|l|}
\hline $\begin{array}{l}\text { Unabhängige Einfluss- } \\
\text { faktoren (timelag) }\end{array}$ & $\begin{array}{l}\text { Korrelations- } \\
\text { koeffizient }\end{array}$ & $\begin{array}{l}\text { Signifikanz } \\
\text { (2-seitig) }\end{array}$ \\
\hline Adrenalin (0) & $-0,326$ & 0,004 \\
\hline Noradrenalin (0) & $-0,208$ & 0,073 \\
\hline Juckreizstärke (-4) & $-0,198$ & 0,098 \\
\hline Grübelintensität (-2) & $+0,307$ & 0,087 \\
\hline Neopterin (-3) & $-0,396$ & 0,001 \\
\hline Introvertiertheit (-2) & $-0,221$ & 0,060 \\
\hline & & \\
\hline & & \\
\hline & & \\
\hline
\end{tabular}

3.18. Abhängige Variable: Schlaferholsamkeit

\begin{tabular}{|c|c|c|}
\hline $\begin{array}{l}\text { Unabhängige Einfluss- } \\
\text { faktoren (timelag) }\end{array}$ & \begin{tabular}{|l|}
$\begin{array}{l}\text { Korrelations- } \\
\text { koeffizient }\end{array}$ \\
\end{tabular} & $\begin{array}{l}\text { Signifikanz } \\
\text { (2-seitig) }\end{array}$ \\
\hline Hautzustand (-2) & $+0,202$ & 0,087 \\
\hline Hautzustand (-1) & $+0,313$ & 0,007 \\
\hline Schlafqualität (0) & $+0,554$ & 0,000 \\
\hline Neopterin (-2) & $+0,190$ & 0,108 \\
\hline Gereiztheit $(-3)$ & $+0,230$ & 0,052 \\
\hline Gereiztheit (0) & $-0,224$ & 0,054 \\
\hline Juckreizstärke (-2) & $+0,212$ & 0,072 \\
\hline Ängstlichkeit (-1) & $-\quad 0,208$ & 0,076 \\
\hline Ängstlichkeit (0) & $-0,236$ & 0,042 \\
\hline Introvertiertheit (-3) & $+0,201$ & 0,090 \\
\hline Desaktivität (-3) & $-0,282$ & 0,017 \\
\hline Extravertiertheit (-2) & $+0,210$ & 0,075 \\
\hline
\end{tabular}

Von allen aufgelisteten Zusammenhängen wurden auf diejenigen herausgefiltert, die in einer kausalen Beziehung zueinander stehen könnten. Sie werden nachfolgend dargestellt. 


\subsubsection{Darstellung und Beschreibung ausgewählter Zusammenhänge}

Es folgt die schematische Darstellung ausgewählter Korrelationen.

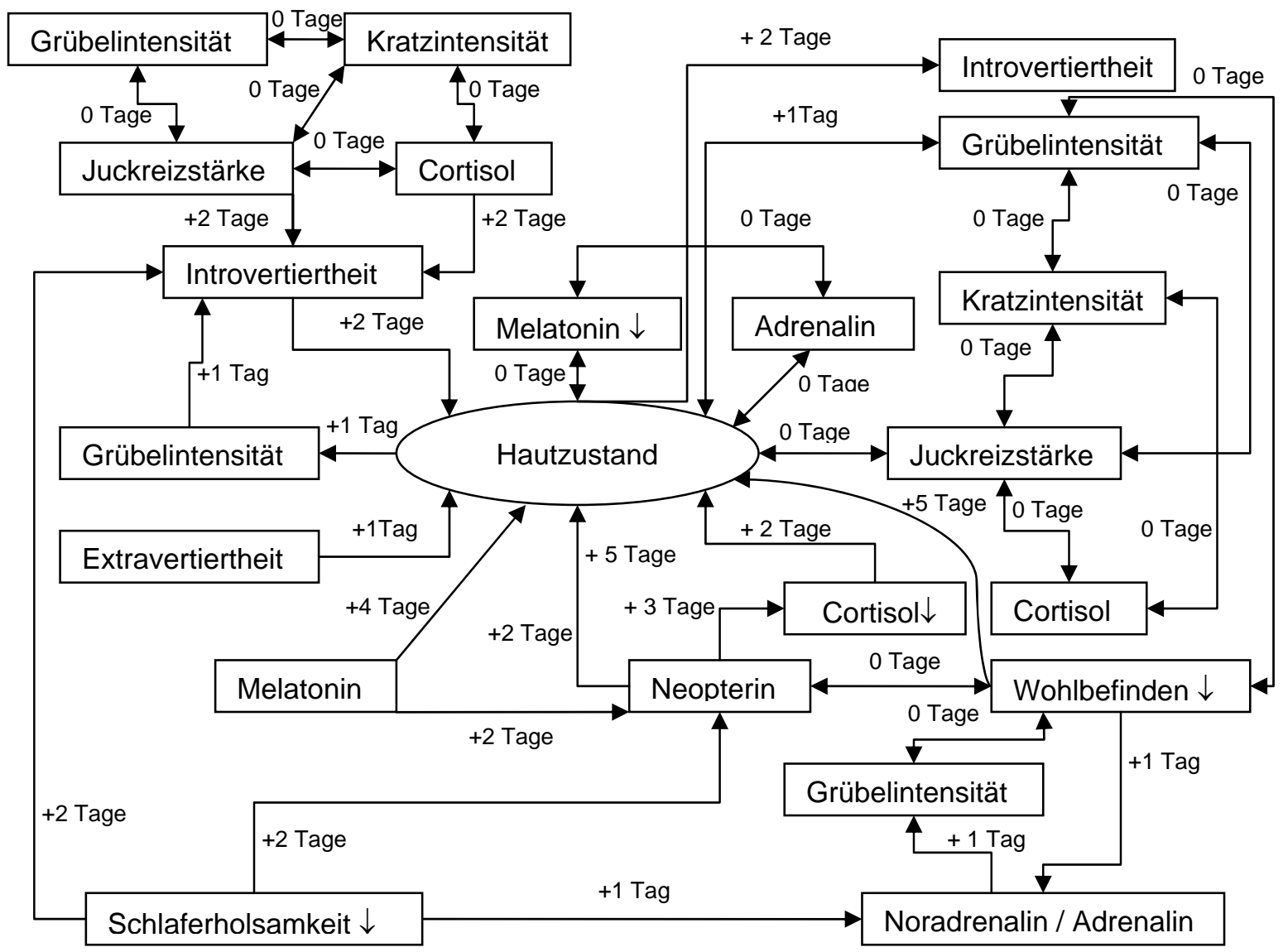

Abb. 6 Beziehungsschema ausgewählter Faktoren zum Hautzustand von AD02

Die Pfeile $(\rightarrow)$ zeigen die Richtung des Zusammenhanges zwischen zwei Faktoren an. Die Zeitverschiebung in der Beziehung der Faktoren zueinander ist neben den Pfeilen in Tagen angegeben. Das Symbol $\downarrow$ bedeutet „vermindert“.

Ausgewählte weitere Beziehungen zwischen den Einflussgrößen sind nachfolgend tabellarisch aufgeführt.

Tab. 4: Übersicht über Beziehungen weiterer ausgewählter Einflussgrößen von AD02 Die Zahlen in Klammern geben die Zeitverschiebung (in Tagen) in der Beziehung der Einflussgrößen zueinander an. $(-)$ bedeutet, dass die Beziehung der abhängigen Variablen vorangeht, (+) bedeutet, dass sie ihr nachfolgt, (0) bedeutet, dass sie am gleichen Tag besteht. Das Symbol $\downarrow$ bedeutet „vermindert".

\begin{tabular}{|l|l|}
\hline Abhängige Variable & Korrelationen mit unabhängigen Einflussgrößen (Zeitverschiebung in Tagen) \\
\hline Neopterin & Melatonin (-2) \\
\hline Cortisol & Melatonin (-1) \\
\hline Juckreizstärke & Extravertiertheit (0), Hautzustand (+2), Grübelintensität (-3, -5) \\
\hline Kratzintensität & Noradrenalin (-2) \\
\hline Gereiztheit & Cortisol (-2), Ängstlichkeit (0), Schlaferholsamkeit $\downarrow$ (0) \\
\hline Introvertiertheit & Gereiztheit (-1), Grübelintensität (-1) \\
\hline
\end{tabular}


Als Ergebnis stellt sich somit ein individuelles Netzwerk dar, welches seinen Ursprung in dem komplexen Beziehungsgeflecht der Einflussgrößen zueinander hat. Die interpretierende Beschreibung dieses Beziehungsgeflechtes unter Berücksichtigung des Hautzustandes von AD02 erfolgt nachfolgend in Form einzelner „Wirkgefüge".

\section{1. „Wirkgefüge“: Haut - Kratzverhalten}

Der Hautzustand korreliert zeitgleich mit der Juckreizstärke. Diese korreliert wiederum zeitgleich mit der Kratzintensität und dem Cortisolspiegel im Nachturin. Die drei Faktoren korrelieren außerdem am selben Tag untereinander. Die Juckreizstärke und die Kratzintensität korrelieren des Weiteren am selben Tag positiv mit der Grübelintensität. Diese Zusammenhänge deuten darauf hin, dass Stress den Juckreiz triggert und letztlich auch ein (konditionierter) „Juck-Kratz-Zirkel“ besteht, obwohl AD02 versucht das Kratzen möglichst zu vermeiden.

\section{2. „Wirkgefüge": Haut - emotionales Befinden - Stresshormone}

Der Hautzustand korreliert positiv sowohl mit der Introvertiertheit 2 Tage vorher als auch 2 Tage später. Außerdem korrelieren sowohl der Cortisolspiegel im Nachturin als auch die Juckreizstärke mit der Introvertiertheit 2 Tage später. Daneben besteht eine positive Korrelation zwischen der Extravertiertheit und dem Hautzustand am folgenden Tag sowie der Juckreizstärke am selben Tag. Dies deutet darauf hin, dass psychoemotionale Faktoren einen Einfluss auf den Hautzustand haben und der Hautzustand auch auf die Psyche zurückwirkt.

\section{3. „Wirkgefüge“: Haut - Stress - Immunsystem}

Der Neopterinspiegel im Nachturin korreliert zwei bzw. fünf Tage später positiv mit dem Hautzustand. Außerdem korreliert der Neopterinspiegel drei Tage später negativ mit dem Cortisolspiegel, welcher wiederum zwei Tage später mit dem Hautzustand korreliert. Des Weiteren korreliert der Neopterinspiegel am selben Tag negativ mit dem Wohlbefinden sowie negativ mit der Schlaferholsamkeit zwei Tage zuvor. Diese beiden Parameter korrelieren außerdem mit dem Noradrenalinspiegel im Nachturin. Dies deutet darauf hin, dass es nach einer Aktivierung des 
zellulären Immunsystems, z. B. durch Stress infolge schlechten Schlafes oder verminderten Wohlbefindens, zu einer Verschlechterung des Hautzustandes kommt.

\section{Fazit:}

Der Hautzustand von AD02 scheint vor allem durch emotionalen Stress beeinflusst zu werden. Mangelnde Schlaferholsamkeit, vermindertes Wohlbefinden und Introvertiertheit sowie erhöhte Grübelintensität stehen z. T. wechselseitig in Beziehung zum Neopterinspiegel, der Juckreizstärke und dem Hautzustand. Die Patientin versucht ihr Kratzverhalten sehr bewusst zu kontrollieren, dennoch besteht ein (konditionierter) Juck-Kratz-Zirkel, obwohl keine Beziehung zwischen dem Kratzverhalten und dem Hautzustand besteht.

\subsection{Patient AD04 - Allgemeine Beschreibung}

Patient AD04 war zum Zeitpunkt der Studie (im Sommer 2000) 42 Jahre alt. Er war zu dieser Zeit allein stehend und hatte bis dahin auch noch keine einzige partnerschaftliche Beziehung in seinem Leben gehabt. Er hat einen Hauptschulabschluss, ist von Beruf Krankenpfleger und arbeitete während der gesamten Studiendauer in Vollzeit (38,5 Stunden/Woche) in einem Wechselschicht-Dienstsystem auf einer onkologischen Station des Göttinger Universitätsklinikums.

Er ist aktives Mitglied im Vorstand eines örtlichen Paddelvereins, an dessen Gründung er beteiligt war. Außerdem ist er Mitinitiator einer psychosomatischen Selbsthilfegruppe, die sich alle 1-2 Wochen trifft. Die Eltern wohnen in der Nähe, die Geschwister (Bruder und Schwester) in Berlin. Soziale Kontakte unterhält er zu seinen Verwandten (Eltern wöchentlich, Geschwister monatlich - überwiegend telefonisch) sowie zu Freunden (drei „Vertraute“ - wöchentlicher Kontakt und eine ehemalige Arbeitskollegin - 14tägiger Kontakt). Die häufigsten sozialen Kontakte ergeben sich über den Paddelverein (1-2 mal pro Woche und 14tägige Unternehmungen). 
Seit seinem ersten Lebensjahr leidet er unter juckenden Hautveränderungen. Er war bereits mehrfach, auch in der Kindheit (u. a. drei längere stationäre Aufenthalte um das zweite Lebensjahr herum), in der Hautklinik des Universitätsklinikums Göttingen in ambulanter und stationärer Behandlung.

Neben der Diagnose atopisches Ekzem wurde differentialdiagnostisch auch das Vorliegen eines eher seborrhoischen Ekzems in Betracht gezogen. Laborchemisch waren das Gesamt-IgE mit $93.1 \mathrm{kU} / \mathrm{l}$ und der Screeningtest auf häufige Atopie-Allergene sowie ein RAST auf Latex unauffällig. Zum Untersuchungszeitpunkt am 14. Juli 2000 ergab sich ein SCORAD von 30, wobei auch an diesem Tag das klinische Bild des Patienten nicht eindeutig als atopische Dermatitis einzuordnen war. Betrachtet man seine Hauterkrankung jedoch als atopisches Ekzem, so ist er an der intrinsischen Variante des atopischen Ekzems erkrankt.

Die Ergebnisse der testpsychologischen Untersuchungen weisen darauf hin, dass AD04 unter einer depressiven Beeinträchtigung leidet, die einhergeht mit einem eher ängstlichen Wesenszug/Grundstimmung.

AD04 fühlt sich durch seine Hauterkrankung emotional belastet und zeigt ein besonders ausgeprägtes krankheitsbezogenes Problembewusstsein. Außerdem empfindet er sich in seiner sozialen Funktionsfähigkeit und emotionalen Rollenfunktion beeinträchtigt. Er ist unzufrieden mit der sozialen Unterstützung, an der es ihm seiner Ansicht nach mangelt. Dabei fühlt er sich jedoch ausreichend sozial integriert.

AD04 hat den Eindruck, dass sein Hautzustand vor allem durch psychische Belastungen beeinflusst wird. Es fällt ihm aber auch sehr schwer sich aufgrund des quälenden Juckreizes nicht ständig zu Kratzen. Häufig kratzt er sich ohne es zu merken. Auch externe Faktoren beeinflussen seine Haut: scheuernde Kleidung (z. B. der Hemdkragen) reibt sie auf und Chlorwasser (im Schwimmbad) reizt die Haut. 


\subsubsection{Darstellung des Hautzustandes und besonderer Ereignisse}

Nachfolgend wird, analog zu Kapitel 3.1.1, der Hautzustand von AD04 in Abb. 7 (Originaldaten) und Abb. 8 (Residualdaten) dargestellt. Als Grundlage dienen wiederum die Tagebuchangaben zur Stärke des Hautbefalls in der Einheit Millimeter. Die mittels ARIMA-Verfahren erzeugten Residualdaten sind dimensionslos und schwanken in Form eines „white noise“ um die Nullinie.

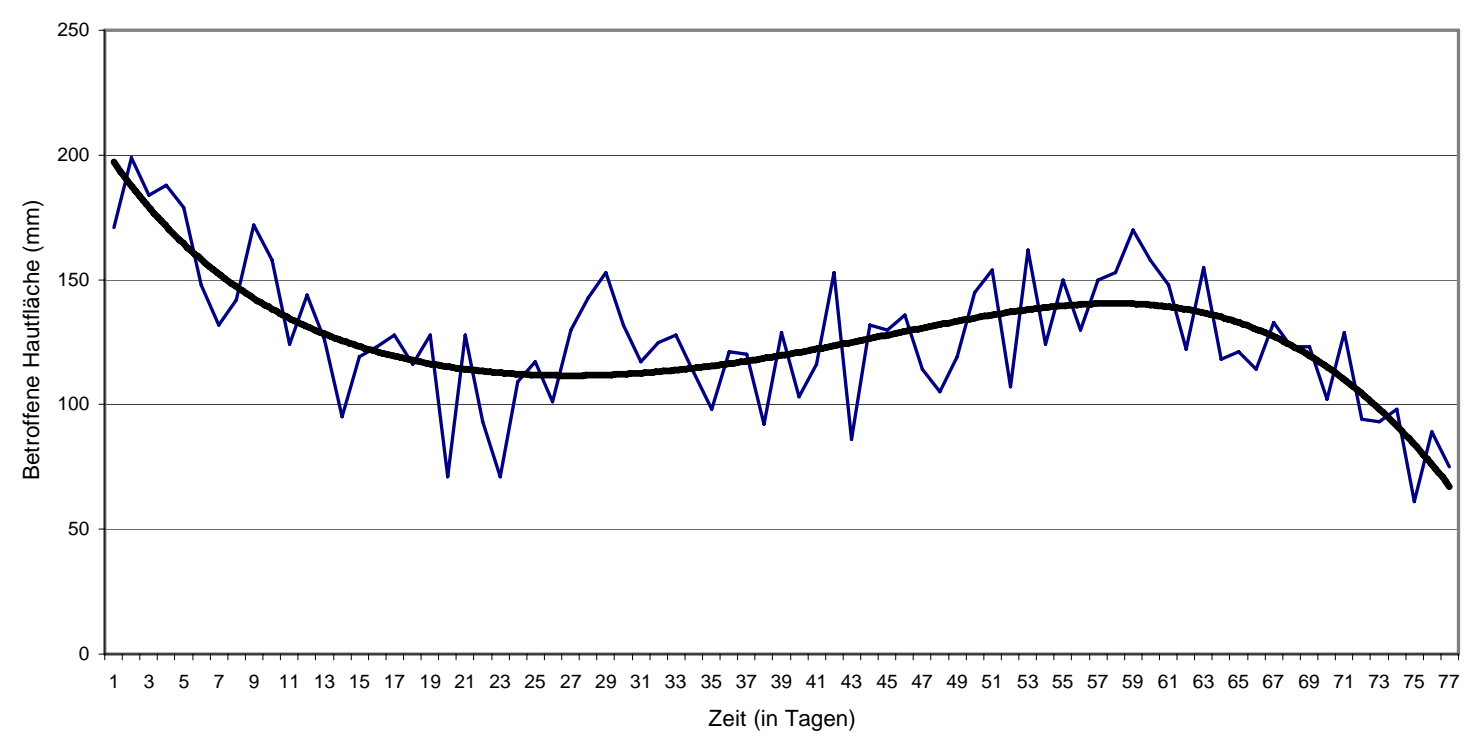

Abb. 7: Hautzustand (betroffene Hautfläche) von AD04 im Studienverlauf (Originaldaten)

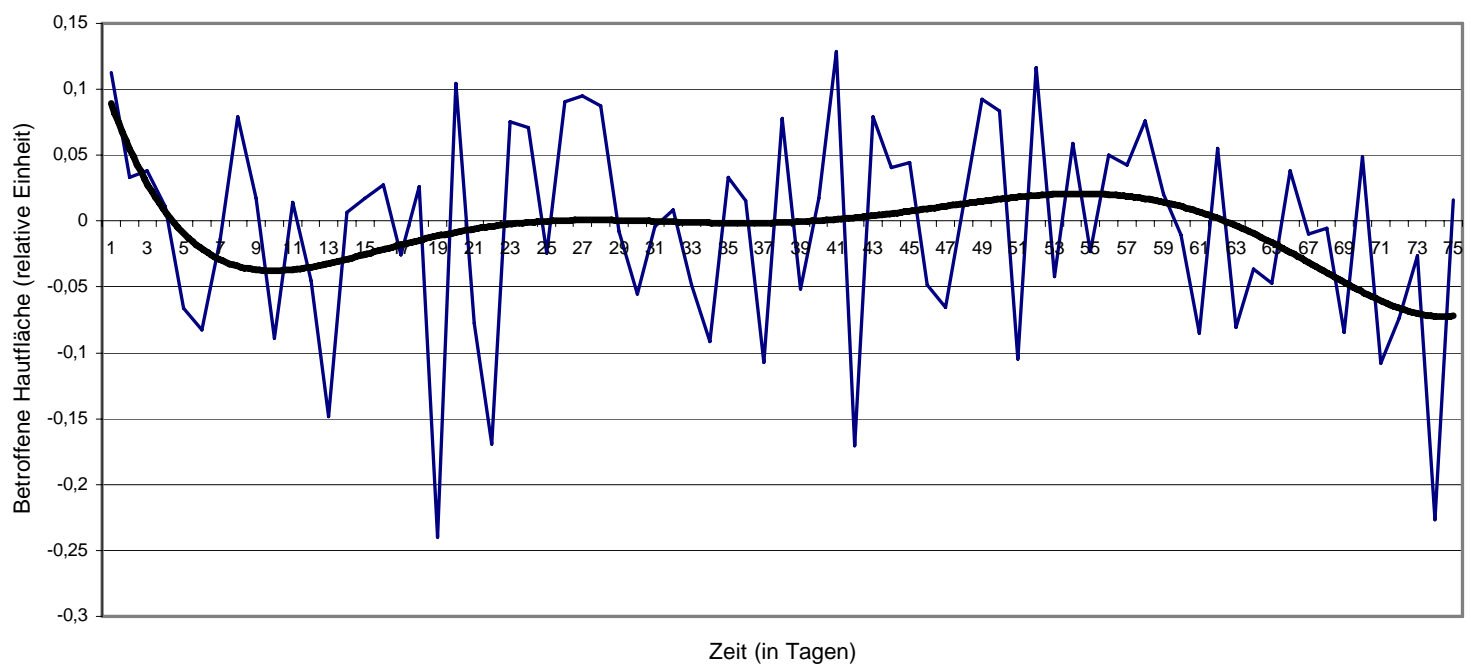

Abb. 8: Hautzustand (betroffene Hautfläche) von AD04 im Studienverlauf (Residualdaten) 
In den Abbildungen zeigt sich, dass das Ausmaß der betroffenen Hautfläche sowohl von Tag zu Tag als auch im Studienverlauf deutlich variiert. Der Hautzustand kann im Studienverlauf in vier Abschnitte unterteilt werden:

1. Studienbeginn: Die betroffene Hautfläche ist relativ groß.

2. Ca. Tag 10-23: Die betroffene Hautfläche ist relativ klein.

3. Ca. Tag 24- 49: Der Hautzustand ist relativ konstant, es treten jedoch insbesondere drei Phasen auf, in denen es zu einer Vergrößerung der betroffenen Hautfläche kommt. Eine Phase etwa zw. Tag 27-29, eine zweite Phase etwa zw. Tag 43-44 und eine dritte Phase etwa zw. Tag 57-59.

4. Studienende: Die betroffene Hautfläche ist in dieser Phase relativ am kleinsten.

Von besonderem Interesse ist nun erneut der Vergleich mit den Tagebuchangaben. Insbesondere bezüglich Hinweisen für das Vorliegen psychischer Belastungen in Phasen, in denen sich zugleich der Hautzustand verschlechtert.

Daher erfolgt auch an dieser Stelle wieder die chronologische Übersicht von Tagebucheinträgen, die psychisch belastende Situationen beschreiben:

1. Tag 1-2 $\rightarrow$ Ärger über nicht eingeplante Arbeit am anstehenden Samstag.

2. Tag 4-9 $\rightarrow$ Grübeln über die Zukunft und das anstehende Treffen der Selbsthilfegruppe.

3. Tag 27-29 $\rightarrow$ Angst vor Hautverschlechterung aufgrund belastender Erinnerungen aus der Kindheit vor einem anstehenden Termin in der Hautklinik.

4. Tag $39 \rightarrow$ Grübeln über PC-Kauf. Ist vom Führen des Tagebuches genervt.

5. Tag 43-44 $\rightarrow$ Geburtstag am Tag 44 alleine verbracht.

6. Tag 49-59 $\rightarrow$ Probleme mit einem Furunkel. Grübeln wegen des anstehenden

Erstgesprächs im Rahmen einer geplanten Psychotherapie.

Ob statistisch signifikante Zusammenhänge zwischen dem Auftreten psychisch belastender Situationen bzw. den damit einhergehenden Veränderungen des emotionalen Befindens und dem Hautzustand vorliegen, wie nach „oberflächlicher“ Betrachtung auch bei AD04 zu vermuten wäre, wurde analog zum Vorgehen bei AD02 mittels Korrelationsanalyse der Residual-Datenreihen geprüft. 


\subsubsection{Darstellung der statistischen Analysen der Residual-Zeitreihen}

Es folgt, analog zu Kapitel 3.1.2, die graphische Darstellung der Kreuzkorrelationsanalysen der Residual-Zeitreihen des Hautzustandes von AD04, welche wiederum eine schnelle optische Durchsicht auf Zusammenhänge erlaubt.

Abb. 9: Kreuzkorrelationsdiagramme des Hautzustandes von AD04 mit allen Faktoren ( a) Noradrenalin, b) Adrenalin,c) Cortisol, d) Neopterin. e) Juckreizstärke, f) Kratzintensität, g) Ängstlichkeit, h) Gereiztheit i) Desaktivität, j) Aktivität, k) Extravertiertheit, l) Introvertiertheit, $\mathrm{m}$ ) Wohlbefinden, n) Melatonin, o) Schlafqualität, p) Schlaferholsamkeit)

Die Lag-Nummern geben die Anzahl der Tage an, um die die jeweilige Variable $\mathrm{x}$ gegenüber dem Hautzustand verschoben ist. Als Bezugszeitpunkt dient der Tag 0 (=Lag-Nummer 0). Zu lesen sind die Diagramme wie folgt: der Hautzustand korreliert mit der Variablen $\mathrm{x}$ zeitversetzt um y Tage. Negative Lag-Nummern weisen auf eine dem Hautzustand vorangehende Korrelation, positive Lag-Nummern auf eine dem Hautzustand nachfolgende Korrelation hin. In Klammern sind die jeweiligen ARIMA-Modelle aufgeführt. CC bedeutet Correlation coefficient (Korrelationskoeffizient)

a) Hautzustand $(101,000)$ - Adrenalin $(100,000)$

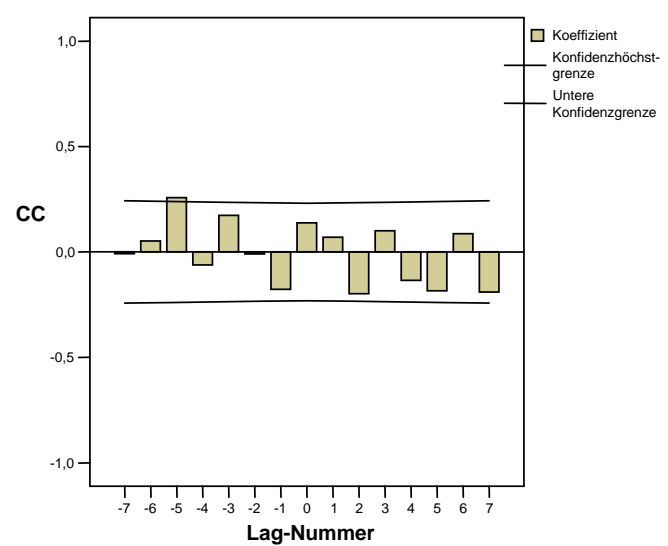

c) Hautzustand $(101,000)-$ Cortisol $(000,001) 7$

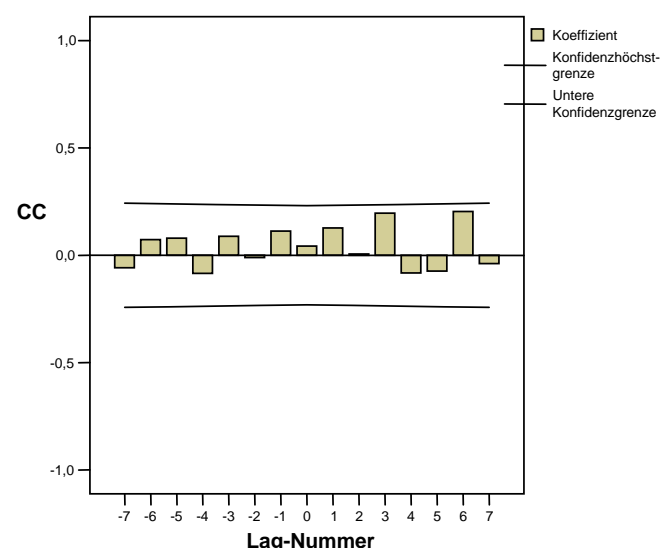

b) Hautzustand $(101,000)$ über Noradrenalin $(000,100) 10$

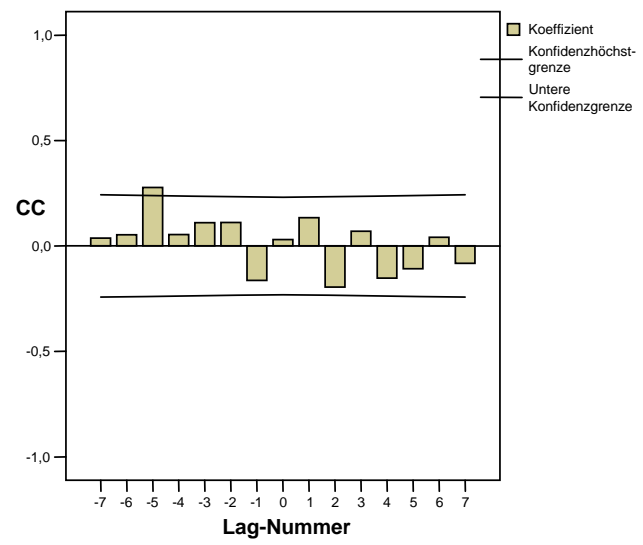

d) Hautzustand $(101,000)$ - Neopterin $(100,001) 6$

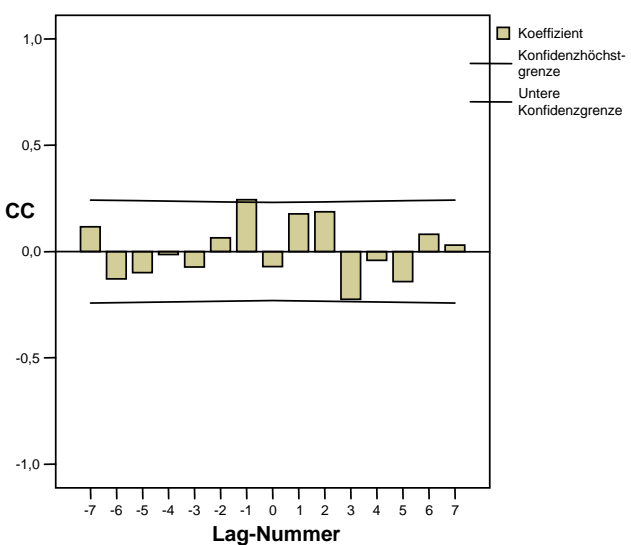


e) Hautzustand $(101,000)$ - Juckintensität $(100,000)$

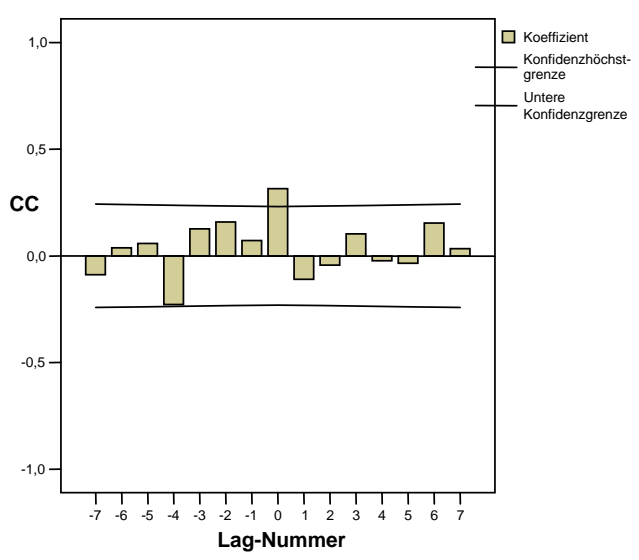

g) Hautzustand $(101,000)$ - Gereiztheit $(101,000)$

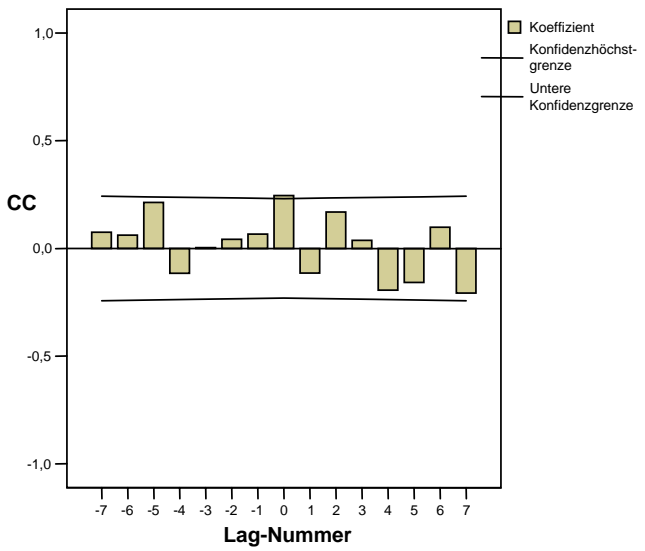

i) Hautzustand $(101,000)$ - Introvertiertheit $(100,000)$

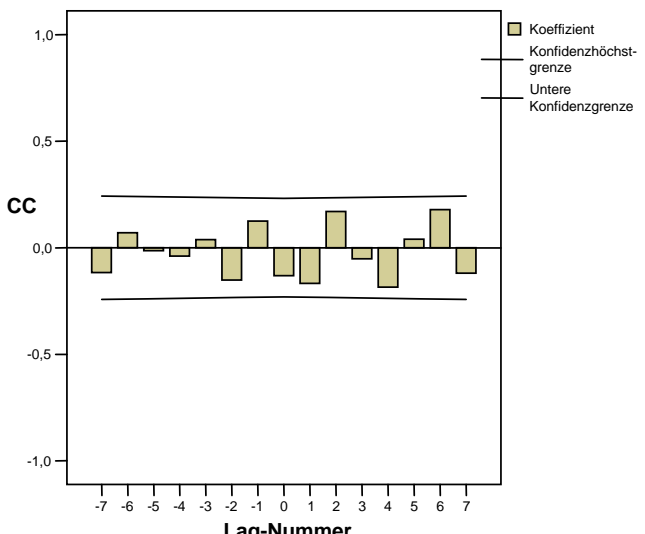

f) Hautzustand $(101,000)$ - Kratzstärke $(011,001) 7$

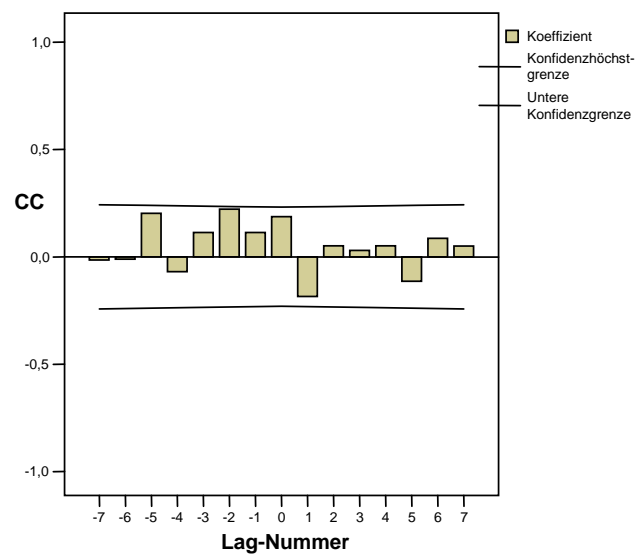

h) Hautzustand $(101,000)$ - Ängstlichkeit $(101,001) 9$

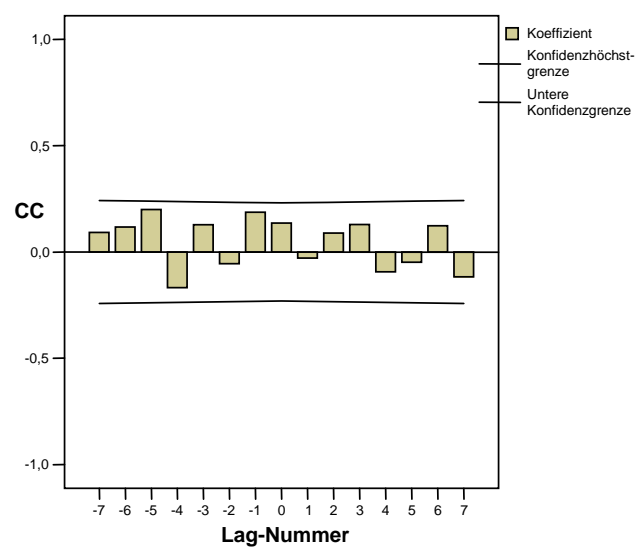

j) Hautzustand $(101,000)$ - Extravertiertheit $(100,000)$

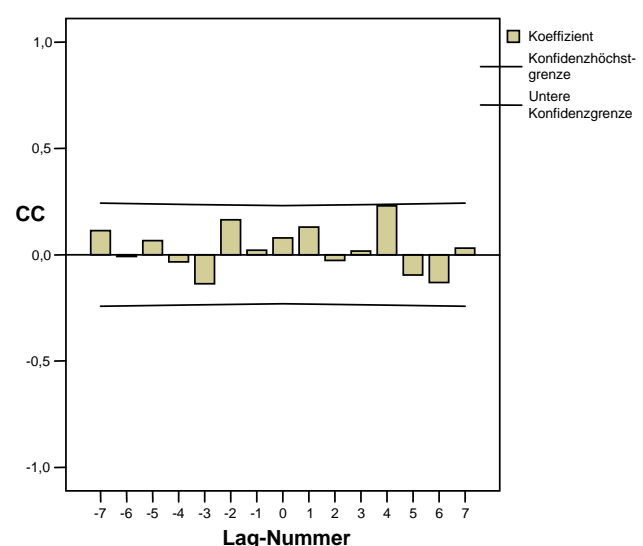


k) Hautzustand $(101,000)$ - Desaktivität $(000,001) 2$

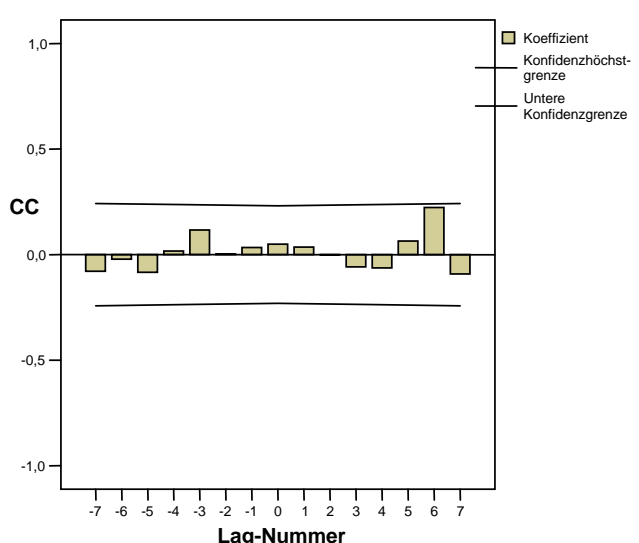

m) Hautzustand $(101,000)$ - Wohlbefinden $(000,001) 9$

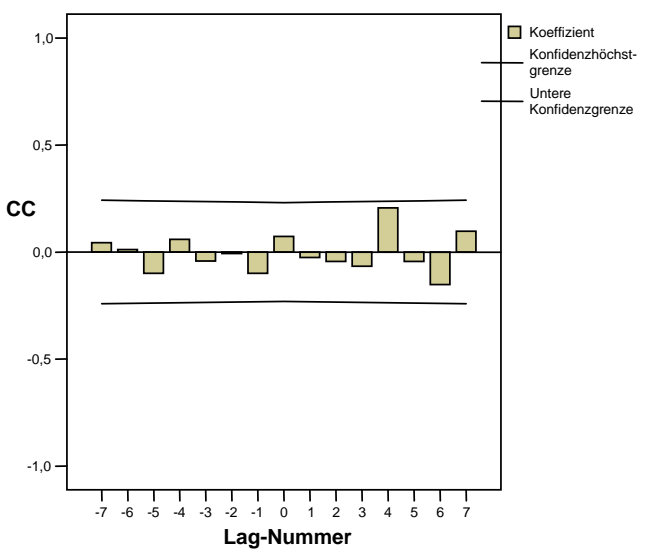

o) Hautzustand $(101,000)$ - Schlafqualität $(000,100) 12$

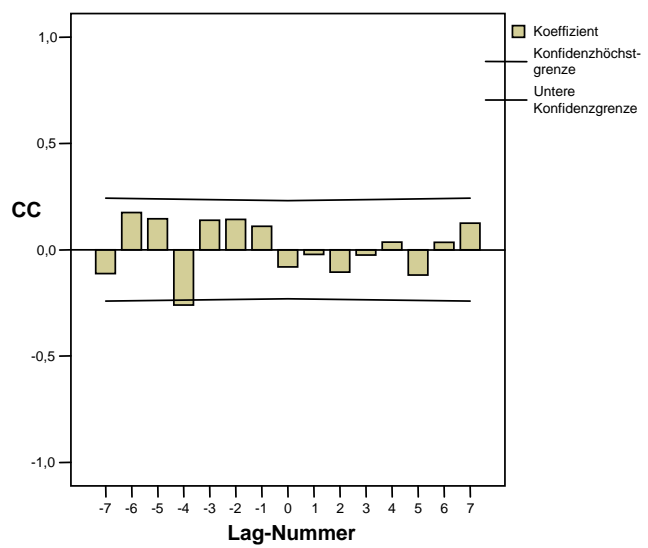

I) Hautzustand $(101,000)$ - Aktivität $(101,000)$

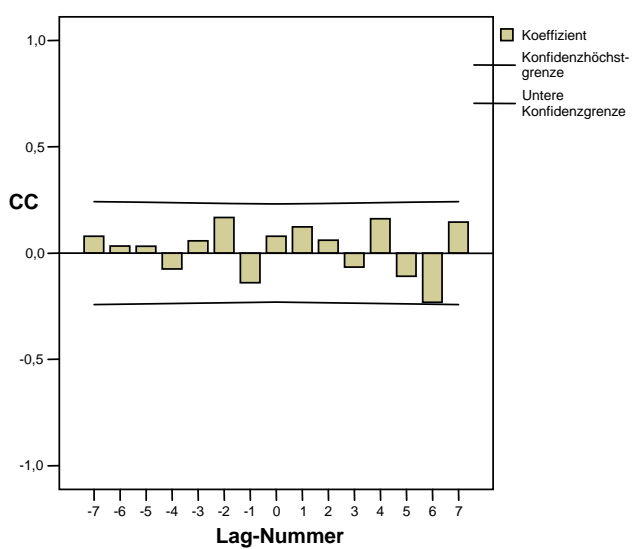

n) Hautzustand $(101,000)$ - Melatonin $(100,000)$

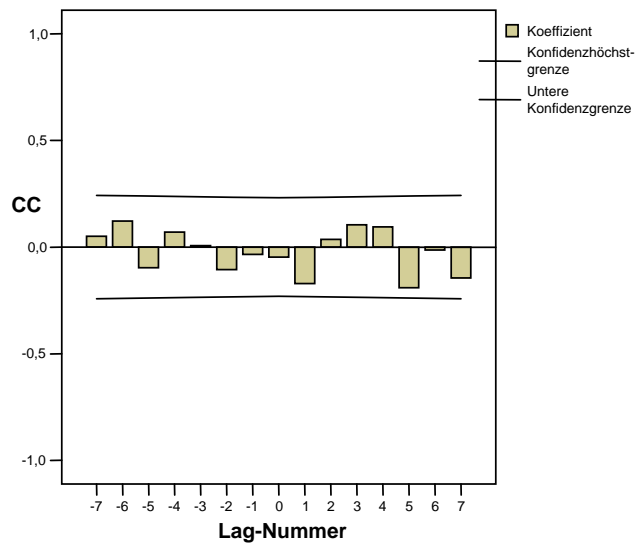

p) Hautzustand $(101,000)$ - Schlaferholsamkeit $(100,000)$

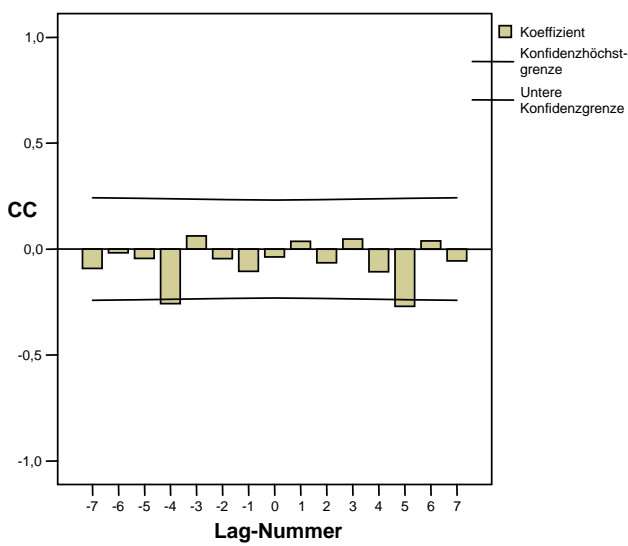




\subsubsection{Darstellung der Ergebnisse der bivariaten Kreuzkorrelations- analyse nach Pearson}

Es folgt, analog zu Abschnitt 3.1.3, die Darstellung der Ergebnisse der bivariaten Korrelationsanalyse der Residual-Zeitreihen nach Pearson für den Patienten AD04. Berücksichtigt sind wiederum Zeitverschiebungen (timelags) der Zeitreihen zueinander bis zu fünf Tagen vor dem aktuell zu betrachtenden Zustand bis zu einem Signifikanzniveau $(\alpha)$ von 0,1.

Tab. 5: Ergebnisse der Kreuzkorrelationsanalysen nach Pearson aller Faktoren (5.1. - 5.18.) von AD04 Dargestellt sind die gefundenen Beziehungen der unabhängigen Variablen (Einflussfaktoren) zur jeweils abhängigen Variablen. Die Zahlen in Klammern geben die Zeitverschiebung (timelag) in Tagen in der Beziehung der unabhängigen Einflussfaktoren zur abhängigen Variable an. Des Weiteren sind die Korrelationskoeffizienten und das jeweilige Signifikanzniveau $(\alpha)=$ Signifikanz (2-seitig) aufgeführt.

5.1. Abhängige Variable: Hautzustand

\begin{tabular}{|l|l|l|}
\hline $\begin{array}{l}\text { Unabhängige Einfluss- } \\
\text { sfaktoren (timelag) }\end{array}$ & $\begin{array}{l}\text { Korrelations- } \\
\text { koeffizient }\end{array}$ & $\begin{array}{l}\text { Signifikanz } \\
\text { (2-seitig) }\end{array}$ \\
\hline Noradrenalin (-5) & $+0,300$ & 0,012 \\
\hline Adrenalin (-5) & $+0,275$ & 0,021 \\
\hline Neopterin (-1) & $+0,252$ & 0,030 \\
\hline Juckreiz (-4) & $-0,247$ & 0,038 \\
\hline Juckreiz (0) & $+0,315$ & 0,006 \\
\hline Kratzintensität (-5) & $+0,216$ & 0,073 \\
\hline Kratzintensität (-2) & $+0,233$ & 0,047 \\
\hline Kratzintensität (-0) & $+0,186$ & 0,109 \\
\hline Allg. Gereiztheit (-5) & $+0,221$ & 0,065 \\
\hline Allg. Gereiztheit (-0) & $+0,246$ & 0,033 \\
\hline Ängstlichkeit (-5) & $+0,209$ & 0,083 \\
\hline Ängstlichkeit (-1) & $+0,192$ & 0,101 \\
\hline Schlafqualität (-4) & $-0,267$ & 0,024 \\
\hline Schlaferholsamkeit (-4) & $-0,268$ & 0,024 \\
\hline
\end{tabular}

5.3. Abhängige Variable: Neopterin

\begin{tabular}{|l|l|l|}
\hline $\begin{array}{l}\text { Unabhängige Einfluss- } \\
\text { faktoren (timelag) }\end{array}$ & $\begin{array}{l}\text { Korrelations- } \\
\text { koeffizient }\end{array}$ & $\begin{array}{l}\text { Signifikanz } \\
\text { (2-seitig) }\end{array}$ \\
\hline Cortisol (0) & $+0,196$ & 0,091 \\
\hline Hautzustand (-3) & $-0,238$ & 0,045 \\
\hline Hautzustand (-2) & $+0,198$ & 0,093 \\
\hline Juckreizstärke (-2) & $+0,271$ & 0,021 \\
\hline Juckreizstärke (-1) & $+0,264$ & 0,023 \\
\hline Kratztintensität (-2) & $+0,239$ & 0,042 \\
\hline Gereiztheit (0) & $+0,222$ & 0,056 \\
\hline Melatonin (-5) & $+0,215$ & 0,073 \\
\hline Melatonin (-2) & $+0,243$ & 0,038 \\
\hline Noradrenalin (-5) & $+0,288$ & 0,058 \\
\hline & & \\
\hline & & \\
\hline & & \\
\hline & & \\
\hline
\end{tabular}

5.2. Abhängige Variable: Melatonin

\begin{tabular}{|l|l|l|}
\hline $\begin{array}{l}\text { Unabhängige Einfluss- } \\
\text { faktoren (timelag) }\end{array}$ & $\begin{array}{l}\text { Korrelations- } \\
\text { koeffizient }\end{array}$ & $\begin{array}{l}\text { Signifikanz } \\
\text { (2-seitig) }\end{array}$ \\
\hline Noradrenalin (-2) & $+0,208$ & 0,078 \\
\hline Noradrenalin (0) & $-0,240$ & 0,038 \\
\hline Kratzintensität (-2) & $-0,104$ & 0,092 \\
\hline Introvertiertheit (-1) & $+0,199$ & 0,089 \\
\hline Desaktivität (-2) & $-0,316$ & 0,007 \\
\hline Schlaferholsamkeit (-2) & $+0,347$ & 0,003 \\
\hline Hautzustand (-5) & $-0,213$ & 0,076 \\
\hline Juckreizstärke (-5) & $+0,199$ & 0,098 \\
\hline Desaktivität (-5) & $+0,203$ & 0,093 \\
\hline & & \\
\hline & & \\
\hline & & \\
\hline & & \\
\hline & & \\
\hline
\end{tabular}

5.4. Abhängige Variable: Cortisol

\begin{tabular}{|c|c|c|}
\hline $\begin{array}{l}\text { Unabhängige Einfluss- } \\
\text { faktoren (timelag) }\end{array}$ & $\begin{array}{l}\text { Korrelations- } \\
\text { koeffizient }\end{array}$ & $\begin{array}{l}\text { Signifikanz } \\
\text { (2-seitig) }\end{array}$ \\
\hline Neopterin (0) & $+0,196$ & 0,091 \\
\hline Hautzustand (-3) & $+0,210$ & 0,076 \\
\hline Juckreizstärke (-2) & $+0,253$ & 0,031 \\
\hline Juckreizstärke (-1) & $+0,192$ & 0,101 \\
\hline Juckreizstärke (0) & $+0,245$ & 0,034 \\
\hline Kratzintensität (-1) & $+0,205$ & 0,080 \\
\hline Schlafqualität (0) & $+0,236$ & 0,042 \\
\hline Schlaferholsamkeit (-2) & $-0,277$ & 0,018 \\
\hline Noradrenalin (-2) & $-0,223$ & 0,058 \\
\hline Noradrenalin (0) & $+0,227$ & 0,050 \\
\hline Adrenalin (-4) & $-0,265$ & 0,025 \\
\hline Adrenalin (-2) & $-0,219$ & 0,063 \\
\hline Adrenalin (0) & $+0,201$ & 0,083 \\
\hline Melatonin (-4) & $-0,197$ & 0,100 \\
\hline
\end{tabular}


5.5. Abhängige Variable: Adrenalin

\begin{tabular}{|l|l|l|}
\hline $\begin{array}{l}\text { Unabhängige Einfluss- } \\
\text { faktoren (timelag) }\end{array}$ & $\begin{array}{l}\text { Korrelations- } \\
\text { koeffizient }\end{array}$ & $\begin{array}{l}\text { Signifikanz } \\
\text { (2-seitig) }\end{array}$ \\
\hline Noradrenalin (0) & $+0,787$ & 0,000 \\
\hline Cortisol (0) & $+0,201$ & 0,083 \\
\hline Kratzintensität (-5) & $-0,256$ & 0,032 \\
\hline Hautzustand (-2) & $-0,212$ & 0,072 \\
\hline Melatonin (-5) & $-0,196$ & 0,104 \\
\hline & & \\
\hline & & \\
\hline & & \\
\hline & & \\
\hline & & \\
\hline
\end{tabular}

5.6. Abhängige Variable: Noradrenalin

\begin{tabular}{|c|c|c|}
\hline $\begin{array}{l}\text { Unabhängige Einfluss- } \\
\text { faktoren (timelag) }\end{array}$ & $\begin{array}{l}\text { Korrelations- } \\
\text { koeffizient }\end{array}$ & $\begin{array}{l}\text { Signifikanz } \\
\text { (2-seitig) }\end{array}$ \\
\hline Adrenalin (0) & $+0,787$ & 0,000 \\
\hline Cortisol (-5) & - 0,279 & 0,019 \\
\hline Cortisol(-4) & - 0,230 & 0,054 \\
\hline Cortisol (0) & $+0,227$ & 0,050 \\
\hline Juckreizstärke (-5) & $-0,277$ & 0,020 \\
\hline Kratzintensität (-5) & $-0,301$ & 0,011 \\
\hline Schlaferholsamkeit (-2) & $-0,235$ & 0,046 \\
\hline Aktivität (0) & $+0,214$ & 0,065 \\
\hline Melatonin (0) & $-0,240$ & 0,038 \\
\hline Hautzustand (-2) & $-0,210$ & 0,074 \\
\hline
\end{tabular}

\subsection{Abhängige Variable: Ängstlichkeit}

\begin{tabular}{|c|c|c|}
\hline $\begin{array}{l}\text { Unabhängige Einfluss- } \\
\text { faktoren (timelag) }\end{array}$ & $\begin{array}{l}\text { Korrelations- } \\
\text { koeffizient }\end{array}$ & \begin{tabular}{|l|} 
Signifikanz \\
(2-seitig)
\end{tabular} \\
\hline Ängstlichkeit (0) & $+0,627$ & 0,000 \\
\hline Ängstlichkeit (-4) & $-0,200$ & 0,094 \\
\hline Desaktivität (-1) & $-0,190$ & 0,105 \\
\hline Introvertiertheit (0) & $+0,291$ & 0,011 \\
\hline Wohlbefinden (0) & $-0,383$ & 0,001 \\
\hline Aktivität (0) & - 0,335 & 0,003 \\
\hline Melatonin (-3) & $-0,311$ & 0,008 \\
\hline Melatonin (-1) & $-0,200$ & 0,088 \\
\hline Adrenalin (- 5) & $+0,242$ & 0,044 \\
\hline Adrenalin (-4) & - 0,197 & 0,099 \\
\hline Neopterin (-5) & $-0,275$ & 0,021 \\
\hline Neopterin (-3) & $-0,276$ & 0,019 \\
\hline Neopterin (0) & $+0,222$ & 0,056 \\
\hline Hauzustand (-4) & $-0,215$ & 0,072 \\
\hline Hautzustand (0) & $+0,246$ & 0,033 \\
\hline Juckreizstärke (-2) & $+0,267$ & 0,023 \\
\hline Kratzintensität (-4) & $+0,205$ & 0,086 \\
\hline Schlafqualität (-1) & $+0,191$ & 0,102 \\
\hline
\end{tabular}

\begin{tabular}{|l|l|l|}
\hline $\begin{array}{l}\text { Unabhängige Einfluss- } \\
\text { faktoren (timelag) }\end{array}$ & $\begin{array}{l}\text { Korrelations- } \\
\text { koeffizient }\end{array}$ & $\begin{array}{l}\text { Signifikanz } \\
\text { (2-seitig) }\end{array}$ \\
\hline Gereiztheit (0) & $+0,627$ & 0,000 \\
\hline Introvertiertheit (0) & $+0,317$ & 0,006 \\
\hline Deasaktivität (-1) & $-0,211$ & 0,071 \\
\hline Wohlbefinden (0) & $-0,517$ & 0,000 \\
\hline Aktivität (0) & $-0,316$ & 0,006 \\
\hline Extravertiertheit (0) & $-0,228$ & 0,049 \\
\hline Melatonin (-3) & $-0,292$ & 0,013 \\
\hline Neopterin (-3) & $-0,290$ & 0,013 \\
\hline Kratzintensität (-4) & $+0,337$ & 0,004 \\
\hline Schlafqualität (-1) & $+0,312$ & 0,007 \\
\hline & & \\
\hline & & \\
\hline & & \\
\hline & & \\
\hline & & \\
\hline & & \\
\hline & & \\
\hline & & \\
\hline
\end{tabular}

5.9. Abhängige Variable: Introvertiertheit

\begin{tabular}{|c|c|c|}
\hline $\begin{array}{l}\text { Unabhängige } \\
\text { Einflussfaktoren (lag) }\end{array}$ & \begin{tabular}{|l|}
$\begin{array}{l}\text { Korrelations- } \\
\text { koeffizient }\end{array}$ \\
\end{tabular} & \begin{tabular}{|l} 
Signifikanz \\
(2-seitig)
\end{tabular} \\
\hline Desaktivität (0) & $+0,386$ & 0,000 \\
\hline Wohlbefinden (0) & $-\quad 0,544$ & 0,000 \\
\hline Aktivität (0) & $-0,636$ & 0,000 \\
\hline Extravertiertheit (0) & $-0,723$ & 0,000 \\
\hline Noradrenalin (-3) & $-0,246$ & 0,037 \\
\hline Adrenalin (-3) & $-0,231$ & 0,051 \\
\hline Melatonin (-5) & $-0,228$ & 0,058 \\
\hline Neopterin $(-4)$ & $+0,197$ & 0,099 \\
\hline Neopterin (-3) & $-0,294$ & 0,012 \\
\hline Neopterin (-2) & $-0,292$ & 0,012 \\
\hline Hautzustand (-4) & $-0,200$ & 0,095 \\
\hline Juckreizstärke (-3) & $-0,353$ & 0,002 \\
\hline Kratzintensität (-3) & $-0,205$ & 0,083 \\
\hline Gereiztheit (-1) & $-0,308$ & 0,008 \\
\hline Gereiztheit (0) & $+0,291$ & 0,011 \\
\hline Gereitzheit (-5) & $-0,221$ & 0,066 \\
\hline Ängstlichkeit (-1) & $-0,252$ & 0,031 \\
\hline Ängstlichkeit (0) & $+0,317$ & 0,006 \\
\hline
\end{tabular}

5.10. Abhängige Variable: Extravertiertheit

\begin{tabular}{|c|c|c|}
\hline $\begin{array}{l}\text { Unabhängige } \\
\text { Einflussfaktoren (lag) }\end{array}$ & $\begin{array}{l}\text { Korrelations- } \\
\text { koeffizient }\end{array}$ & $\begin{array}{l}\text { Signifikanz } \\
\text { (2-seitig) }\end{array}$ \\
\hline Noradrenalin (-3) & $+0,332$ & 0,004 \\
\hline Adrenalin (-3) & $+0,292$ & 0,013 \\
\hline Neopterin (-3) & $+0,201$ & 0,090 \\
\hline Neopterin (-2) & $+0,243$ & 0,038 \\
\hline Cortisol (-4) & $-0,263$ & 0,027 \\
\hline Cortisol (-3) & $+0,196$ & 0,099 \\
\hline Hautzustand $(-4)$ & $+0,251$ & 0,035 \\
\hline Juckreizstärke (-3) & $+0,258$ & 0,029 \\
\hline Juckreizstärke (-2) & $-\quad 0,257$ & 0,028 \\
\hline & & \\
\hline & & \\
\hline & & \\
\hline & & \\
\hline & & \\
\hline & & \\
\hline & & \\
\hline
\end{tabular}




\begin{tabular}{|l|l|l|}
\hline $\begin{array}{l}\text { Unabhängige Einfluss- } \\
\text { faktoren (timelag) }\end{array}$ & $\begin{array}{l}\text { Korrelations- } \\
\text { koeffizient }\end{array}$ & $\begin{array}{l}\text { Signifikanz } \\
\text { (2-seitig) }\end{array}$ \\
\hline Aktivität (0) & $-0,468$ & 0,000 \\
\hline Extravertiertheit (0) & $-0,527$ & 0,000 \\
\hline Melatonin (-1) & $+0,193$ & 0,099 \\
\hline Juckreizstärke (-3) & $-0,311$ & 0,008 \\
\hline Kratzintensität (-4) & $-0,249$ & 0,036 \\
\hline Kratzintensität (-3) & $-0,266$ & 0,024 \\
\hline Schlaferholsamkeit (-1) & $-0,208$ & 0,075 \\
\hline Wohlbefinden (0) & $+0,350$ & 0,002 \\
\hline & & \\
\hline & & \\
\hline
\end{tabular}

5.13. Abhängige Variable: Wohlbefinden

\begin{tabular}{|l|l|l|}
$\begin{array}{l}\text { Unabhängige Einfluss- } \\
\text { faktoren (timelag) }\end{array}$ & $\begin{array}{l}\text { Korrelations- } \\
\text { koeffizient }\end{array}$ & $\begin{array}{l}\text { Signifikanz } \\
\text { (2-seitig) }\end{array}$ \\
\hline Deasktivität (0) & $-0,350$ &, 002 \\
\hline Aktivität (0) & $+0,609$ & 0,000 \\
\hline Extravertiertheit (0) & $+0,575$ & 0,000 \\
\hline Adrenalin (-3) & $+0,263$ & 0,026 \\
\hline Cortisol (-4) & $-0,201$ & 0,093 \\
\hline Juckreizstärke (-3) & $+0,227$ & 0,055 \\
\hline Juckreizstärke (-2) & $-0,213$ & 0,070 \\
\hline Ängstlickeit (0) & $-0,517$ & 0,000 \\
\hline Introvertiertheit (0) & $-0,544$ & 0,000 \\
\hline Gereiztheit (0) & $-0,383$ & 0,001 \\
\hline Hautzustand (-4) & $+0,224$ & 0,061 \\
\hline Juckreizstärke (-2) & $-0,213$ & 0,070 \\
\hline
\end{tabular}

5.15. Abhängige Variable: Juckreizstärke Unabhängige Einfluss- Korrelations$\begin{array}{lll}\text { faktoren (timelag) } & \text { koeffizient } & \text { (2-seitig) }\end{array}$

\begin{tabular}{|l|l|l|}
\hline Cortisol $(-3)$ & $+0,241$ & 0,042 \\
\hline
\end{tabular}

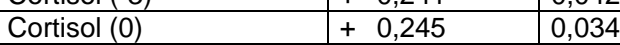

\begin{tabular}{l|l|l} 
Hautzustand $(0)$ & $+0,315$ & 0,006 \\
\hline
\end{tabular}

\begin{tabular}{|l|l|l}
\hline Kratzintensität $(0)$ & $+0,679$ & 0,000 \\
\hline
\end{tabular}

\begin{tabular}{|l|l|l|}
\hline Schlafqualität (-4) & $-0,227$ & 0,057 \\
\hline
\end{tabular}

\begin{tabular}{|lll}
\hline Aktivität (-4) & $-0,227$ & 0,057 \\
\hline Extravertert & 0,070 \\
\hline
\end{tabular}

\begin{tabular}{lll|l}
\hline Extravertiertheit (-4) & $-0,227$ & 0,057 \\
\hline Angsichkeit (-4) & + & 0,198 & 0,100
\end{tabular}

\begin{tabular}{|l|l|l|}
\hline Ängstlichkeit (-4) & $+0,198$ & 0,100 \\
\hline
\end{tabular}

5.17. Abhängige Variable: Schlafqualität

\begin{tabular}{|l|l|l|}
\hline $\begin{array}{l}\text { Unabhängige Einfluss- } \\
\text { faktoren (timelag) }\end{array}$ & $\begin{array}{l}\text { Korrelations- } \\
\text { koeffizient }\end{array}$ & $\begin{array}{l}\text { Signifikanz } \\
\text { (2-seitig) }\end{array}$ \\
\hline Melatonin (-4) & $-0,215$ & 0,072 \\
\hline Noradrenalin (-5) & $-0,212$ & 0,078 \\
\hline Cortisol (0) & $+0,236$ & 0,042 \\
\hline Gereiztheit (-1) & $+0,274$ & 0,018 \\
\hline & & \\
\hline & & \\
\hline & & \\
\hline & & \\
\hline & & \\
\hline & & \\
\hline & & \\
\hline & & \\
\hline & & \\
\hline
\end{tabular}

5.11. Abhängige Variable: Desaktivität

5.12. Abhängige Variable: Aktivität

\begin{tabular}{|l|l|l|}
\hline $\begin{array}{l}\text { Unabhängige Einfluss- } \\
\text { faktoren (timelag) }\end{array}$ & $\begin{array}{l}\text { Korrelations- } \\
\text { koeffizient }\end{array}$ & $\begin{array}{l}\text { Signifikanz } \\
\text { (2-seitig) }\end{array}$ \\
\hline Extravertiertheit (0) & $+0,687$ & 0,000 \\
\hline Noradrenalin (-3) & $+0,247$ & 0,037 \\
\hline Noradrenalin (-1) & $+0,203$ & 0,082 \\
\hline Adrenalin (-3) & $+0,301$ & 0,010 \\
\hline Adrenalin (-1) & $+0,264$ & 0,023 \\
\hline Neopterin (-3) & $+0,208$ & 0,080 \\
\hline Cortisol (-2) & $-0,202$ & 0,086 \\
\hline Cortisol (-4) & $-0,258$ & 0,030 \\
\hline Juckreizstärke (-3) & $+0,327$ & 0,005 \\
\hline Schlaferholsamkeit (-4) & $+0,217$ & 0,069 \\
\hline
\end{tabular}

5.14. Abhängige Variable: Grübelstärke

\begin{tabular}{|l|l|l|}
\hline $\begin{array}{l}\text { Unabhängige Einfluss- } \\
\text { faktoren (timelag) }\end{array}$ & $\begin{array}{l}\text { Korrelations- } \\
\text { koeffizient }\end{array}$ & $\begin{array}{l}\text { Signifikanz } \\
\text { (2-seitig) }\end{array}$ \\
\hline Ängstlichkeit (0) & $+0,259$ & 0,111 \\
\hline Wohlbefinden (-2) & $+0,272$ & 0,098 \\
\hline Wohlbefinden (-5) & $+0,392$ & 0,018 \\
\hline Extravertiertheit (-2) & $+0,445$ & 0,005 \\
\hline Introvertiertheit (-2) & $-0,293$ & 0,074 \\
\hline Desaktivität (-2) & $-0,328$ & 0,038 \\
\hline & & \\
\hline & & \\
\hline & & \\
\hline & & \\
\hline & & \\
\hline & & \\
\hline
\end{tabular}

5.16. Abhängige Variable: Kratzintensität

\begin{tabular}{|l|l|l|}
$\begin{array}{l}\text { Unabhängige Einfluss- } \\
\text { faktoren (timelag) }\end{array}$ & $\begin{array}{l}\text { Korrelations- } \\
\text { koeffizient }\end{array}$ & $\begin{array}{l}\text { Signifikanz } \\
\text { (2-seitig) }\end{array}$ \\
\hline Gereiztheit (-4) & $+0,226$ & 0,058 \\
\hline Melatonin (-4) & $-0,197$ & 0,099 \\
\hline Adrenalin (-5) & $-0,215$ & 0,073 \\
\hline Adrenalin (-3) & $+0,289$ & 0,014 \\
\hline Neopterin (-2) & $-0,226$ & 0,054 \\
\hline Cortisol (-3) & $+0,254$ & 0,031 \\
\hline Juckreizstärke (-2) & $-0,211$ & 0,073 \\
\hline Introvertiertheit (-1) & $+0,209$ & 0,074 \\
\hline Hautzustand (0) & $+0,186$ & 0,109 \\
\hline
\end{tabular}

5.18. Abhängige Variable: Schlaferholsamkeit

\begin{tabular}{|l|l|l|}
$\begin{array}{l}\text { Unabhängige Einfluss- } \\
\text { faktoren (timelag) }\end{array}$ & $\begin{array}{l}\text { Korrelations- } \\
\text { koeffizient }\end{array}$ & $\begin{array}{l}\text { Signifikanz } \\
\text { (2-seitig) }\end{array}$ \\
\hline Adrenalin (-5) & $-0,207$ & 0,085 \\
\hline Hautzustand (-5) & $-0,312$ & 0,009 \\
\hline Juckreizstärke (-3) & $+0,262$ & 0,026 \\
\hline Gereiztheit (-5) & $-0,311$ & 0,009 \\
\hline Gereiztheit (-4) & $-0,230$ & 0,054 \\
\hline Ängstlichkeit (-5) & $-0,224$ & 0,063 \\
\hline Desaktivität (-1) & $+0,230$ & 0,049 \\
\hline Aktivität (-3) & $-0,247$ & 0,037 \\
\hline Aktivität (-1) & $-0,366$ & 0,001 \\
\hline Schlafqualität (-5) & $+0,256$ & 0,036 \\
\hline Neopterin (-2) & $+0,190$ & 0,108 \\
\hline Wohlbefinden (-1) & $-0,340$ & 0,003 \\
\hline Extravertiertheit (-1) & $-0,342$ & 0,003 \\
\hline
\end{tabular}

Von allen aufgelisteten Zusammenhängen wurden erneut diejenigen herausgefiltert, die in einer kausalen Beziehung zueinander stehen könnten. Sie werden nachfolgend dargestellt. 


\subsubsection{Darstellung und Beschreibung ausgewählter Zusammenhänge}

Es folgt, analog Kapitel 3.1.4, die schematische Darstellung ausgewählter Korrelationen.

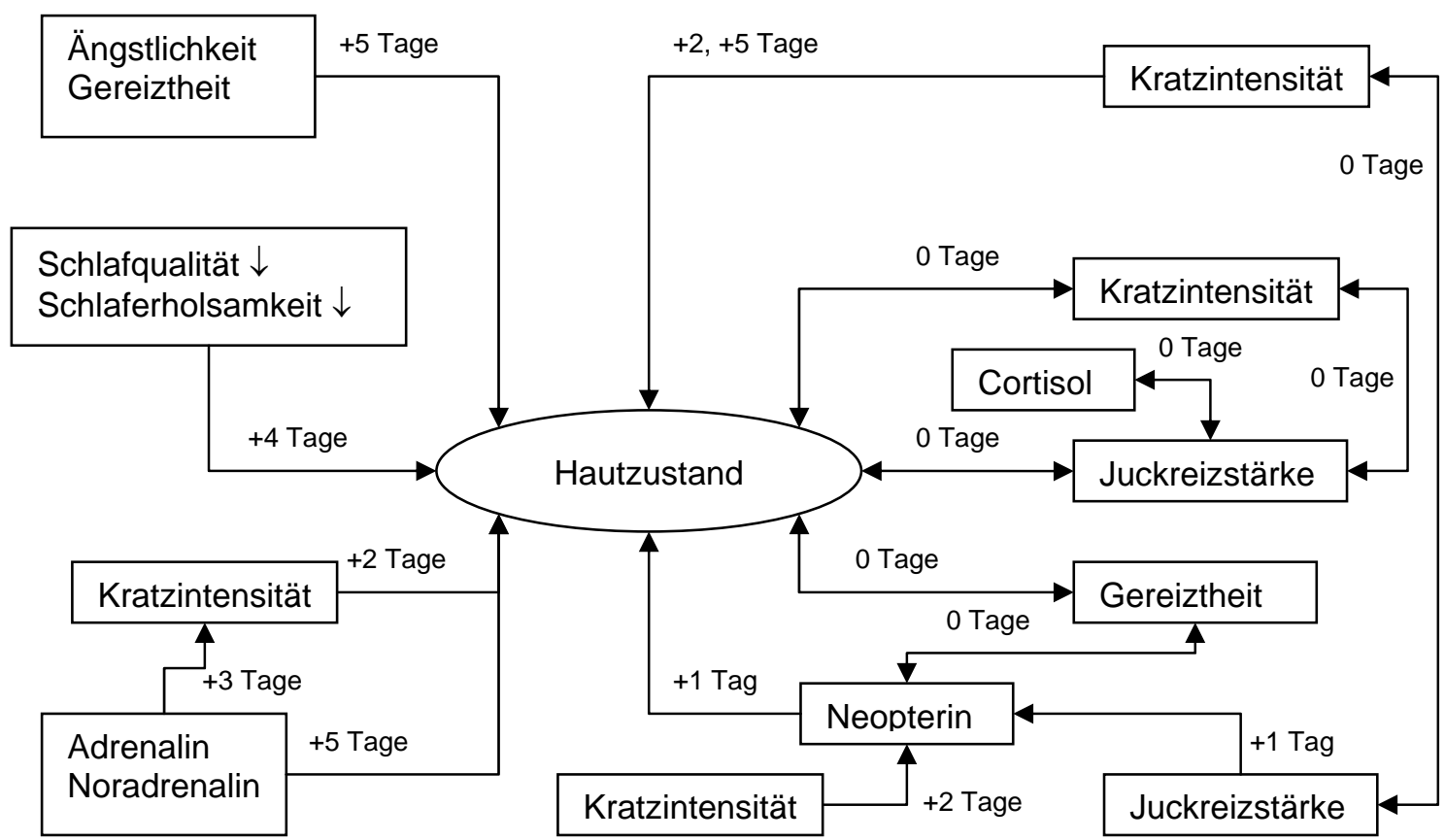

Abb. 10: Beziehungsschema ausgewählter Faktoren zum Hautzustand von AD04

Die Pfeile $(\rightarrow)$ zeigen die Richtung des Zusammenhanges zwischen zwei Faktoren an. Die Zeitverschiebung in der Beziehung der Faktoren zueinander ist neben den Pfeilen in Tagen angegeben. Das Symbol $\downarrow$ bedeutet „vermindert“.

Weitere ausgewählte Beziehungen zwischen den Einflussgrößen sind nachfolgend tabellarisch aufgeführt.

Tab. 6: Übersicht über Beziehungen weiterer ausgewählter Einflussgrößen von AD04 Die Zahlen in Klammern geben die Zeitverschiebung (in Tagen) in der Beziehung der Einflussgrößen zueinander an. $(-)$ bedeutet, dass die Beziehung der abhängigen Variablen vorangeht, (+) bedeutet, dass sie ihr nachfolgt, (0) bedeutet, dass sie am gleichen Tag besteht. Das Symbol $\downarrow$ bedeutet „,vermindert“.

\begin{tabular}{|l|l|}
\hline Abhängige Variable & Korrelationen mit unabhängigen Einflussgrößen (Zeitverschiebung in Tagen) \\
\hline Neopterin & Cortisol (0), Gereiztheit (0) \\
\hline Cortisol & Adrenalin (0), Noradrenalin (0) \\
\hline Kratzintensität & Cortisol (+1) \\
\hline Juckreizstärke & Neopterin (+2), Cortisol (0), Gereiztheit (+2) \\
\hline Gereiztheit & Introvertiertheit (0), Ängstlichkeit (0), Aktivität $\downarrow$ (0), Neopterin (0) \\
\hline Schlaferholsamkeit $\downarrow$ & Noradrenalin (+2), Cortisol (+2) \\
\hline
\end{tabular}


Auch bei AD04 zeigt sich ein individuelles Muster der Einflussgrößen. Die interprepretierende Beschreibung der Wirkungen der Einzelfaktoren in diesem Netzwerk auf den Hautzustand erfolgt auch an dieser Stelle in Form einzelner „Wirkgefüge“.

\section{1. „Wirkgefüge“ Haut - Stress - Immunsystem}

Nach schlechtem Schlaf baut sich in den kommenden zwei Tagen „Stress" auf. Dies führt zu einem Anstieg des Noradrenalin- und Cortisolspiegels. Beide Hormone wirken konzentrationsabhängig initial immunstimulierend. Dies bedingt Juckreiz und nachfolgend Kratzen. Die Kratzintensität wiederum korreliert positiv mit dem Neopterinspiegel zwei Tage später und dieser korreliert mit dem Hautzustand am darauf folgenden Tag positiv. Hieraus ergibt sich die Kausalkette: Stress führt über Kratzen zur Aktivierung des zellulären Immunsystems, welches Einfluss auf den Hautzustand nimmt.

\section{2. „Wirkgefüge“ Haut - Juckreiz - Kratzen - Emotionen}

Der Hautzustand korreliert zeitgleich mit der Juckreizstärke und Kratzintensität sowie der emotionalen Gereiztheit, das heißt, es besteht ein „Juck-Kratz-Zirkel“.

\section{3. „Wirkgefüge“ Haut - Emotionen - Katecholamine - Kratzintensität}

Eine („Stress“)-Situation, in der AD04 sich emotional gereizt und ängstlich fühlt, steht in positiver Beziehung zum Hautzustand fünf Tage später. Des Weiteren stehen die Stresshormone Adrenalin und Noradrenalin in positiver Beziehung zum Hautzustand fünf Tage später, wobei auch eine positive Beziehung zwischen den beiden Katecholaminen und der Kratzintensität drei Tage später besteht. Dieses Wirkgefüge ist allerdings nicht direkt kausal interpretierbar.

\section{Fazit:}

Der Hautzustand von AD04 scheint durch mehrere Faktoren beeinflusst zu werden. Von Bedeutung sind offenbar die Schlaferholsamkeit, unklare Stresssituationen, die einen Einfluss auf den Katecholamin-Spiegel und die Stimmungslage haben, sowie die Juckreizstärke und Kratzintensität. Bei AD04 scheint eine Art „Stress-Juck-Kratz-Immunaktivierungs-Hautverschlechterungs-Gereiztsein-Zirkel“ zu bestehen. Außerdem korreliert der Neopterin- mit dem Cortisolspiegel in derselben Nacht positiv, was nicht physiologisch ist und als Folge einer veränderten Aktivität der HHNR-Achse gedeutet werden kann. 


\subsection{Ergebniszusammenfassung}

Die Auswertung der Ergebnisse der beiden Einzelfallstudien zeigt viele Zusammenhänge (sowohl ähnliche als auch unterschiedliche) zwischen dem Hautzustand, dem Befinden und biochemischen Parametern auf. An dieser Stelle sind in Tab. 7 noch einmal die Beziehungen der Einflussgrößen zum Hautzustand übersichtlich im direkten Vergleich dargestellt.

Tab. 7: Vergleichende Ergebnisübersicht der Beziehung zwischen dem Hautzustand von AD02 und AD04 und verschiedenen Einflussgrößen

Die Zahlen in Klammern geben die Zeitverschiebung (in Tagen) in der Beziehung der unabhängigen Einflussfaktoren zum Hautzustand an. (-) bedeutet, dass die Beziehung dem Hautzustand vorangeht, (+) bedeutet, dass sie dem Hautzustand nachfolgt, (0) bedeutet, dass sie am gleichen Tag besteht. Das Symbol $\downarrow$ bedeutet „vermindert“.

Abhängige Variable: Hautzustand

\begin{tabular}{|c|c|}
\hline Unabhängige Einflussfaktoren AD02 & Unabhängige Einflussfaktoren AD 04 \\
\hline Biochemische Faktoren: & Biochemische Faktoren: \\
\hline Melatonin (-4) & \\
\hline Melatonin $\downarrow$ (0) & Adrenalin (-5), Noradrenalin (-5) \\
\hline Adrenalin (0) & Neopterin (-1) \\
\hline Neopterin(-5) & \\
\hline Neopterin(-2) & Juckreiz I Kratzverhalten: \\
\hline Cortisol (-2) & Juckreizstärke (0) \\
\hline Juckreiz I Kratzverhalten: & Kratzintensität (-5) \\
\hline Juckreizstärke (0) & Kratzintensität (-2) \\
\hline & Kratzintensität (-0) \\
\hline & Emotionen I Befinden: \\
\hline & Ängstlichkeit (-5) \\
\hline Emotionen / Befinden: & Ängstlichkeit (-1) \\
\hline Wohlbefinden $\downarrow(-5)$ & Allg. Gereiztheit (-5) \\
\hline Extravertiertheit (-1) & Allg. Gereiztheit (-0) \\
\hline Introvertiertheit (-2) & Schlaf: \\
\hline Introvertiertheit (+2) & Schlafqualität $\downarrow(-4)$ \\
\hline Schlaf: & Schlaferholsamkeit $\downarrow(-4)$ \\
\hline Schlafqualität (-3) &
\end{tabular}

Eine zeitgleiche Beziehung des Hautzustandes zu stressvollen Lebensereignissen zeigte sich bei beiden Patienten jeweils nur an einem einzigen Tag, dem Tag des jeweils höchsten Cortisolgehaltes im Nachturin. An diesem Tag bestand bei beiden Patienten eine vorhersehbare, jedoch nicht einschätzbare psychische Belastungssituation, die zugleich mit erhöhten Werten für Ängstlichkeit und Deprimiertheit einherging. Alle anderen Beziehungen zwischen psychischen Belastungen und dem Hautzustand konnten nicht direkt anhand der Tagebuchangaben zu derartigen Ereignissen erfasst werden. Sie wurden indirekt über das Befinden ermit- 
telt. Diesbezüglich konnte gezeigt werden, dass in beiden Fällen typische, mit psychischem Stress assoziierte Emotionen und Stimmungen (Birbaumer und Schmidt 1999, S. 60, 94, 661) wie Gereiztheit, Introvertiertheit, Grübeln und vermindertes Wohlbefinden sowie auch eine verminderte Schlafqualität in Beziehung zum späteren Hautzustand bzw. den Stresshormonen und dem Neopterinspiegel stehen. Das heißt, dass in beiden Fällen der Hautzustand durch psychischen Stress beeinflusst wird. Der psychische Stress wirkt dabei sowohl über das Kratzverhalten als auch über eine Aktivierung des Immunsystems auf den Hautzustand ein. Dabei kommt bei AD04 dem Kratzverhalten offenbar eine stärkere Bedeutung zu als bei AD02.

In der vorliegenden Arbeit konnte erstmals nachgewiesen werden, dass der Neopterinspiegel bei Patienten mit AEDS in einer direkten Beziehung sowohl zum Hautzustand als auch zum emotionalen Befinden (vermindertes Wohlbefinden bei AD02, emotionale Gereiztheit bei AD04) steht.

Des Weiteren konnte erstmals gezeigt werden, dass auch Melatonin in einer direkten Beziehung zum Hautzustand stehen kann, ein Zusammenhang, der sich bei AD02 fand.

Viele der in der vorliegenden Arbeit erhaltenen Ergebnisse konnten, aufgrund der in Kapitel 1 beschriebenen pathogenetischen Zusammenhänge, beim AEDS erwartet werden. Das Vorgehen im Rahmen des Einzelfallstudienkonzeptes bot darüber hinaus die Möglichkeit, jeweils individuell unterschiedliche Ausprägungsmuster zu ermitteln und bisher unbekannte Zusammenhänge zu beschreiben.

Die Bewertung der umfangreichen Ergebnisse erfolgt in der nachfolgenden Diskussion. 


\section{Diskussion}

Die derzeitigen Kenntnisse zur Pathogenese des AEDS zeigen, dass vielfältige komplex miteinander wechselwirkende Beziehungen zwischen den pathogenetischen Einflussgrößen bestehen. Ziel dieser Arbeit war es, zeitliche Zusammenhänge zwischen neuroendokrinologischen und immunologischen Parametern (als Indikatoren für Stress und die zelluläre Immunaktivität) sowie dem psychoemotionalen Befinden und dem Hautzustand beim AEDS aufzudecken.

Nachfolgend werden zunächst die Methodik, dann die Auswertungsverfahren und anschließend die gefundenen Ergebnisse kritisch betrachtet und vergleichend diskutiert sowie hieraus Schlussfolgerungen abgeleitet.

\subsection{Methodik, Vorgehensweise, Auswertungsverfahren}

Als Forschungsmethode wurde die integrative naturalistische Einzelfallstudie gewählt. Sie ist insbesondere bei multifaktoriell bedingten Erkrankungen gut geeignet, Informationen über das komplexe, dynamisch-interaktive Zusammenwirken der verschiedenen, an der Pathogenese beteiligten Faktoren zu liefern.

Erkenntnisse, die in Einzelfallstudien gewonnen werden, dienen in erster Linie dazu, weitergehende Einsichten in das Krankheitsgeschehen zu gewinnen sowie die Formulierung neuartiger Hypothesen anzuregen (Bortz und Döring 2002, S. 579). Allerdings können sie nicht verallgemeinert auf andere Individuen übertragen werden. Hierzu wäre z. B. ein Gruppenvergleich von vielen Einzelfällen Voraussetzung. Auf Grund dessen und auf Grund der Tatsache, dass zudem ein hoher Aufwand zu ihrer Durchführung notwendig ist, werden sie nur relativ selten als Forschungsinstrument eingesetzt. Dennoch wurden insbesondere in der psychodermatologischen Forschung zum AEDS einige interessante Einzelfallstudien durchgeführt, auf die in Kapitel 4.2 näher eingegangen wird. 
Zur Datenanalyse wurden ausschließlich etablierte mathematische Verfahren eingesetzt. In der vorliegenden Arbeit das ARIMA-Verfahren nach Box und Jenkins (1976) zur Zeitreihenanalyse. Damit das ARIMA-Verfahren zuverlässige Ergebnisse liefern kann, wird eine Mindestanzahl von 50 Messwerten empfohlen. In dieser Studie bestand jede der 18 Zeitreihen aus 75 einzelnen Messwerten. Somit konnte für jede Zeitreihe ein zuverlässiges ARIMA-Modell ermittelt und damit zugleich die inneren Abhängigkeiten der Einzelwerte voneinander identifiziert und eliminiert werden. Mit den auf diese Weise erzeugten Residualzeitreihen wurden dann die weitergehenden mathematischen Analysen (Korrelationsanalysen) zur statistischen Prüfung auf Zusammenhänge vorgenommen.

Diese von vielen Autoren (siehe bei Bortz und Döring 2002, S. 568) empfohlene Vorgehensweise wird nicht von allen auf dem Gebiet der Psychosomatik forschenden Wissenschaftlern angewandt. So plädieren Brosig und Brähler (2001) für die Analyse der Originaldaten mittels vektorautoregressiver Modelle, die die Möglichkeit bieten, sowohl Autokorrelationen als auch multivariate Wechselwirkungen in einem gemeinsamen kausalen Modell simultan darzustellen. In der vorliegenden Arbeit musste auf die Anwendung derartiger multivariater (pfadanalytischer) Auswertungsmethoden zur Kausalanalyse der Daten verzichtet werden, da diese speziellen Methoden nicht zur Verfügung standen.

Dementsprechend lag das Hauptanliegen darin, „einfache“ bidirektionale Zusammenhänge aufzudecken, um auf diesem Weg Informationen über mögliche Ursache-Wirkungs-Zusammenhänge zu erhalten. Hierzu wurden alle im ARIMAVerfahren erzeugten „Residualzeitreihen“ bidirektional statistisch untersucht. Hätten eindeutige Annahmen über Ursache-Wirkungs-Relationen vorgelegen, so wäre auch ein vorherige Filterung der abhängigen (lag-)Variable (z.B. Hautzustand) im Rahmen eines sog. Transferfunktionsmodells mit dem ARIMA-Modell der unabhängigen (lead-)Variable (z.B. Juckreiz) wie z.B. bei Helmbold et al. (1996) angewandt, geeignet gewesen. Dies war in der vorliegenden Arbeit nicht der Fall. Vielmehr musste von einer wechselseitigen Beeinflussung der Parameter ausgegangen werden, weshalb die Vorgehensweise von Helmbold et al. (1996) nicht übernommen wurde. Auch ein kombiniertes Vorgehen, wie bei Schubert HJ (1989, S. 78-82) beschrieben, führte, wie sich in einem vergleichenden Testdurchgang vor- 
ab zeigte, nicht zu nennenswerten Ergebnisveränderungen. Deshalb wurde auch auf die Anwendung dieses Verfahren verzichtet.

Fehlerbetrachtung:

Fehlende Messdaten stellen bei Zeitreihenstudien ein besonderes Problem dar. Sie müssen ergänzt werden, damit die zeitliche Struktur in den betroffenen Datenreihen erhalten bleibt. Ginge diese verloren, wäre eine spätere vergleichende Analyse der Zeitreihen nicht mehr sinnvoll. In der vorliegenden Arbeit wurden fehlende Werte (fehlende Tagebuchangaben, fehlende Urinproben) durch Interpolierung der zwei vorangehenden und nachfolgenden Werte ergänzt. Bei AD02 fehlten fünf Urinproben, die Tagebuchangaben waren vollständig. Bei AD04 fehlten drei Urinproben, die Tagebuchangaben waren vollständig.

Die möglichen Fehler, die durch die notwendige Datenergänzung aufgetreten sein können, sind in ihrer Größenordnung schwer einzustufen. Es kann jedoch davon ausgegangen werden, dass der Charakter der einzelnen Datenreihen durch die Datenergänzung nicht entscheidend verändert wurde, zumal auch die ARIMAProzedur der eigentlichen Prüfung auf Zusammenhänge vorgeschaltet war. Die Qualität der ARIMA-Modelle war bis auf wenige Ausnahmen sehr zufriedenstellend. Die Messungenauigkeit im Rahmen der Laboranalytik war niedrig. Genaue Angaben hierzu finden sich in den jeweiligen Methodik-Kapiteln und im Anhang.

\subsection{Zusammenhang zwischen Hautzustand und psychoemotionaler Befindlichkeit}

AD02 reagiert auf ein vermindertes Wohlbefinden fünf Tage später sowie auf eine introvertierte Stimmungslage zwei Tage später mit einer Hautverschlechterung. Diese wiederum steht in positiver Beziehung zur Grübelintensität am Folgetag und zur introvertierten Stimmungslage zwei Tage später. AD04 reagiert auf eine gereizte/ängstliche Stimmungslage ebenfalls fünf Tage später sowie einen Tag später mit einer Hautverschlechterung. Außerdem steht der Hautzustand bei AD04 am selben Tag in positiver Beziehung zur emotionalen Gereiztheit. 
Diese Ergebnisse zeigen, dass sich der Hautzustand und das emotionale Befinden wechselseitig direkt und indirekt beeinflussen. Die Ergebnisinterpretation muss jedoch darüber hinaus noch weiter gefasst werden, da bestimmte Befindlichkeitslagen, wie z. B. Ängstlichkeit, emotionale Gereiztheit und vermindertes Wohlbefinden als auch eine verminderte Schlafqualität/Schlaferholsamkeit, zugleich mit dem Vorliegen von psychischem Stress verknüpft sein können (Birbaumer und Schmidt 1999, S.60, S.94, S.661). Daher deuten die Ergebnisse der vorliegenden Studie auch darauf hin, dass in beiden untersuchten Einzelfällen eine wechselseitige Beziehung zwischen dem Hautzustand und psychischem Stress besteht. Ähnliche Ergebnisse, die einen Zusammenhang zwischen dem Hautzustand und psychischen Vorgängen beim AEDS aufzeigen, fanden sich auch in anderen Längsschnittstudien.

Schubert HJ (1989) konnte im Rahmen zeitreihenanalytischer Studien bei sechs Patienten mit AEDS zeigen, dass zeitsynchrone Beziehungen zwischen dem Hautzustand (ermittelt als Ausmaß der betroffenen Körperfläche und Schwere der Hautsymptomatik), der emotionalen Befindlichkeit, dem Juckreiz und der Kratzhäufigkeit sowie alltäglichen Stressereignissen bestehen. Darüber hinaus gehende, zeitlich um ein oder zwei Tage versetzte Zusammenhänge zwischen Stressereignissen und dem Hautzustand konnte er in seiner Studie allerdings nicht nachweisen.

Auch bei Heinemann (1992) zeigten sich zeitsynchrone Zusammenhänge zwischen psychischem Befinden und AEDS-typischen Krankheitssymptomen.

Brosig et al. (1993) konnten in einer Zeitreihenstudie bei einem 28-jährigen Patienten mit AEDS einen klaren Zusammenhang zwischen dem Hautzustand und der Stimmung „Aggressive Hemmung“ aufzeigen, die am selben Tag kulminierten.

Kupfer (1994) beschrieb in einer zeitreihenanalytischen Untersuchung wechselseitige zeitsynchrone Zusammenhänge zwischen Emotionen und Hautsymptomen. Dabei konnte auch der positve Einfluss von stationären psychotherapeutischen 
Interventionen auf den Speichel-Kortisol-Gehalt und den Hautzustand gezeigt werden.

Helmbold et al. (2000) demonstrierten in einer Zeitreihenstudie den Einfluss von mentalem Stress auf die periphere Eosinophilenkonzentration und auf den Hautzustand bei zwei Patientinnen mit AEDS. Die Autoren konnten zeigen, dass mentaler Stress zu einem Abfall der peripheren Eosinophilenkonzentration am selben Tag führt. Und sie konnten zeigen, dass mentaler Stress mit einer Verschlechterung des Hautzustandes am selben Tag einhergeht.

Gaisbauer (2000) untersuchte bei einer 21-jährigen Patientin über 50 Tage den Einfluss von psychischem Stress (ermittelt über Daily stressor inventory) auf den Hautzustand und periphere Lymphozytenpopulationen und konnte in dieser Zeitreihenuntersuchung nachweisen, dass ein Stressanstieg am Folgetag zur Verstärkung subjektiver Krankheitssymptome wie Juckreiz und Schlaflosigkeit sowie zwei Tage später zur Verschlimmerung des Hautzustandes führte, der mittels SCORAD bestimmt worden war.

Brosig et al. (2000) sowie Brosig und Brähler (2001) beschrieben Interaktionen von depressiver Stimmung, Hautbeschwerden und psychoneuroimmunologischen Parametern (Speichel-Cortisol und sekretorischen Speichel-IgA) bei einer Patientin mit AEDS während stationärer Psychotherapie. Sie konnten zeigen, dass depressive Episoden und erhöhte Cortisolausschüttungen in Beziehung zu einer erniedrigten Produktion von sekretorischem IgA im Speichel stehen. Der erniedrigte IgA-Gehalt im Speichel sagt den Hautzustand zwei Tage später vorher. Somit konnte eine psychoneuroimmunologisch vermittelte Immunreaktion nachgewiesen werden, die zugleich einen Prädiktor für den Hautzustand darstellt.

Auch in der "Tagebuch-Studie" von King und Wilson (1991) zeigte sich bereits, dass interpersoneller Stress in Beziehung zum Hautzustand am Folgetag steht und dieser wiederum einen Tag später mit einer depressiven Stimmungslage einhergeht. King und Wilson werteten Tagebuchdaten zu Stressereignissen, zur 
Stimmungsqualität und zum Hautzustand von 50 Patienten mit AEDS (18 Männer, 32 Frauen) über einen Zeitraum von 14 Tagen aus. Interessanterweise war der Grad an interpersonellem Stress bei erkrankten Patienten nicht größer als in einer Kontrollgruppe von Nicht-Erkrankten. Als Gründe für die erhöhte Vulnerabilität des Hautzustandes gegenüber derartigen psychischen Belastungen bei AEDS-Patienten führen King und Wilson eine Reihe von Ursachen an:

1. Interpersoneller Stress wirkt auf die Haut infolge physiologischer Konsequenzen der stressinduzierten Arousal-Situation.

2. Die Zunahme an Hautsymptomen macht den Betroffenen zugleich anfälliger für interpersonellen Stress.

3. Ein erhöhtes interpersonelles Stressniveau führt dazu, dass die Erkrankten ihren Hautzustand als schlechter einstufen, als er es objektiv betrachtet ist.

4. Ein schlechter Hautzustand führt dazu, dass die Reaktionen im Rahmen zwischenmenschlicher Interaktionen eher negativer eingeschätzt werden.

5. Auch weitere Faktoren, wie z.B. die Persönlichkeitsstruktur und der persönliche Reaktionsstil können die Einschätzung von zwischenmenschlichen Interaktionen und des Hautzustands beeinflussen.

Damit beschreiben King und Wilson zugleich eine wesentliche Problematik bei der Durchführung von Studien, die auf Tagebuchdaten basieren. Derartige Überlegungen sind auch bezüglich der Ergebnisse der vorliegenden Arbeit anzustellen. Denn auch in dieser Studie muss davon ausgegangen werden, dass über die physiologisch ablaufenden, neuroendokrinoimmunologischen Vorgänge hinaus Wechselwirkungen zwischen der Persönlichkeitsstruktur, der Stimmungslage und der subjektiven Einschätzung des Hautzustandes bestehen und umgekehrt. Diese Wechselwirkungen können zu subjektiven Fehleinschätzungen bei Tagebucheinträgen führen. Dessen muss man sich bewusst sein, ohne dass es jedoch möglich ist, den Einfluss derartiger „Fehlerquellen“ in einem solchen Studiendesign zu beseitigen. An dieser Stelle sei noch einmal darauf hingewiesen, dass zumindest das ARIMA-Verfahren dazu beiträgt, dass die Wahrscheinlichkeit des Auftretens autokorrelativ bedingter Scheinkorrelationen zwischen zwei sich gegenseitig beeinflussenden Faktoren erheblich vermindert wird (Bortz und Döring 2002, S. 569). 
Auch in einigen älteren Studien fanden sich Hinweise auf psychodermatologische Zusammenhänge beim AEDS.

Brown und Bettley (1971) fanden bei 93 untersuchten Personen in zwei Drittel der Fälle eine Beeinflussung der Erkrankung durch psychische Faktoren.

Jordan und Whitlock (1975) deckten bei 18 Patienten mit AEDS im Vergleich mit einer ebenso großen Patientengruppe erhöhte Werte für Neurotizismus, Angst und unterdrückte Feindseligkeit auf.

Faulstich et al. (1985) fanden bei zehn untersuchten Patienten im akuten Krankheitsstadium eine erhöhte Angstneigung im Vergleich zu einer Kontrollgruppe ohne AEDS.

Gieler et al. (1999) konnten in einer Clusteranalyse von ebenfalls 93 erkrankten Patienten vier unterschiedliche Subgruppen identifizieren, die sich durch unterschiedliche psychische Auffälligkeiten im Vergleich zu einer gesunden Kontrollgruppe unterschieden. Hochsignifikante Unterschiede zwischen Patienten und Kontrollpersonen zeigten sich dabei in den Skalen Angst, Erregung, Antriebsverlust, depressive Verstimmung und Neurotizismus. Insbesondere eine Patientengruppe $(n=17)$ war psychisch besonders auffällig. Sie zeichnete sich durch eine frühe Erstmanifestation der Erkrankung aus, gab mehr psychosomatische Beschwerden an, war mit der Lebens- und Arbeitssituation unzufriedener und gab eher psychische Faktoren als Krankheitsursache an. Interessanterweise litten die Patienten dieser Gruppe weniger stark an Juckreiz und kratzten sich auch weniger. Wohingegen die Gruppe, die sich als psychisch besonders stabil darstellte, stärkeren Juckreiz und stärkeres Kratzen aufwies. Auch empfand sich diese Gruppe subjektiv weniger entstellt als die Erstgenannte, obwohl die Ärzte dies objektiv anders einschätzten. Zwei weitere Untergruppen lagen in ihren Angaben zwischen den beiden beschriebenen Extremen.

Dass Emotionen und Selbsteinschätzungen zum Körperbild eine wichtige Rolle beim AEDS spielen, konnten Linnet und Jemec (2001) an 31 Patienten nachweisen. Aus ihren Ergebnissen lässt sich ableiten, dass Aggression und Vorstellungen zum Körperideal wichtige Indikatoren für Angstgefühle im Zusammenhang mit dem AEDS sind. 
Schneider und Gieler (2001) weisen aber daraufhin, dass sich aus den vorliegenden Forschungsergebnissen keine eindeutigen Hinweise für spezifische Persönlichkeitsauffälligkeiten beim AEDS ergeben hätten. Die beschriebenen Auffälligkeiten fänden sich auch bei anderen psychosomatisch beeinflussten (dermatologischen) Krankheitsbildern.

Interessante Hinweise für den Einfluss der Psyche auf die Haut ergaben sich auch aus der Studie von Kodama et al. (1999). Sie konnten in einer Fragebogenuntersuchung von 1457 Patienten (745 Männer, 712 Frauen) nachweisen, dass es bei Patienten mit AEDS nach dem großen Erdbeben von Hanshin in den am stärksten betroffenen Regionen in 38\% bzw. 34\% der Fälle zu einer Exazerbation von Hautsymptomen kam, im Vergleich zu 7\% bei Kontrollpersonen. Dabei war der subjektiv empfundene Stress der beste Prädiktor für die Exazerbation der Hautsymptome. Dies ist interessant, da sich bei einem großen Patientenkollektiv zeigt, dass subjektive Einschätzungen, wie sie auch in dieser Studie maßgeblich vorliegen, sehr wohl als verlässliche Parameter zur Beschreibung von emotionalen Einflüssen auf den Hautzustand herangezogen werden können.

\subsection{Zusammenhang zwischen Hautzustand und neuroendokrinen Faktoren}

Hinweise auf die enge Verzahnung von Körper und Psyche fanden sich auch durch die Analyse der Zusammenhänge zwischen den neuroendokrinologischen faktoren und dem Hautzustand. Adrenalin, Noradrenalin und Cortisol sind klassische Indikatoren für Stress (Schandry 1998, S. 74-79).

\subsubsection{Zusammenhang zwischen Hautzustand und Katecholaminen}

Die Katecholamine Adrenalin und Noradrenalin stellen empfindliche Indikatoren für emotionale und physische Belastungen dar. Sie werden in der Nebennierenrinde 
sowie in postganglionären Nervenenden freigesetzt (Birbaumer und Schmidt 1999, S. 80). Starke psychische Belastungen erhöhen eher den Adrenalinspiegel, wohingegen normale bzw. chronische emotionale sowie physische Belastungen eher den Noradrenalinspiegel beeinflussen. Beide Katecholamine interagieren außerdem direkt mit der HHNR-Achse, indem sie die Freisetzung von $\mathrm{CRH}$ und ACTH stimulieren. Die immunologischen Effekte werden hauptsächlich über ß-adrenerge Rezeptoren vermittelt und führen zu einer Verschiebung der $\mathrm{TH}_{1} / \mathrm{TH}_{2}$-Balance in die $\mathrm{TH}_{2}$-Richtung.

Als indirektes nichtinvasives Verfahren für die Abschätzung der Sekretion und der Blutspiegel dieser Stresshormone wurde in der vorliegenden Studie die Methode der Messung im nächtlichen Sammelurin eingesetzt, die, wie im entsprechenden Methodik-Kapitel dargelegt, hierfür sehr gut geeignet ist.

Die Erfassung von Katecholaminkonzentrationen mittels Nachturinbestimmungen wird allerdings in der psychobiologischen Forschung nur extrem selten angewandt. Ein Beispiel findet sich bei Wilson et al. (2002). Sie untersuchten gesunde afroamerikanische Erwachsene, die in ihrer Gemeinschaft entweder Gewalt ausgesetzt waren, diese gesehen oder davon gehört hatten, hinsichtlich des Einflusses dieser Erlebnisse auf den Blutdruck. Ein direkter Adrenalineinfluss auf den nächtlichen Blutdruck konnte nicht nachwiesen werden, aber die Adrenalinspiegel von Männern, die von Gewalt gehört hatten, waren tagsüber höher als die von Frauen, die auch von Gewalt gehört hatten.

In der psychodermatologischen AEDS-Forschung findet sich keine einzige Studie, in die Katecholaminspiegel im Nachturin gemessen wurden, so dass die vorliegende Arbeit hierzu neue Erkenntnisse liefert.

Der Hautzustand von AD02 weist eine bidirektionale zeitgleiche Beziehung zum Adrenalinspiegel im Nachturin auf. Der Cortisolspiegel im Nachturin steht in negativer Beziehung zum Hautzustand zwei Tage später. Der Adrenalin- und Noradrenalinspiegel korreliert positiv am selben Tag miteinander, es besteht jedoch keine Korrelation zum Cortisolspiegel. 
Bei AD04 zeigt sich eine positive Beziehung zwischen dem Adrenalin- und Noradrenalinspiegel und dem Hautzustand fünf Tage später. Dementsprechend besteht hier kein direkter Einfluss. Der Cortisolspiegel korreliert überhaupt nicht dem Hautzustand. Alle drei Stresshormone korrelieren miteinander am selben Tag.

Die Interpretation dieser Ergebnisse ist nur im Kontext der Kenntnisse, Theorien und Hypothesen möglich, die im Rahmen der Stressforschung entstanden sind und an dieser Stelle kurz angeführt werden.

Stress bewirkt bekanntermaßen eine Adaptationsreaktion (Schandry 1998), die in mehrere Phasen unterteilt werden kann: eine Alarmreaktion, eine Widerstandsphase und eine Erschöpfungsphase. Es kann differenziert werden zwischen der Art der Stressoren, z. B. Gefahrensituationen für Leib und Leben, (sensorische) Deprivation, Lärm, Leistungsstress, sozialer Stress, Noxen und Infektionen, sowie deren Wirkdauer: kurzfristig oder lang anhaltend. Insbesondere die Adaptationsprozesse bei Langzeitbelastungen erfordern eine stabile Anpassung und können pathogene Auswirkungen haben. Besonders starke körperliche Belastungen bzw. Belastungssituationen, die als nicht kontrollierbar erlebt werden, führen zu einer verstärkten Aktivierung des HHNR-Systems mit erhöhter Cortisolausschüttung. Sie können auch zu depressivem Verhalten führen. Belastungssituationen die potentiell als bewältigbar eingeschätzt werden, bewirken primär eine Aktivierung des SAM-Systems, einhergehend mit verstärkter Adrenalin und Noradrenalinausschüttung. Es wird seit langem angenommen (Henry und Stephens 1977, S. 161-166, 184), dass eine dauerhafte Aktivierung des SAM-Systems mit Gefühlen wie Wut oder Angst einhergeht und langfristig Herz-Kreislauf-Erkrankungen oder auch Erkrankungen des Muskel- und Halteapparates mit bedingen kann. Eine Überaktivierung des HHNR-Systems ist hingegen eher mit Gefühlen der Unsicherheit, Hilflosigkeit und Depression assoziiert und begünstigt langfristig psychosomatische Störungen und Erkrankungen, bei denen das Immunsystem eine stärkere ursächliche Rolle spielt.

Die Vermutung, dass Stress Auswirkungen auf die psychophysiologische Reaktivität bei Patienten mit AEDS hat, konnte u. a. von Faulstich et al. (1985) bestätigt werden. Sie fanden bei zehn Patienten erhöhte Werte für Muskelaktivität im Elektromyogramm während einer Belastungsphase sowie eine erhöhte Herzfre- 
quenz nach einer Belastungsphase durch Kältestress im Vergleich zu einer Kontrollgruppe Gesunder. Außerdem bestand eine signifikant höhere psychische Belastung, die sich in erhöhten Werten der Skalen für Angst, Somatisierung, Zwanghaftigkeit und Depression in der Symptomcheckliste-90-R ausdrückte.

Schmidt-Ott et al. (2001) fanden erhöhte Herzfrequenzen und erhöhte Blutdruckwerte bei AEDS-Patienten, die psychologischem Stress ausgesetzt waren.

Bielfeldt (2001) fand bei 18 erwachsenen Patienten mit AEDS eine erhöhte psychische Belastung und erhöhte systolische Blutdruckwerte im akuten Krankheitsstadium.

Buske-Kirschbaum et al. (2002a, b) konnten bei 36 Patienten mit AEDS einen verstärkten stressbedingten Anstieg von Adrenalin und Noradrenalin im Blut feststellen, im Vergleich zu einer gleich großen Kontrollgruppe. Buske-Kirschbaum weist allerdings auch darauf hin, dass die physiologischen Wirkungen der erhöhten Katecholaminspiegel bezüglich der Aktivität des Immunsystems unklar bleiben, zumal andere Veränderungen beim AEDS gefunden wurden, die eher zu einer Abschwächung der Katecholaminsignalwirkung in den Zielzellen führen. Hierzu gehören die bereits erwähnte erniedrigte ß-Rezeptordichte auf peripheren Monozyten sowie eine erhöhte cAMP-PDE-Aktivität. Die Herzraten der Patienten lagen zwar tendenziell, jedoch nicht signifikant über denen der Kontrollgruppe.

Seiffert et al. (2005) fanden in einer Untersuchung mit 15 Patienten Hinweise auf eine erhöhte vegetative Erregbarkeit bei Patienten mit AEDS im Vergleich zur Kontrollgruppe. Die psychobiologischen Reaktionen in Stresssituationen waren zwar ähnlich, es zeigten sich jedoch erhöhte Herzfrequenzraten sowie eine geringere vagale Aktivität während Stress- und Pausenphasen. Auch zeigten sich unabhängig von der jeweiligen Krankheitsaktivität signifikant höhere Werte für Ängstlichkeit, Depression und emotionale Erregbarkeit. Insgesamt betrachtet deuten die angeführten Studienergebnisse darauf hin, dass bei Patienten mit AEDS eine erhöhte sympathische Grundaktivität besteht. 
Auch die in der vorliegenden Arbeit gefundene wechselseitige Beziehung zwischen dem Hautzustand und dem Adrenalinspiegel im Nachturin bei AD02 kann in diesem Sinne interpretiert werden, wobei unklar bleibt inwieweit der Hautzustand selbst als potentieller Stressor für eine erhöhte Adrenalinausschüttung verantwortlich ist.

Im Gegensatz dazu deuten die bei AD04 gefundenen Beziehungen der Katecholamine zum Hautzustand mit einer Zeitverschiebung von fünf Tagen nicht auf direkte Zusammenhänge zwischen dem sympathischen Aktivitätsniveau und dem Hautzustand hin. Es muss ein unklarer Einfluss auf die Immunaktivität angenommen werden, wobei vermutlich auch noch andere als die untersuchten Faktoren in dieses Beziehungssystem eingebunden sind.

Darüber hinaus fanden sich bei AD02 Korrelationen zwischen einem verminderten Wohlbefinden und der Noradrenalinausschüttung einen Tag später sowie zwischen einer verminderten Schlaferholsamkeit und den Spiegeln beider Katecholamine einen Tag später, beides im Sinne einer verzögert einsetzenden Stressreaktion. Diese wiederum steht in Beziehung zum Neopterin, welches zeitversetzt um zwei sowie um fünf Tage später in Korrelation zum Hautzustand steht. Diese komplexen Verbindungen zeigen eindeutig, dass psychoneuroimmunologische Wechselwirkungen bei AD02 vorliegen. Die immunologischen Aspekte werden nachfolgend eingehend diskutiert.

Obwohl keine zeitnahen, kausal direkt nachvollziehbaren Verbindungen zwischen dem Hautzustand und dem Adrenalin- bzw. Noradrenalinspiegel bei AD04 vorliegen, weisen andere Korrelationen darauf hin, dass auch bei AD04 psychoneuroimmunologische Wechselwirkungen bestehen. Hervorzuheben ist stellvertretend der in Kapitel 3.2.4 dargestellte Zusammenhang zwischen der Juckreizstärke, dem Kratzverhalten, Neopterin und dem Hautzustand. Auch hierauf wird später noch eingegangen. 


\subsubsection{Zusammenhang zwischen Hautzustand und Cortisol}

Normalerweise sezernieren hypothalamische Neurone sieben- bis zehnmal täglich (infolge Stress auch häufiger) $\mathrm{CRH}$, welches dann im Hypohysenvorderlappen eine Freisetzung $u$. a. von ACTH im gleichen pulsatilen Rhythmus bewirkt. ACTH seinerseits wirkt auf Zellen der Nebennierenrinde und bewirkt dort die Produktion und Freisetzung von Cortisol. Diese folgt einem zirkadianen Rhythmus mit einem Peak in den Morgenstunden und einem Tief in den Nachtstunden. Bei normaler Funktion der Nebennierenrinde können die Cortisolwerte somit als Indikator für die Aktivierung der HHNR-Achse dienen (Birbaumer und Schmidt 1999, S. 81).

Zu erwartende Normalwerte im Nachturin schwanken in einem relativ weiten interindividuellen Bereich und können infolge von Stress um das drei- bis zehnfache ansteigen. Hinweise zur methodischen Vorgehensweise der Bestimmung von Cortisol im Nachturin (Urinsammlung und -aufbewahrung) sowie zur Beschreibung des wissenschaftlichen Hintergrundes finden sich bei Doering et al. (2001). Die nächtliche Cortisolbestimmung weist eine ausreichende Korrelation zu der im 24Stunden-Urin auf. In einer Reihe von Studien (siehe bei Doering et al. 2001) konnte gezeigt werde, dass die Methode geeignet ist, um eine veränderte basale Aktivität der HHNR-Achse unter dem Einfluss endokrinologischer Erkrankungen, psychosozialer Stressbelastungen und psychiatrischer Erkrankungen aufzudecken.

Forschungsergebnisse belegen, dass traumatische Erlebnisse, aber auch chronische kaum zu bewältigende Belastungen langfristig zu Veränderungen in der HHNR-Achse führen (siehe z. B. Heim et al. 2000). Diese Veränderungen können auf unterschiedlichen Ebenen der Achse stattfinden und sich dementsprechend unterschiedlich ausdrücken. So kann die Feedbacksensitivität der HHNR-Achse erhöht sein, so dass weniger $\mathrm{CRH}$ und/oder ACTH gebildet wird. Die Aktivität der NNR kann vermindert sein mit der Folge einer geringeren Cortisolsekretion im zirkadianen Rhythmus. Oder die Cortisolwirkung an den Zielzellen könnte vermindert sein, z. B. durch Veränderung der Rezeptorsensitivität. 
Dieses Konzept einer Dysregulation / Dysfunktion von Teilen der HHNR-Achse und des Glukokortikoidrezeptors mit der Folge eines relativen Hyper- bzw. Hypocortisolismus konnte z. B. bei affektiven Erkrankungen wie der Depression bestätigt werden (Holsboer 1989, Rupprecht et al. 1989). Neuere Ergebnisse aus Tierversuchen belegen ebenfalls eine Abnahme der Antwort der HHNR-Achse nach Einwirken von chronischem Stress bereits auf der Ebene der $\mathrm{CRH}$-Sekretion (Ostrander et al. 2006).

Auch beim AEDS wird vermutet, dass Veränderungen in der HHNR-Achse vorliegen und mitverantwortlich für den Krankheitsverlauf sein könnten (BuskeKirschbaum et al. 2001).

Dass diesbezüglich natürlich auch Einflüsse durch die therapeutische Behandlung mit Glukokortikoiden bestehen können, zeigten Ellison et al. (2000). Sie fanden bei Kindern mit einer schweren Verlaufsform des AEDS, die zugleich auch eine potente lokale Glukokortikoidtherapie erhielten, eine verminderte HHNR-Reaktion nach medikamentöser Stimulation. Keine Veränderungen in der HHNR-Antwort zeigten sich in dieser Untersuchung bei Kindern mit milderer Verlaufsform und einer Lokaltherapie mit weniger potenten Glukokortikoiden.

Einige Studienergebnisse lassen sogar die Vermutung zu, dass es durch langfristige Anpassungen beim AEDS zu einer lang anhaltenden Hyporeaktivität der HHNR-Achse kommt.

Rupprecht et al. (1995) konnten bei 15 Patienten zeigen, dass es nach intravenöser Gabe von 100ug CRH bei den Erkrankten im Vergleich zu Gesunden nur zu einem abgeschwächten ACTH- und Cortisolanstieg kam, wohingegen ein adäquater Anstieg von ß-Endorphin gefunden wurde. Es besteht also eine selektive Störung der Sekretion derjenigen Peptide, die sich vom POMC ableiten und damit eine Dysregulation im HHNR-System bedingen. Als Ursache nehmen die Autoren eine länger bestehende Unterstimulation durch endogenes $\mathrm{CRH}$ oder eine erhöhte durch den Glukokortikoidrezeptor vermittelte Feedbacksensitivität des Systems an. 
In den bereits erwähnten Studien von Buske-Kirschbaum et al. (2002a, b) zeigten sich bei den Erkrankten ein signifikant geringerer Cortisol- und ACTH-Anstieg nach Stresseinfluss im Vergleich zu den Kontrollpersonen. Auch diese Autoren gehen von einer suprahypophysären „Störung“ bzw. einer sensitiver gewordenen Feedbackhemmung aus.

Unklar bleibt die Bedeutung dieser Befunde in der Pathogenese des AEDS, da nicht bekannt ist, ob genetische und/oder erworbene Ursachen eine Hyporeaktivität der HHNR-Achse begünstigen, ob eventuell noch andere psychische Komponenten mit eingebunden sind oder ob sie Folge der chronischen Erkrankung selbst ist. Dennoch besteht letztlich die begründete Annahme, dass beim AEDS eine „intrinsische" Dysfunktion der HHNR-Achse vorliegt. Je nach Ausprägung dieser Dysfunktion ist zu erwarten, dass sich keine eindeutige Beziehung zwischen dem Hautzustand und dem Cortisolspiegel findet bzw. am ehesten keine oder eine negative Korrelation des Hautzustandes mit dem Cortisolspiegel vorliegt. Von daher bestätigen die Ergebnisse der vorliegenden Arbeit (bei AD04 besteht keine Korrelation zwischen dem Hautzustand und Cortisol, bei AD02 korreliert der Hautzustand negativ mit dem Cortisolspiegel zwei Tage zuvor) die Annahmen und Erwartungen.

\subsection{Zusammenhang zwischen Hautzustand und Immunsystem}

Neopterin ist biologisch stabil und wird ausschließlich renal eliminiert. Daher eignet es sich hervorragend für Urinuntersuchungen. Physiologisch wird es überwiegend nachts zwischen $2.30 \mathrm{Uhr}$ bis $6.30 \mathrm{Uhr}$ im Urin ausgeschieden (Auzeby et al. 1988), da normalerweise nachts die Aktivität des zellulären Immunsystems höher ist als tagsüber (Plytycz und Seljelid 1997). Dementsprechend wichtig ist es auch in dieser Studie gewesen, dass die Urinsammlung immer in dem gleichen Zeitfenster zwischen 20.00 Uhr bis 8.00 Uhr erfolgte. Unregelmäßigkeiten hätten fehlerhafte Messwerte zur Folge haben können. 
Neopterin ist ein unspezifischer Indikator für die zelluläre Immunaktivität. Es wird nach Stimulation durch TNF- $\alpha$, insbesondere jedoch nach Stimulation durch INF- $\gamma$ vor allem in Makrophagen verstärkt produziert und freigesetzt (Hamerlinck 1999). Dementsprechend finden sich bei vielen Erkrankungen, die mit einer Aktivierung des zellulären Immunsystems einhergehen, erhöhte Neopterinwert im Urin oder Serum. Hierzu gehören virale Erkrankungen, Autoimmunerkrankungen und Neoplasien (z. B. chronisch-entzündliche Darmerkrankungen, die rheumatoide Arthritis, der Lupus erythemathodes, die dilatative Kardiomyopathie, das Kolonkarzinom, das hepatozelluläre Karzinom). Bei vielen dieser Erkrankungen dient Neopterin als Indikator für die Krankheitsaktivität und kann als Verlaufsmarker sinnvoll eingesetzt werden, da eine enge Korrelation der Neopterinwerte mit der Schwere und dem Verlauf der Erkrankungen besteht (Fuchs et al. 1993, Hamerlinck 1999, Hoffmann et al. 2003). Die Bestimmung von Neopterin erfolgt allerdings selten, weil die Untersuchung teuer ist und somit in der klinischen Routine nicht eingesetzt werden kann.

Inwieweit sich Neopterin auch beim AEDS als Indikator für die Krankheitsaktivität eignet, ist nicht bekannt. Erhöhte Werte wären in der chronischen Phase zu vermuten, da diese durch eine verstärkte Aktivität des zellulären Immunsystems gekennzeichnet ist.

Sequenzielle Analysen von Hautbiopsien zeigen, dass es im Rahmen von Krankheitsschüben beim AEDS zunächst zu einer initialen $\mathrm{TH}_{2}$-Antwort des Immunsystems mit erhöhten IL-4-Konzentrationen kommt und im Anschluss daran nach ca. 24 Stunden ein Wechsel in Richtung $\mathrm{TH}_{1}$-Antwort des Immunsystems mit erhöhter INF- $\gamma$-Sekretion erfolgt (Thepen et al. 1996). Dieses Modell einer sequenziellen TH-Zellen Aktivierung wird zunehmend akzeptiert (Buske-Kirschbaum und Hellhammer 2003).

Zeitreihenuntersuchungen zu Neopterin wurden von Schubert C et al. (1999) im Rahmen einer Einzelfallstudie einer Patientin mit systemischen Lupus erythemathodes durchgeführt. Er fand eindeutige Hinweise auf psychosomatische Zu- 
sammenhänge in dem Sinne, dass sich 24-48 Stunden nach einem emotional belastenden Ereignis, einhergehend mit hohem interpersonellen Stress, erhöhte Neopterinurinwerte fanden. Diese wurden zugleich als Indikator für eine erhöhte Krankheitsaktivität gedeutet.

Auch in der vorliegenden Studie wurden psychosomatische Wechselwirkungen nachgewiesen: der Neopterinspiegel im Nachturin korreliert am selben Tag positiv mit vermindertem Wohlbefinden (bei AD02) bzw. mit der Gereiztheit (bei AD04) und er korreliert positiv mit verminderter Schlafqualität zwei Tage zuvor (bei AD02). Des Weiteren besteht bei beiden Patienten eine positive Korrelation zwischen Neopterin und dem Hautzustand 24 Stunden später (bei AD04) bzw. 48 und 120 Stunden später (bei AD02). Dies lässt folgende Interpretationen zu:

1. Der Hautzustand wird dann, wenn eine $\mathrm{TH}_{1}$-vermittelte zelluläre Immunaktivität vorherrscht, von dieser mitbestimmt, wobei die Rhythmik dieses Einflusses individuell unterschiedlich zu sein scheint. Dieser Befund bestätigt indirekt auch das oben beschriebene Modell einer sequenziellen TH-Zellen-Aktivierung, da er zeigt, dass offensichtlich ein $\mathrm{TH}_{1}$-Einfluss besteht.

2. Der beim AEDS beschriebene Wechsel von einer $\mathrm{TH}_{2}$-Immunreaktion hin zu einer $\mathrm{TH}_{1}$-Immunreaktion hätte darüber hinaus erwarten lassen, dass auch ein Zusammenhang zwischen dem Hautzustand und dem Neopterinurinspiegel in umgekehrter Richtung bestehen würde. Dass dies nicht der Fall ist, unterstützt die in der Einleitung beschriebene Annahme, dass beim AEDS zwischen einem AAEDS und einem NAAEDS unterschieden werden muss. Die Ergebnisse der vorliegenden Arbeit deuten darauf hin, dass bei Patienten mit NAAEDS der Hautzustand maßgeblich von der Aktivität des zellulären Immunsystems mit beeinflusst wird.

Interessant ist diesem Kontext des Weiteren die, bei AD02 vorgefundene, negative Korrelation von Cortisol mit dem Hautzustand zwei Tage später. Somit liegt bei AD02 zwei Tage vor einer Hautverschlechterung eine Konstellation mit erhöhter zellulärer Immunaktivität und zugleich verminderter Immunsupression vor.

All diese Ergebnisse bestätigen, dass psychoimmunologische Wechselwirkungen beim AEDS vorliegen. Für ein genaueres Verständnis dieser Zusammenhänge sind allerdings noch weitergehende Forschungen notwendig. 


\subsection{Zusammenhang zwischen Hautzustand und Melatonin}

Melatonin ist ein Hormon der Zirbeldrüse, welches zirkadian vor allem in der Nacht zwischen 2.00 und 4.00 Uhr, insbesondere infolge von sympathogenen Reizen ausgeschüttet wird. Die sympathogenen Reize werden von der Umgebungshelligkeit beeinflusst und dann über ß-adrenerge Rezeptoren vermittelt (Vanecek 1998). Melatonin selbst ist stark lipophil, kann in jede Zelle diffundieren und hat einen omnipotenten Einfluss auf den Organismus. Es reguliert den Schlafrhythmus, da etwa 2-3 Stunden nach seiner ersten Ausschüttung die Schlafphase beginnt. Es wirkt als hochpotenter Radikalfänger und scheint einen erheblichen Einfluss auf den Alterungsprozess zu haben.

Beim AEDS gibt es Hinweise für eine erniedrigte Melatoninproduktion und -ausschüttung in der Nacht (Schwarz et al. 1988, Fischer T et al. 1999), jedoch stehen die Melatoninwerte in keinem Zusammenhang zum jeweils aktuellen Hautzustand. Es wird postuliert, dass Melatonin möglicherweise negative Stressauswirkungen antizipiert, indem es oxidativen Stress mindert. Melatoninkonzentrationen im Serum korrelieren mit denen im Urin, so dass die Bestimmung im Urin eine sinnvolle Messmethode darstellt. Studien, in denen die Melatoninkonzentration im Nachturin bei Patienten mit AEDS bestimmt wurde, existieren bisher nicht.

Die in der vorliegenden Arbeit gefundene Beziehung zwischen Melatonin und dem Hautzustand bei AD02 (negative zeitgleiche bidirektionale Korrelation sowie positive Korrelation mit dem Hautzustand vier Tage später) stellt einen bisher nicht bekannten Zusammenhang dar, dessen Bedeutung derzeit jedoch auch nicht kausal interpretiert werden kann. Bekannt sind die Studienergebnisse von Schwarz et al. (1988), der erniedrigte Melatoninspiegel bei Patienten mit AEDS, aber keinen direkten Zusammenhang mit dem Hautzustand nachweisen konnte. Barriga et al. (2001) fanden einen erniedrigten mitternächtlichen Melatoninpeak sowie eine veränderte Phagozytoseaktivität bei Makrophagen von Mäusen nach Stresseinwirkung. Interessant sind in diesem Kontext auch die gefundenen Beziehungen zwischen Melatonin, Neopterin und dem Hautzustand bei AD02 (siehe Abb. 6), deren Bedeutung derzeit ebenfalls noch unklar ist. Zur Einordnung in einen pathogenetischen Kontext sind auch diesbezüglich weitergehende Forschungen notwendig. 


\subsection{Wechselwirkungen zwischen anderen Einflussfaktoren}

Bei beiden Patienten korreliert der Hautzustand zeitsynchron mit der Juckreizstärke. Daneben zeigte sich bei beiden Patienten eine zeitgleiche Korrelation der Juckreizstärke mit dem Cortisolspiegel im Nachturin und mit der Kratzintensität. Das Bestehen einer direkten Korrelation mit dem Cortisolspiegel begründet die Annahme, dass der Juckreiz in jedem Fall einen erheblichen Stressfaktor darstellt. Außerdem findet sich sowohl bei AD04 als auch in abgemilderter Form bei AD02 der, für das AEDS so typische „klassische“ Juck-Kratz-Zirkel. Des Weiteren fand sich bei AD02 auch ein zeitgleicher Zusammenhang zwischen der Juckreizstärke und der Grübel- und Kratzintensität. Diese Beziehungen stehen in Übereinstimmung mit Erkenntnissen zur wechselseitigen Beeinflussung von Juckreiz, Kratzverhalten und dem psychoemotionalen Befinden und deuten zugleich auf mögliche Konditionierungsmechanismen hin, die beim AEDS ebenfalls gut untersucht und bekannt sind (Rühle 2000, Paus et al. 2006).

Interessant sind des Weiteren die in der vorliegenden Arbeit gefundenen Beziehungen zwischen der verminderten Schlafqualität und dem Hautzustand bei AD04. Sie sind allerdings nicht eindeutig interpretierbar, weil ein zeitlicher Versatz von vier Tagen besteht. Bei AD02 findet sich keine direkte, sondern nur eine indirekte Beziehung zwischen einer verminderten Schlafqualität und dem Hautzustand. So stellt eine verminderte Schlafqualität bei AD02 offensichtlich einen Stressfaktor dar und führt zu einem Adrenalin- und Noradrenalinanstieg und zu einer introvertierten Stimmungslage sowie einem Neopterinanstieg zwei Tage später. Dass beim AEDS häufig eine verminderte Schlafqualität besteht, insbesondere bedingt durch nächtlichen Juckreiz und nächtliches Kratzen, ist bekannt, wobei in diesen Fällen jedoch ein unmittelbarer zeitlicher Zusammenhang zwischen den Einflussfaktoren besteht. Somit finden sich in der vorliegenden Arbeit auch bezüglich des Einflusses der Schlafqualität auf den Hautzustand interessante individuelle Aspekte, die allerdings noch genauer erforscht werden müssen, um ihre psychosomatische Bedeutung besser einstufen zu können, insbesondere vor dem Hintergrund einer möglichen psychotherapeutischen oder medikamentösen Intervention zur Verbesserung der Schlafqualität. 


\subsection{Schlussfolgerungen und Ausblick}

Die Ergebnisse der vorliegenden Arbeit stützen bekannte bzw. vermutete Zusammenhänge zwischen dem emotionalen Befinden, Juckreiz und Kratzverhalten sowie der Immunaktivität und dem Hautzustand beim AEDS.

Es konnte nachgewiesen werden, dass psychosomatische Wechselwirkungen vorliegen und Stress bzw. das emotionale Befinden in Beziehung zum Hautzustand selbst sowie zur zellulären Immunaktivität steht. Außerdem bestehen somatopsychische Rückwirkungen in dem Sinne, dass der Hautzustand selbst Einfluss auf das emotionale Befinden, die Juckreizstärke und Kratzintensität hat.

Interessant sind auch die gefundenen Beziehungen zwischen dem nächtlichen Neopterinurinspiegel und dem Hautzustand. Sie deuten darauf hin, dass der Hautzustand beim NAAEDS nach ca. 24-48 Stunden von einer $\mathrm{TH}_{1}$-geprägten Immunreaktion mitbestimmt wird. Dieser Zusammenhang konnte in der vorliegenden Arbeit erstmals mittels Neopterinbestimmung nachgewiesen werden. Des Weiteren zeigten sich psychosomatische Wechselwirkungen zwischen dem Neopterinspiegel im Nachturin und negativen Emotionen bei beiden Patienten. Weitergehende Studien sind notwendig, um die Rolle des Neopterins beim AEDS genauer beschreiben zu können.

Ebenfalls erstmals nachgewiesen wurde in der vorliegenden Arbeit, dass eine direkte Beziehung zwischen Melatonin und dem Hautzustand besteht. Auch diesbezüglich sind weitergehende Studien notwendig, um die Bedeutung von Melatonin beim AEDS verstehen zu können.

Individuelle Unterschiede zeigen sich bezüglich der Kratzintensität, welche bei AD04 eine starke Beziehung zum Hautzustand aufweist, wohingegen bei AD02 keine Beziehung besteht, da AD02 sehr bewusst versucht Kratzen zu vermeiden. Dennoch weisen weitere Korrelationen zwischen der Juckreizstärke und der Kratzintensität daraufhin, dass bei beiden Patienten ein Juck-Kratz-Zirkel vorliegt. 
Weiterhin konnte gezeigt werden, dass eine verminderte Schlafqualität psychosomatische Auswirkungen im Sinne einer Stressreaktion hat und auf diesem Weg indirekt auch den Hautzustand beim AEDS beeinflusst.

Eine zeitgleiche Beziehung des Hautzustandes zu stressvollen Lebensereignissen zeigte sich bei beiden Patienten jeweils nur an einem einzigen Tag, dem Tag mit dem höchsten Cortisolspiegel im Nachturin. An diesen beiden Tagen bestand jeweils eine vorhersehbare, jedoch nicht einschätzbare Stresssituation, die zugleich mit erhöhten Werten für Ängstlichkeit und Deprimiertheit einherging. Alle anderen Beziehungen zwischen psychischem Stress und dem Hautzustand konnten indirekt über das emotionale Befinden erfasst werden.

Insgesamt bestätigen die Ergebnisse der vorliegenden Arbeit die Vermutung, dass ein komplexes psychoneuroimmunoendokrinologisches Netzwerk den Hautzustand beim AEDS bestimmt. Die Wechselwirkungen in diesem Netzwerk sind allerdings, wie auch von anderen Forschern angemerkt wird (Buske-Kirschbaum et al. 2001), so komplex, dass sie selbst in Einzelfallstudien nur in Teilbereichen erfasst werden können. Die vorliegende Studie konnte den netzwerkartigen Zusammenhang vieler Faktoren belegen. Um genauere Kenntnisse über einzelne Faktoren und Teilbereiche zu erhalten, sind jedoch noch genauere Erfassungen der beschriebenen sowie zusätzlicher psychologischer und immunologischer Parameter an einer größeren Patientenzahl, möglichst über einen noch längeren Zeitraum hinweg, erforderlich. Noch längere Messreihen hätten außerdem einen noch günstigeren Einfluss auf die Datenqualität hinsichtlich der späteren Datenanalyse und Datenauswertung.

Eine derart aufwendige Erweiterung des Studiendesigns wird sich vermutlich kaum umsetzen lassen. Dennoch sollte darüber nachgedacht werden, ob sich der Aufwand einer solchen Studie nicht doch lohnen würde, da zu erwarten ist, dass auf diesem Wege weitere bedeutsame psychobiologische Erkenntnisse beim AEDS gewonnen werden, die auch therapeutisch von Nutzen sein könnten. 


\section{Zusammenfassung}

Klinisch ist der Zusammenhang zwischen psychischen Belastungen und einer Verschlechterung des Hautzustandes beim AEDS allgemein akzeptiert, obwohl es bisher nur relativ wenige konkrete Forschungsergebnisse hierzu gibt. Insbesondere in Längsschnittstudien (wie z. B. Zeitreihenanalysen) bestätigten sich aber in vielen Fällen derartige Zusammenhänge. Mittels integrativer Einzelfallforschung ist es in hervorragender Weise möglich, individuell bedeutsame Krankheitsfaktoren beim AEDS zu identifizieren und Zusammenhänge zwischen den einzelnen Faktoren aufzudecken.

In der hier vorgestellten Studie wurden bei zwei Patienten (eine 25-jährige Studentin und ein 42-jähriger Krankenpfleger), die beide bereits seit der Kindheit an der intrinsischen Variante des AEDS erkrankt sind, über 75 Tage Daten zum emotionalen Befinden, dem Hautzustand, biochemischen Stressmarkern und Neopterin als Indikator für die zelluläre Immunaktivität erhoben. Die Tagebuchtechnik diente als Instrument zur Erhebung der psychoemotionalen und dermatologischen Daten. Die biochemischen Parameter Cortisol, Adrenalin, Noradrenalin, Melatonin und Neopterin wurden im täglich zwischen 20.00 Uhr bis 8.00 Uhr am Folgetag gesammelten Nachturin bestimmt. Insgesamt wurden 18 verschiedene Einflussfaktoren erfasst, mit dem bereits mehrfach in der Zeitreihenanalyse eingesetzten ARIMA-Verfahren analysiert und anschließend mit Hilfe von bivariaten Korrelationsanalysen auf statische Zusammenhänge untersucht.

Auf diese Weise wurden mit der hier durchgeführten kombinierten Analyse von Tagebuchangaben und nächtlichen Urinproben erstmals beim AEDS sehr viele verschiedene biopsychologische Parameter gemeinsam über einen längeren Zeitraum hinweg erfasst und in Beziehung zum Hautzustand betrachtet.

Die Ergebnisse zeigen bei beiden Patienten, dass das emotionale Befinden in einem bidirektionalen Verhältnis zum Hautzustand steht, im Sinne sowohl psychosomatischer als auch somatopsychischer Wirkungen. Psychische Belastungen, 
die mit negativem emotionalen Befinden und schlechtem Schlaf einhergehen, stehen im Zusammenhang mit der Aktivität des zellulären Immunsystems.

In der vorliegenden Arbeit konnte erstmals gezeigt werden, dass der Neopterinspiegel im Nachturin beim AEDS in einer direkten Beziehung zum Hautzustand 24 Stunden bzw. 48 und 120 Stunden später steht. Diese zeitlichen Zusammenhänge weisen darauf hin, dass die Aktivität des zellulären Immunsystems den Hautzustand beim NAAEDS grundsätzlich in bedeutsamer Weise beeinflusst. Sie bestätigen des Weiteren indirekt die zunehmend anerkannte Theorie, dass der Hautzustand beim AEDS ab etwa dem zweiten Tag nach einer Verschlechterung durch die verstärkte Aktivität des zellulären Immunsystems infolge einer dann verstärkt einsetzenden $\mathrm{TH}_{1}$-Immunantwort mitbestimmt wird.

Des Weiteren wurde bei beiden Patienten der typische "Juck-Kratz-Zirkel" vorgefunden, wobei der Juckreiz zugleich einen starken Stressor darstellt. In beiden Fällen korreliert er zeitgleich mit der Cortisolsekretion, dem Stressmarker für starken, kaum bewältigbaren Stress.

Letztlich konnte in dieser Studie eindeutig belegt werden, dass der Hautzustand beim AEDS von verschiedenen pathogenetisch wirksamen Faktoren mitbestimmt wird, die als Teile eines hochkomplex interagierenden psychoneuroimmunoendokrinologischen Netzwerkes in vielfältiger Weise zueinander in Beziehung stehen. Diese Beziehungen weisen individuelle Besonderheiten, aber auch interindividuelle Gemeinsamkeiten auf. Die Wechselwirkungen in diesem Netzwerk sind allerdings so komplex, dass sie auch in Einzelfallstudien nur in Aspekten erfasst werden können. Um genauere Kenntnisse über Teilbereiche zu erhalten, wäre es wünschenswert, wenn detaillierte Einzelstudien hierzu durchgeführt werden würden. Nur die möglichst spezifische Identifikation psychoemotionaler, verhaltenstypischer, neuroendokriner und immunologischer Zusammenhänge kann dazu beitragen, die Pathogenese multifaktoriell beeinflusster Erkrankungen besser zu verstehen und eine individuell optimierte Therapie als Kombination von differenzierter medikamentöser und psychologischer Behandlung gestalten zu können. 
6.

Anhang - ARIMA-Modelle, Tagebuch

Tab. 8: ARIMA-Modelle von AD02

Aufgeführt sind sämtliche, in der vorliegenden Arbeit ermittelten ARIMA-Modelle für die untersuchten Faktoren (Variablen) von AD02 sowie deren Gütekriterien: das Akaike Information Criterion (AIC) und das Schwarz-Bayesian Criterion (SBC) sowie die Residualvarianz. Die ARIMA-Modelle sind in folgender Form dargestellt: $(p, d, q)(s p, s d, s q) s$. Dabei bezeichnet $p$ die Ordnung des autoregressiven Prozesses, d die Anzahl der notwendigen Differenzierungsschritte bis zur Stationarität, q die Ordnung des moving- average-Prozesses, sp,sd sowie sq die korrespondierdenden saisonalen Komponenten und s die saisonale Komponente (das Intervall der vorgefundenen Periodizität).

\begin{tabular}{|l|l|l|l|l|}
\hline Variable & ARIMA-Modell & AIC & SBC & Residualvarianz \\
\hline Hautzustand & $(100,000)$ & $-217,49$ & $-212,81$ & 0,003 \\
\hline Urin-Adrenalin & $(100,000)$ & $-41,52$ & $-36,64$ & 0,035 \\
\hline Urin-Noradrenalin & $(001,000)$ & $-136,29$ & $-128,97$ & 0,011 \\
\hline Urin-Cortisol & $(100,100) 5$ & $-114,37$ & $-107,05$ & 0,015 \\
\hline Urin-Neopterin & $(001,000)$ & $-272,49$ & $-267,61$ & 0,002 \\
\hline Urin-Melatonin & $(100,000)$ & $-99,69$ & $-95,03$ & 0,015 \\
\hline Juckreizstärke & $(100,000)$ & $-110,12$ & $-105,05$ & 0,014 \\
\hline Kratzintensität & $(100,000)$ & $-24,02$ & $-19,34$ & 0,042 \\
\hline Gereiztheit & $(011,100) 3$ & $-207,95$ & $-200,96$ & 0,004 \\
\hline Ängstlichkeit & $(011,000)$ & $-181,08$ & $-176,42$ & 0,005 \\
\hline Introvertiertheit & $(100,000)$ & $-322,78$ & $-318,09$ & 0,001 \\
\hline Extravertiertheit & $(011,100) 8$ & $-203,03$ & $-198,36$ & 0,004 \\
\hline Aktivität & $(011,000)$ & $-307,93$ & $-303,27$ & 0,001 \\
\hline Desaktivität & $(011,001) 7$ & $-207,03$ & $-200,04$ & 0,003 \\
\hline Wohlbefinden & $(111,000)$ & $-213,56$ & $-206,57$ & 0,003 \\
\hline Schlafqualität & $(001,100) 3$ & $-89,87$ & $-82,84$ & 0,017 \\
\hline Schlaferholsamkeit & $(100,100) 6$ & $-95,16$ & $-88,13$ & 0,016 \\
\hline Grübelintensität & $(001,100) 12$ & $-31,18$ & $-26,52$ & 0,017 \\
\hline
\end{tabular}


Tab. 9: ARIMA-Modelle von AD04

Aufgeführt sind sämtliche, in der vorliegenden Arbeit ermittelten ARIMA-Modelle für die untersuchten Faktoren (Variablen) von AD04 sowie deren Gütekriterien: das Akaike Information Criterion (AIC) und das Schwarz-Bayesian Criterion (SBC) sowie die Residualvarianz. Die ARIMA-Modelle sind in folgender Form dargestellt: $(p, d, q)(s p, s d, s q) s$. Dabei bezeichnet $p$ die Ordnung des autoregressiven Prozesses, d die Anzahl der notwendigen Differenzierungsschritte bis zur Stationarität, $q$ die Ordnung des moving- average-Prozesses, sp,sd sowie sq die korrespondierdenden saisonalen Komponenten und s die saisonale Komponente (das Intervall der vorgefundenen Periodizität).

\begin{tabular}{|l|l|l|l|l|}
\hline Variable & ARIMA-Modell & AIC & SBC & Residualvarianz \\
\hline Hautzustand & $(101,000)$ & $-166,13$ & $-159,10$ & 0,006 \\
\hline Urin-Adrenalin & $(100,000)$ & $+11,32$ & $+16,00$ & 0,066 \\
\hline Urin-Noradrenalin & $(000,100) 10$ & $-92,79$ & $-88,10$ & 0,017 \\
\hline Urin-Cortisol & $(000,001) 7$ & $-38,08$ & $-33,39$ & 0,034 \\
\hline Urin-Neopterin & $(100,001) 6$ & $-123,08$ & $-116,05$ & 0,011 \\
\hline Urin-Melatonin & $(100,000)$ & $-36,91$ & $-32,22$ & 0,035 \\
\hline Juckreizstärke & $(100,000)$ & $-121,36$ & $-116,67$ & 0,012 \\
\hline Kratzintensität & $(011,001) 7$ & $-66,89$ & $-59,91$ & 0,023 \\
\hline Gereiztheit & $(101,000)$ & $-182,39$ & $-175,36$ & 0,005 \\
\hline Ängstlichkeit & $(101,001) 9$ & $-132,21$ & 122,83 & 0,009 \\
\hline Introvertiertheit & $(100,000)$ & $-99,95$ & $-95,26$ & 0,016 \\
\hline Extravertiertheit & $(100,000)$ & $-187,05$ & $-182,36$ & 0,005 \\
\hline Aktivität & $(101,000)$ & $-234,28$ & $-227,25$ & 0,003 \\
\hline Desaktivität & $(000,001) 2$ & $-158,79$ & $-154,11$ & 0,007 \\
\hline Wohlbefinden & $(000,001) 9$ & $-229,98$ & $-225,30$ & 0,003 \\
\hline Schlafqualität & $(000,100) 12$ & $-73,45$ & $-69,01$ & 0,018 \\
\hline Schlaferholsamkeit & $(100,000)$ & $-105,08$ & $-100,64$ & 0,012 \\
\hline Grübelintensität & $(100,000)$ & $+18,32$ & $+21,69$ & 0,086 \\
\hline
\end{tabular}




\section{Tagebuch}

von

Code:

für die Woche

vom bis

Bitte beantworten Sie die Fragen im Tagebuch täglich zu Beginn und zum Ende Threr Urinsammlung. 


\title{
Georg-August-Universität Göttingen \\ Zentrum Psychologische Medizin (16) \\ Abteilung Psychosomatik und Psychotherapie
}

\author{
Klinik und Poliklinik für \\ Psychosomatik und Psychotherapie \\ Direktor. Prof. Dr. med. Ulirich Rüger
}

Psychosomatik u. Psychotherapie, · v.-Siebold-Straße 5 - D-37075 Göttingen

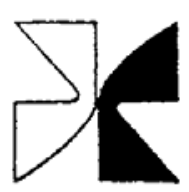

von-Siebold-Straße 5

D-37075 Gottingen

$\begin{array}{lll}\text { Sekretanat } & (0551) & 39-6706 / 6707 \\ \text { Telefax } & (0551) & 39-4592\end{array}$

\section{Informationen zur nächtlichen Urin-Sammlung}

Der Beginn der täglichen Nacht-Urin-Sammeiperiode sollte zwischen 18.00 und 22.00 Uhr, das Ende der Sammelperiode am nächsten Morgen solite zwischen 6.00 und 10.00 Uhr liegen.

Die Sammelperiode sollte immer im gleichen Zeitraum liegen (z. B. immer $20.00-8.00 \mathrm{Uhr}$ ).

Bitte wählen Sie sich dementsprechend eine Standard-Sammelperiode und tragen Sie die Sammelzeiten täglich in Ihrem „Tagebuch“" ein. Sollten Sie von Ihrer Standard-Sammelperiode abweichen (z. B. weil Sie abends noch länger unterwegs sind), so ist es wichtig, daß Sie dies notieren.

Wichtig ist, daß eine möglichst vollständige Sammelreihe über den gesamten Studienverlauf hinweg vorliegt. Bitte unterbrechen Sie die Urinsammlung daher nur im „Notfall“ ( $z$. B. Urlaub). Bitte markieren Sie die entsprechenden Tage im Tagebuch sorgfältig und füllen Sie das Tagebuch auch an diesen Tagen ( $z$. B. im Urlaub) vollständig aus.

\section{Anleitung zur Urinsammlung}

1. Füllen Sie den bereitgestellten Konservierungsstoff (weißes Pulver) aus einem der k!einen Plastik-Behälter in den großen braunen Urinsammelbehälter.

2. Entleeren Sie vor dem Beginn Ihrer Sammelperiode noch einmal die Blase auf der Toilerte.

3. Notieren Sie im Tagebuch den Beginn lhrer Sammelperiode (z.B. 20.00 Uhr).

t. Während der anschließenden nächtlichen Sammelperiode benutzen Sie zum Urinieren bitte ausschlieBtich den braunen Sammeibehälter. Nach jeder Füllung Sammelflasche bitte verschließen.

5. Zum Ende der nächtlichen Sammeiperiode geben Sie lhren Morgenurin in den braunen Sammeibehälter ab.

6. Notieren Sie im ragebuch das Ende Ihrer Sammelperiode (z.B. 8.00 Uhr).

7. Lesen Sie die gesammelte Urinmenge an der Skala ab ( Angabe in Milliliter $=\mathbf{m l}$ ) und vermerken Sie die Menge im Tagebuch.

8. Schwenken Sie den Urinsammelbehälter zum Durchmischen und schütten Sie dann vorsichtig etwas Urin in das kleine Plastikfläschchen. Füllen Sie das Plastikfläschchen jedoch nur zu etwa drei Vierte!!

9. Kleben Sie ein Etikett (jeweils laufende Nummer) auf das Plastikfläschchen und bewahren Sie es in der Tiefkühltruhe auf. Vermerken Sie die jeweilige Etikettennummer im .,Tagebuch“.

10. Entleeren Sie den Urinsammelbehälter und reinigen Sie ihn durch Spülen für die kommende Nacht. Verwenden Sie zum Reinigen ausschlieBlich Leitungswasser (!) und auf keinen Fall Reinigungsmittel.

11. Vermerken Sie im Tagebuch besondere Vorkommnisse, wie z. B.:

- am Abend mit Alkohol gefeiert.

- vergessen in den Sammelbehälter zu urinieren (wie oft ?, wieviel ungefähr ?).

Diese Angaben sind für die Auswertung der Labordaten von großer Bedeutung!

12. Bringen Sie thre tiefgefrorenen Urinproben bitte zu den wöchentlichen Gesprächen in die Klinik mit. 
Tagebuch - Beispiel: Montag - Seite 1

Montag, der

Bitte beantworten Sie die Fragen zum Hautzustand, die Fragen zum Erleben und Verhalten, die Fragen zu Ereignissen sowie die Eigenschaftswörterliste abends zu Beginn Ihrer Urin-Sammelperiode.

Die Fragen zur Urinsammlung und die Fragen zum Schlaf beantworten Sie dann bitte morgens zum Ende Ihrer Urinsammlung.

\section{FRAGEN ZUM HAUTZUSTAND}

Welche Körperteile sind zur Zeit befallen? Wie stark? (bitte ankreuzen)
nicht
leicht
stark
sehr stark

( ) Gesicht

( ) Hals

( ) Hände

( ) Arme

( ) Rumpt

( ) Beine

nicht

leicht

stark

sehr stark

Stärke des Juckreizes in den letzen 24 Stunden? (bitte ankreuzen)

kein leicht stark unerträglich

Stärke des Kratzens in den letzten 24 Stunden? (bitte ankreuzen)

kein leicht $\quad$ stark


Tagebuch - Beispiel: Montag - Seite 2

\section{FRAGEN ZUM ERLEBEN UND VERHALTEN}

1. Wie beurteilen Sie Ihre körpertiche Belastung in den letzten 24 Stunden? (bitte ankreuzen) (die Art der körperlichen Belastung kann ganz unterschiedlich sein. z.B. ein Skiausflug, ein ausgedehnter Spaziergang oder anstrengende Hausarbeit)

keine stark

Art der körperlichen Belastung:

Dauer der körperlichen Belastung:

2. Wieviet Flüssigkeit haben Sie in den letzten 24 Stunden zu sich genommen? (bitte ankreuzen)

$\begin{array}{cccc}(1) & \text { (3) } & \text { (3) } & \text { (4) } \\ \text { bis zu } 1 \text { Liter } & 1 \text { bis } 2 \text { Liter } & 2 \text { bis } 3 \text { Liter } & \text { menr ats } 3 \text { Liter }\end{array}$

Alkoholkonsum?

$\ldots . . . . .$. Liter Bier
........... Liter Schnaps

Liter Wein/Sekt

Liter Anderes:

Koffeinkonsum?

Tassen Kaffee

Gläser anderer koffeinhaltiger Getränke (z.B. Cola)

3. Wie viele Zigaretten/Zigarillos o.ä. haben Sie in den letzten 24 Stunden geraucht? (bitte ankreuzen)

$\begin{array}{cccccc}\text { (1) } & \text { (2) } & \text { (3) } & \text { (4) } & \text { (5) } & \text { (6) } \\ \text { keine/Nichtraucher } & 1 \text { bis } 5 & 6 \text { bis } 10 & 11 \text { bis } 20 & 21 \text { bis } 30 & \text { mehr als } 30\end{array}$

4. Weiche Medikamente haben sie eingenommen/angewandt?

(hierunter fallen z.B. auch Schmerz-, Schlaf-, Abführ-, Stärkungsmittel usw.)

\begin{tabular}{|c|c|c|c|}
\hline Präparat & $\mathrm{mg}$ & Anzahl & Uhrzeit \\
\hline ................... & ........... & ...................... & \\
\hline . & …....... & 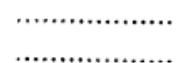 & \\
\hline
\end{tabular}

5. Hatten Sie Regelblutungen? (bitte ankreuzen)

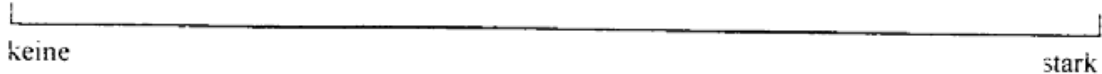

Besonderheiten (z.B. Schmerzen):

6. Wie beurteilen Sie Ihren aktuellen Gesundheitszustand?

o ich habe sicher keine andere Erkrankung (z.B. Erkältung, Grippe)

o möglicherweise habe ich eine andere Erkrankung, und zwar

o ich habe sicher eine andere Erkrankung, und zwar 
$\underline{\text { Tagebuch - Beispiel: Montag - Seite } 3}$

\section{FRAGEN ZU EREIGNISSEN}

Bitte notieren Sie Ereignisse des vergangenen Tages stichwortartig. Diese Stichwörter sollen Ihnen als Gedächtnisstütze für die wöchentlichen Interviews dienen.

Ereignisse können unter anderem sein: Veränderungen. Belastungen. Schwierigkeiten oder Neuigkeiten in den Bereichen Familie, Kinder, Partnerschatt, Freundeskreis, Beruf., Geldfragen. Umwelt. Krankheit (z.B. Allergien), Ernährung (z.B. ,Diätfehler") usw.

Belastende oder unangenehme Ereignisse in den letzten 24 Stunden:

Entlastende oder angenehme Ereignisse in den letzten 24 Stunden:

Beunruhigende Grübelgedanken in den letzten 24 Stunden: (bitte ankreuzen)

$L_{\text {keine }}^{\text {stark }}$

Thema: 
Tagebuch - Beispiel: Montag - Seite 4

\section{EIGENSCHAFTSWÖRTERLISTE}

Dies ist eine Liste von Wörtern. mit denen man beschreiben kann. wie man sich augenhlicklich fühlt. Gehen Sie alle Wörter der Liste nacheinander durch, und wählen Sie aus den vier Antwortmöglichkeiten diejenige aus. die am besten angibt, wie Ihr augenblickliches Befinden ist.

\begin{tabular}{|c|c|c|c|c|c|c|c|c|c|}
\hline & 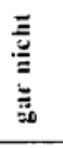 & $\frac{n}{z}$ & 站 & 总 & & 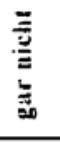 & $\stackrel{n}{\stackrel{n}{E}}$ & $\frac{\bar{g}}{\overline{n g}}$ & $\frac{i}{\frac{n}{n}}$ \\
\hline 1. ängstlich & $=$ & $=$ & $\because$ & $\bar{z}$ & 31. zappelig & 7 & 2 & 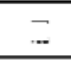 & $z$ \\
\hline 2. energielos & $=$ & $=$ & $=$ & $\Xi$ & 32. gesprächig & $\Xi$ & $=$ & 3 & - \\
\hline 3. lustig & $=$ & 2 & - & 2 & 33. traurig & 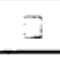 & $=$ & 2 & 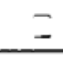 \\
\hline 4. benebelt & 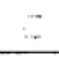 & $\ldots$ & ב & 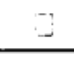 & 34. lahm & $=$ & E & 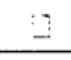 & $z$ \\
\hline 5. menschenscheu & $\therefore$ & $\Xi$ & $=$ & $z$ & 35. freudig & $\Xi$ & 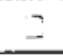 & $z$ & $=$ \\
\hline 6. selbstsicher & 3 & $\therefore$ & $z$ & 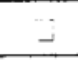 & 36. verträumt & $=$ & $I$ & $\square$ & 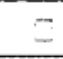 \\
\hline 7. betrübt & ב & 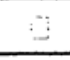 & $\approx$ & 4 & 37. benommen & $\square$ & 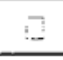 & $D$ & $\mathrm{G}$ \\
\hline 8. lasch & 3 & $=$ & $z$ & $\underline{z}$ & 38. angsterfüilt & $\mathrm{I}$ & 9 & $\Xi$ & $\Sigma$ \\
\hline 9. zutraulich & - & 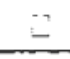 & 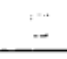 & こ & 39. beständig & $\square$ & $\Xi$ & 3 & こ \\
\hline 10. energisch & ב & $=$ & $z$ & 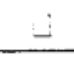 & 40. abgesondert & 2 & $\exists$ & Z & $\mathrm{Z}$ \\
\hline 11. gereizt & $\beth$ & 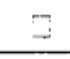 & $\Xi$ & $\Xi$ & 41. eifrig & {[]} & 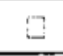 & $\square$ & $\square$ \\
\hline 12. erregt & 2 & $\square$ & $=$ & $\square$ & 42. gedankenverloren & $\Xi$ & 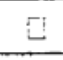 & $\square$ & $\square$ \\
\hline 13. dösig & $\square$ & ב & $\Xi$ & 2 & 43. nervös & $\square$ & $=$ & $ב$ & $z$ \\
\hline 14. emptindlich & 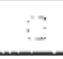 & 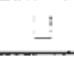 & 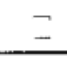 & $\Xi$ & 44. kraftlos & $\Xi$ & 2 & $\sqsupset$ & ב \\
\hline 15. wortkarg & 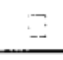 & 3 & $=$ & 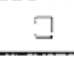 & 45. kontaktfreudig & $\square$ & 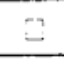 & 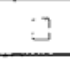 & 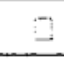 \\
\hline 16. aufmerksam & 2 & 1 & z & 5 & 46. müde & $\mathrm{C}$ & ב & 3 & I \\
\hline 17. selbstzufrieden & J & 3 & $=$ & 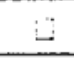 & 47. furchtsam & $\mathrm{E}$ & $\because$ & ] & ] \\
\hline 18. träumerisch & 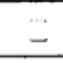 & - & $=$ & $\square$ & 48. ausdauernd & 19 & - & 1 & ב \\
\hline 19. ärgerlich & 2 & $\stackrel{-}{-}$ & 3 & $E$ & 49. einsilbig & ב & $\exists$ & 2 & $=$ \\
\hline 20. elend & 2 & $\bar{z}$ & $\underline{z}$ & $\mathrm{~J}$ & 50. sorgenvoll & $\square$ & $=$ & 9 & E \\
\hline 21. zermürbt & $\because$ & 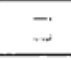 & $\therefore$ & $ב$ & 51. verwundbar & $\Xi$ & 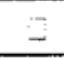 & 3 & ב \\
\hline 22. erregbar & $\because$ & I & $\stackrel{-}{-}$ & $=$ & 52. froh & - & $=$ & 3 & 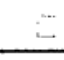 \\
\hline 23. aktiv & 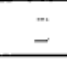 & 5 & $\therefore$ & $\mathrm{Z}$ & 53. schlaftrunken & $\Xi$ & $=$ & $\Xi$ & $\Sigma$ \\
\hline 24. beklommen & $=$ & 2 & $\bar{z}$ & E & 54. wütend & 2 & ב & $\Xi$ & $=$ \\
\hline 25. heiter & $\therefore$ & $=$ & - & $\therefore$ & 55. selbstbewußt & 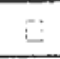 & - & $\Xi$ & $=$ \\
\hline 26. schlätrig & 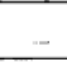 & z & 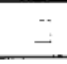 & $=$ & 56. tatkräftig & $=$ & Z & 2 & - \\
\hline 27. konzentriert & - & $z$ & 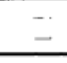 & $=$ & 57. gesellig & $=$ & - & $\Xi$ & - \\
\hline 28. verärgert & $\therefore$ & - & $=$ & $=$ & 58. aufgeregt & $\bar{z}$ & $=$ & $\Xi$ & $\Xi$ \\
\hline 29. versonnen & $\therefore$ & - & 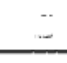 & 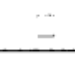 & 59. abgespannt & $\Xi$ & $\ddot{z}$ & 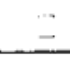 & ב \\
\hline 30. unbekümmert & $\beth$ & $z$ & $=$ & $\Xi$ & 60. verletzbar & $\Xi$ & $\ddot{z}$ & $\Xi$ & - \\
\hline
\end{tabular}


Tagebuch - Beispiel: Montag - Seite 5

\section{FRAGEN ZUR URINSAMMLUNG}

Sammelperiode von Uhr (abends) bis Uhr (morgens).

Urinmenge: $\mathrm{ml}$

Codenummer auf dem Sammelettikett:

Besonderheiten bei der Urinsammiung:

\section{FRAGEN ZUM SCHLAF IN DER VERGANGENEN NACHT}

1. Wann haben Sie gestern das Licht ausgemacht? Uhr

2. Wie lange haben Sie gebraucht, um einzuschlafen? Minuten

3. Wie oft sind Sie in der vergangenen Nacht aufgewacht? mal

4. Wann sind Sie in der vergangenen Nacht das letzte Mal aufgewacht? Uhr

5. Wie lange waren Sie in der vergangenen Nacht insgesamt wach (ohne die Einschlafzeit)? Minuten

6. Wie viele Stunden haben Sie in der vergangenen Nacht insgesamt geschlafen? Stunden

7. Verglichen mit der durchschnittlichen Schlafqualität im letzten Monat, wie gut war Ihr Schlaf in der letzten Nacht?

Wählen Sie eine Zahl aus der linken Liste:

8. Wie erholsam und erfrischend war Ihr Schlaf?

Wählen Sie einen Buchstaben aus der rechten Liste:

1. Viel schlechter als gewöhniich

2. Etwas schlechter als sonst

3. So wie immer

4. Etwas besser als sonst

5. Viel besser als gewöhniich
A. Uberhaupt nicht erholsam

B. Ein wenig erholsam

C. Zwar erholsam, aber insgesamt nicht ausreichend

D. Ausreichend erholsam

E. Sehr erholsam: fühle mich frisch und fit 


\section{Literaturverzeichnis}

Akdis CA, Akdis M, Simon D, Dibbert B, Weber M, Gratzl S, Kreyden O, Disch R, Wüthrich B, Blaser K, Simon H-U (1999): Role of T-cells and cytokines in the intrinsic form of atopic dermatitis. Curr Probl Dermatol $\underline{28}, 37-44$

Akdis CA, Akdis M, Trautmann A, Blaser K (2000): Immune regulation in atopic dermatitis. Curr Opin Immunol 12, 641-646

Akdis M, Trautmann A, Klunker S, Blaser K, Akdis CA (2001): Cytokine network and dysregulated apoptosis in atopic dermatitis. Acta Odontol Scand $\underline{59}, 178-182$

Alenius H, Laouini D, Woodward A, Mizoguchi E, Bhan AK, Castigli E, Oettgen HC, Geha RS (2002): Mast cells regulate IFN- $\gamma$ expression in the skin and circulating IgE levels in allergen-induced skin inflammation.

J Allergy Clin Immunol 109, 106-113

Allam J-P, Novak N (2005): The pathophysiology of atopic eczema.

Clin Exp Dermatol $\underline{31}, 89-93$

Angelova-Fischer I, Hipler UC, Bauer A, Fluhr JW, Tsankov N, Fischer TW, Elsner P (2006): Significance of interleukin-16, macrophage-derived chemokine, eosinophil cationic protein and soluble E-selectin in reflecting disease activity of atopic dermatitis - from laboratory parameters to clinical scores.

$\mathrm{Br} J$ Dermatol 154, 1112-1117

Anton AH, Sayre DF (1962): A study of the factors affecting the aluminiumoxide-trihydroxyindole procedere for the analysis of catecholamines. J Pharmacol Exp Ther 138, 360-375

Antonovsky A (1993): The structure and properties of the Sense of Coherence Scale. Soc Sci Med 36: 725-733 
AuzebyA, Bogdan A, Krosi Z, Toultou Y (1988): Time-dependence of urinary neopterin, a marker of cellular immune aktivity. Clin Chem $\underline{34}$, 1866-1867

Ballmer-Weber BK (1998): Atopische Dermatitis. Praxis $\underline{87}, 1293-1299$

Bardana EJ (2004): Immunoglobulin E-(IgE) and non-IgE-mediated reactions in the pathogenesis of atopic eczema/dermatitis syndrom (AEDS). Allergy $\underline{59}, 25-29$

Barriga C, Martin MI, Tabla R, Ortega E, Rodriguez E (2001): Circadian rhythm of melatonin, corticosterone and phagocytosis: effect of stress.

J Pineal Res $\underline{30}$, 180-187

Bauch HJ, Kelsch U, Hauss WH (1986): Einfache, schnelle, selektve und quantitative Bestimmung von Adrenalin und Noradrenalin im Plasma durch Kombination von Flüssigkeitsextraktion, HPLC-Trennung und elektrochemischer Detektion. J Clin Chem Clin Biochem 24, 651-658

Beltrani VS (1999): The clinical spectrum of atopic dermatitis. J Allergy Clin Immunol 104, 87-98

Benninghoff A: Anatomie. Makroskopische Anatomie, Embryologie und Histologie des Menschen. Band 1; 15. Auflage; Urban \& Schwarzenberg, München 1994a

Benninghoff A: Anatomie. Makroskopische Anatomie, Embryologie und Histologie des Menschen. Band 2; 15. Auflage; Urban \& Schwarzenberg, München 1994b

Besedovsky HO, Del Rey A (1996): Immune-Neuro-Endocrine Interactions: Facts and Hypotheses. Endocr Rev 17, 64-102

Biedermann T, Röcken M (2001): Immunologische Grundlagen des atopischen Ekzems. Monatsschr Kinderheilkd 149, 534-541 
Bielfeldt S: Psychobiologische Belastungsparameter bei Personen mit chronischrezidivierender atopischer Dermatitis unter Berücksichtigung des aktuellen Symptomstatus. Med. Diss. Kiel 2001

Birbaumer N, Schmidt RF: Biologische Psychologie. 4. Auflage, Springer-Verlag, Berlin 1999

Böhm I, Bauer R (1997): Th1-Zellen, Th2-Zellen und atopische Dermatitis. Hautarzt $\underline{48}, 223-227$

Bortz J, Döring N: Forschungsmethoden und Evaluation. 3. Auflage, SpringerVerlag, Berlin 2002

Bowcock AM, Cookson WO (2004): The genetics of psoriasis, psoriatic arthritis and atopic dermatitis. Hum Mol Genet $\underline{13}, 43-55$

Box GEP, Jenkins GM: Time-series analysis: forecasting and control. 1. Auflage, Holden-Day, San Francisco 1976

Braun-Falco O, Plewig G, Wolff HH: Dermatologie und Venerologie. 4. Auflage, Springer-Verlag, Berlin 1995

Brehler R, Luger TA (1999): Atopy: immunodeviation and environment. J Allergy Clin Immunol 104, 1128-1130

Brosig B, Brähler E (2001): Haut - Psyche - Immunsystem: Ein VektorZeitreihen-Modell. Z Klin Psychol Psychiatr Psychother 49 , 279-296.

Brosig B, Kupfer J, Brähler E: Neurodermitis und Asthma - ARIMA-ImpactAnalyse eines stationären Therapieverlaufs. In: Gieler U, Stangier U, Brähler E (Hrsg.). Hautkrankheiten in psychologischer Sicht. Jahrbuch der Medizinischen Psychologie, 9.Auflage, Hogrefe Verlag, Göttingen 1993, 119-124 
Brosig B, Kupfer J, Köhnlein B, Niemeier V, Gieler U (2000): Atopic dermatitis in psychoanalytic psychotherapy - a psychobiological case study.

Dermatol Psychosom 소 19-25

Brown D, Bettley F (1971): Psychiatric treatment of eczema: a controlled trial. Br Med J 1971,2, 729-734

Büchner SA (2001): Atopische Dermatitis. Schweiz Med Forum 19, 484-490

Bühl A, Zöfel P: SPSS 12, Einführung in die moderne Datenanalyse unter Windows. 9. Auflage, Pearson Studium, München 2005

Buhk H, Muthny FA (1997): Psychophysiologische und psychoimmunologische Ergebnisse zur Neurodermitis. Übersicht und kritische Bilanz. Hautarzt $\underline{48}, 5-11$

Bullinger M, Kirchberger I: Fragebogen zum Gesundheitszustand „Short-Form-36 Health Survey“. Hogrefe, Göttingen 1998

Buske-Kirschbaum A, Hellhammer DH (1999): Psychobiologische Aspekte der atopischen Dermatitis. Z Dermatol $\underline{185}, 67-71$

Buske-Kirschbaum A, Hellhammer DH (2003): Endocrine and immune responses to stress in chronic inflammatory skin disorders. Ann NY Acad Sci 992, 231-240

Buske-Kirschbaum A, Geiben A, Hellhammer DH (2001): Psychobiological Aspects of Atopic Dermatitis: An Overview. Psychother Psychosom 므, 6-16

Buske-Kirschbaum A, Geiben A, Höllig H, Morschhauser E, Hellhammer DH. (2002a): Altered responsiveness of the hypothalamus-pituitary-adrenal axis and the sympathetic adrenomedullary system to stress in patients with atopic dermatitis. J Clin Endocrinol Metab 87, 4245-4251 
Buske-Kirschbaum A, Gierens A, Höllig H, Hellhammer DH (2002b): Stressinduced immunomodulation is altered in patients with atopic dermatitis. J Neuroimmunol $\underline{129}, 161-167$

Choi E-H, Brown BE, Crumrine D, Chang S, Man M-Q, Peter ME, Kenneth RF (2005): Mechanisms by which psychologic stress alters cutaneous permeability barrier homeostasis and stratum corneum integrity.

J Invest Dermatol 124, 587-595

Chrousos GP (1995): The hypothalamic-pituitary-adrenal axis and immunemediated inflammation. N Engl J Med 332, 1351-1362

Coleman R, Trembath RC, Harper JI (1997): Genetic studies of atopy and atopic dermatitis. Br J Dermatol $\underline{136}, 1-5$

Collins WA, Read SJ (1990): Adult attachment, working models and relationship quality in dating couples. J Pers Soc Psychol $\underline{58}$, 644-663

Cookson WO (2001): The genetics of atopic dermatits: strategies, candidate genes and genome screens. J Am Acad Dermatol 느, 7-9

Cookson WO, Moffatt MF (2002): The genetics of atopic dermatitis.

Curr Opin Allergy Clin Immunol 2, 383-387

Cooper KD, Stevens SR (2001): T-cells in atopic dermatitis.

$\mathrm{J}$ Am Acad Dermatol 4도 $10-12$

Correale CE, Walker C, Murphy L, Craig TJ (1999): Atopic dermatitis: a review of diagnosis and treatment. Am Fam Physician $\underline{60}$, 1191-1210 
Crompton R, Clifton VL, Bisits AT, Read MA, Smith R, Wright IM (2003):

Corticotropin-releasing hormone causes vasodilation in human skin via mast-celldependent pathways. J Clin Endocrinol Metab 88; 5427-5432

De Meer G, Janssen AH, Brunekreef B (2005): Early childhood enviroment related to microbial exposure and the occurrence of atopic disease at school age.

Allergy $\underline{60}, 619-625$

Dhabhar FS, McEwen BS (1999): Enhancing versus suppressive effects of stress hormones on skin immune function. Proc Natl Acad Sci $\underline{96}, 1059-1064$

Dienstbier RA (1989): Arousal and physiological toughness: implications for mental and physical health. Psychol Rev $\underline{96}, 84-100$

Diepgen TL und Blettner M (1996): Analysis of familial aggregation of atopic eczema and other atopic diseases by Odds Ratio regressions models. J Invest Dermatol $\underline{106}$, 977-981

Doering S, Wedekind D, Pilz J, Bandelow B, Adler L, Huether G (2001): Cortisolbestimmung im Nachturin - Vorstellung einer Methode für die psychoneuroendokrinologische Forschung. Z Psychosom Med Psychother 4, 42-57

Ebata T, Aizawa H, Kamide R, Niimura M (1999): The characteristics of nocturnal scratching in adults with atopic dermatitis. $\mathrm{Br} \mathrm{J}$ Dermatol $\underline{141}, 82-86$

Ehlken B, Möhrenschläger M, Kugland B, Berger K, Quednau K, Ring J (2005): Krankheitskostenstudie bei Patienten mit atopischem Ekzem in Deutschland. Hautarzt $\underline{56}, 1144-1151$

Eichenfield LF (2004): Consensus guidelines in diagnosis and treatment of atopic dermatitis. Allergy $\underline{59}, 86-92$ 
Elenkov IJ und Chrousos GP (1999): Stress hormones, TH1/TH2 patterns pro/anti-inflammatory cytokines and susceptibility to disease.

Trends Endocrinol Metab $\underline{10}$, 359-361

Ellison JA, Patel L, Ray DW, David TJ, Clayton PE (2000): Hypothalamicpituitary-adrenal function and glucocorticoid sensitivity in atopic dermatitis. Pediatrics 105, 794-798

Esposito P, Gheorghe D, Kandere K, Pang X, Connolly R, Jacobson S, Theoharides TC (2001): Acute stress increases permeability of blood-brainbarrier through activation of brain mast cells. Brain Res $\underline{888}, 117-127$

European Task Force on Atopic Dermatitis (1993): Severity Scoring of Atopic Dermatitis: The SCORAD Index: Consensus Report. Dermatology 186, 23-31

Farwanah H: Untersuchung der Ceramide des Stratum corneum in der nicht involvierten Haut bei Neurodermitis- und Psoriasis-Patienten mit Hilfe der AMD-HPTLC und der HPLC/APCI-MS. Med. Diss. Halle-Wittenberg 2005

Faulstich M, Williamson D, Duchmann E, Cornely S, Brantley P (1985): Psychophysiological analysis of atopic dermatitis. J Psychosom Res $\underline{29}, 415-417$

Firooz A, Davoudi SM, Farahmand AN, Majdzadeh R, Kashani MN, Dowlati $Y$ (1999): Validation of the diagnostic criteria of atopic dermatitis. Arch Dermatol 135, 514-516

Fischer S, Ring J, Abeck D (2003): Atopisches Ekzem. Provokationsfaktoren und Möglichkeiten ihrer Wirkungsvollen Reduktion bzw. Elimination. Hautarzt $\underline{54}, 914-924$

Fischer T, Wigger-Alberti W, Elsner P (1999): Melatonin in der Dermatologie. Experimentelle und klinische Aspekte. Hautarzt 50, 5-11 
Fölster-Holst R, Pape M, Buss YL, Christophers E, Weichenthal M (2006): Low prevalence of the intrinsic form of atopic dermatitis among adult patients. Allergy $\underline{61}$, 629-632

Forrest S, Dunn K, Elliott K, Fitzpatrick E, Fullerton J, McCarthy M, Brown J, Hill D, Williamson R (1999): Identifying genes predisposing to atopic excema.

J Allergy Clin Immunol $\underline{104}$, 1066-1070

Fuchs D, Weiss G, Wachter H (1993): Neopterin, biochemistry and clinical use as a marker for cellular immune reactions. Int Arch Allergy Immunol 101, 1-6

Gaisbauer G: Psychischer Stress und atopisches Ekzem - eine zeitreihenanalytische Einzelfalluntersuchung. Med. Diss. Leipzig 2000

Garg A, Chren M-M, Sands LP, Matsui MS, Kenneth DM, Kenneth RF, Peter ME (2001): Psychological stress perturbs epidermal permeability barrier homeostasis. Arch Dermatol 137, 53-59

Gelmetti C, Colonna C (2004): The value of SCORAD and beyond. Towards a standardized evaluation of severity? Allergy $\underline{59}, 61-65$

Gibbs S, Surridge H, Adamson R, Cohen B, Bentham G, Reading R (2004): Atopic dermatitis and the hygiene hypothesis: a case control study. Int J Epidemol 3푸 199-207

Gieler U, Ehlers A, Höhler T, Burkhard G (1999): Die psychosoziale Situation der Patienten mit endogenem Ekzem. Eine clusteranalytische Studie zur Korrelation psychischer Faktoren mit somatischen Befunden. Hautarzt 411, 416-423

Greaves M (2000): Mast cell mediators other than histamine induced pruritus in atopic dermatits patients - a dermal microdialysis study.

Br J Dermatol 142, 1079-1083 
Grize L, Gassner M, Wüthrich B, Bringolf-Isler B, Takken-Sahli K, Sennhauser FH, Stricker T, Eigenmann PA, Braun-Fahrländer C (2006): Trends in the prevalence of asthma, allergic rhinitis and atopic dermatitis in 5-7-year old Swiss children from 1992 to 2001. Allergy $\underline{61}, 556-562$

Groneberg DA, Bester C, Grützkau A, Serowka F, Fischer A, Henz BM, Welker $P$ (2005): Mast cells in vasculature in atopic dermatitis - potential stimulus of neo-angiogenesis. Allergy $\underline{60}, 90-97$

Gupta MA, Gupta AK, Schork NJ, Ellis CN (1994): Depression modulates pruritus perception: a study of pruritus in psoriasis, atopic dermatitis, and chronic idiopathic urticaria. Psychosom Med $\underline{56}$, 36-40.

Hamerlinck FFV (1999): Neopterin: a review. Exp Dermatol $\underline{8}, 167-176$

Hanifin JM, Rajka G (1980): Diagnostic features of atopic dermatitis. Arch Dermatol $\underline{113}, 663-670$

Hashizume H, Horibe T, Ohshima A, Ito T, Yagi H, Takigawa M (2005): Anxiety accelerates T-helper 2-titled immune responses in patients with atopic dermatitis. Br J Dermatol 152, 1161-1164

Hausen A, Fuchs D, König K, Wachter H (1982): Determination on neopterin in human urine by reversed-phase high-performance liquid chromatography. J Chromatogr $\underline{227}, 61-70$

Hautzinger M (1988): Die CES-D Skala. Ein Depressionsinstrument für Untersuchungen in der Allgemeinbevölkerung. Diagnostica 34, 167-173

He J-Q, Chang-Yeung M, Becker AB, Dimich-Ward H, Ferguson AC, Manfreda J, Watson WTA, Sandford AJ (2003): Genetic variants of the IL13 and IL4 genes and atopic diseases in at-risk children. Genes Immun $\underline{4}$, 385-389 
Heaton T, Mallon D, Venaille T, Holt P (2003): Staphylococcal enterotoxin induced IL-5 stimulation as a cofactor in the pathogenesis of atopic disease: the hygiene hypothesis in reverse? Allergy $\underline{58}, 252-256$

Heim C, Ehlert U, Dirk H, Hellhammer D (2000): The potential role of hypocortisolism in the pathophysiology of stress-related bodily disorders.

Psychoneuroendocrinology $\underline{25}, 1-35$

Heinemann B: Zeitreihenanalytische Einzelfalluntersuchung zur Aktualgenese von Neurodermitis unter besonderer Berücksichtigung psychischer Faktoren. Med. Diss. Hamburg 1992

Heinzmann A, Daser A (2002): Mouse models for the genetic dissection of atopy. Int Arch Allergy Immunol 127, 170-180

Helmbold P, Gaisbauer G, Kupfer J, Seikowski K, Brähler E, Haustein UF (1996): Atopisches Ekzem: Der Einfluss von psychischem Stress auf periphere Leukozytenpopulationen und Krankheitsaktivität. Z Med Psychol $\underline{5}, 119-124$.

Helmbold P, Gaisbauer G, Kupfer J, Haustein UF (2000): Longitudinal case analysis in atopic dermatitis. Acta Derm Venereol $\underline{80}, 348-352$

Henry JP, Stephens PM: Stress, health and the social environment: A sociobiological approach to medicine. Springer-Verlag, New York 1977 Heratizadeh A, Breuer K, Kapp A, Werfel T (2003): Symptomatische Therapie der atopischen Dermatitis. Hautarzt $\underline{54}, 937-945$

Higashi N, Bang K, Gesser B, Lund M, Thestrup-Pedersen K (2001): Cytokine expression of skin T-lymphocytes from patients with atopic dermatitis. Acta Derm Venereol $\underline{\text { 81, 3-7 }}$ 
Hoffmann G, Wirleitner B, Fuchs D (2003): Potential role of immune system activation-associated production of neopterin derivatives in humans. Inflamm Res $\underline{52}, 313-321$

Holsboer T (1989): Psychiatric implications of altered limbic-hypothalamicpituitary-adrenocortical activity. Eur Arch Psychiatry Neurol Sci 238, 302-322

Horrobin DF (2000): Essential fatty acid metabolism and its modification in atopic eczema. Am J Clin Nutr $\underline{71}, 367-372$

Hüther G (1996): The central adaption syndrome: psychosocial stress as a trigger for adaptive modifications of brain structure and brain function.

Prog Neurobiol $\underline{48}, 569-612$

Hüther G, Döring S, Rüger U, Schüßler G (1996): Psychische Belastungen und neuronale Plastizität. Ein erweitertes Modell des Stress-Reaktions-Prozesses als Grundlage für das Verständnis zentralnervöser Anpassungsprozesse. Z Psychosom Med Psychother 42, 107-127

Imokawa G (2001): Lipid abnormalities in atopic dermatitias.

J Am Acad Dermatol $\underline{45}, 29-32$

Jahnz-Rozyk K, Targowski T, Paluchowska E, Owczarek W, Kucharczyk A (2005): Serum thymus and activation-regulated chemokine, macrophage-derived chemokine and eotaxin as markers of serverity of atopic dermatitis.

Allergy $\underline{60}, 685-688$

Janeway CA, Travers P: Immunologie. 5. Auflage, Spektrum Akademischer Verlag $\mathrm{GmbH}$, Heidelberg 2002

Janke W, Debus G: Die Eigenschaftswörterliste. Hogrefe, Göttingen 1978 
Järvikallio A, Harvima IT, Naukkarinen A (2003): Mast cells, nerves and neuropeptides in atopic dermatitis and nummular eczema. Arch Dermatol Res $\underline{295}, 2-7$

Johannsson SG, Hourihane JO, Bruijnzeel-Koomen C, Dreborg S, Haahtela T, Kowalski ML, Mygind N, Ring J, van Cauwenberge P, van Hage-Hamsten M, Wüthrich B (2001): EAACl (the European Academy of Allergy and Clinical Immunology) nomenclature task force. A revised nomenclature for allergy. An EAACl position statement from the EAACl nomenclature task force. Allergy $\underline{56}, 813-824$

Jordan JM, Whitlock FA (1975): Atopic dermatitis axiety and conditioned scratch responses. J Psychosom Res $\underline{18}$, 297-299

Kalliomaki M, Salminen S, Poussa T, Arvilommi H, Isolauri E (2003): Probiotics and prevention of atopic disease: 4-year follow-up of a randomised placebocontrolled trial. Lancet $\underline{361}, 1869-1871$

Kang K, SR Stevens (2003): Pathophysiology of atopic dermatitis. Clin Dermatol 21, 116-121

Karalis K, Sano H, Redwine J, Listwak S, Wilder RL, Chrousos GP (1991): Autocrine or paracrine inflammatory actions of corticotropine-releasing hormone in vivo. Science $\underline{254}, 421-422$

Kerschenlohr K, Decard S, Darsow U, Ollert M, Wollenberg A (2003): Clinical and immunologic reactivity to aeroallergens in "intrinsic" atopic dermatitis patients. J Allergy Clin Immunol 111, 195-197

King RM, Wilson GV (1991): Use of a diary technique to investigate psychosomatic relations in atopic dermatitis. J Psychosom Res $\underline{35}$, 697-706 
Koblenzer CS (2005): The emotional impact of chronic and disabling skin disease: a psychoanalytic perspective. Dermatol Clin $\underline{23}$, 619-627

Kodama A, Horikawa T, Suzuki T, Ajiki W, Takashima T, Harada S, Ichihashi M (1999): Effect of stress on atopic dermatitis: investigation in patients after the great hanshin earthquake. J Allergy Clin Immunol 104, 173-176

Köhler T, Niepoth L (1988): Der Einfluß von belastenden Lebensereignissen auf den Verlauf der Neurodermitis diffusa. Verhaltensmodif Verhaltensmed $\underline{9}, 11-21$.

Korting HC (2003): Leitlinie Psychosomatische Dermatologie. Fassung vom 15.1.2002. J Dtsch Dermatol Ges 1, 494-502

Kupfer JPB: Eine immunologische Verlaufsstudie bei Patienten mit atopischer Dermatitis. Med. Diss. Giessen 1994.

Lang U, Kornemark M, Aubert ML, Paunier L, Sizonenko PC (1981):

Radioimmunological determination of urinary melatonin in humans: correlation with plasma levels and typical 24-hour rhythmicity.

J Clin Endocrinol Metab $\underline{53}$, 645-650.

Lange S, Zschocke I, Langhardt S, Amon U, Augustin M (1999): Effekte kombinierter therapeutischer Maßnahmen bei Patienten mit Psoriasis und atopischer Dermatitis. Hautarzt $\underline{50}, 791-797$.

Larsen FS, Holm NV Henningsen K (1986): Atopic dermatitis: a geneticepidemiologic study in a population-based twin sample.

J Am Acad Dermatol $\underline{15}, 487-494$

Laux L, Glanzmann P, Schaffner P, Spielberger CD: Fragebogen:

Das State-Trait-Angstinventar. Beltz, Weinheim 1981 
Leung DYM (1991): Immune mechanisms in atopic dermatitis and relevance to treatment. Allergy Proc 12, 339-346

Leung DYM (1997): Atopic dermatitis: immunobiology and treatment with immune modulators. Clin Exp Immunol 107, 25-30

Leung DYM (2000): Atopic dermatitis: new insights and opportunities for therapeutic intervention. J Allergy Clin Immunol 105, 860-876

Leung DYM (2001): Atopic dermatitis and the immune system: the role of superantigens and bacteria. J Am Acad Dermatol $\underline{45}$, 13-16

Leung DYM, Bieber T (2003): Atopic dermatitis. Lancet $\underline{361}$, 151-160

Leung DYM, Boguniewicz M, Howell MD, Nomura I, Hamid QA (2004):

New insights into atopic dermatitis. J Clin Invest $\underline{113}, 651-657$

Lever R (2001): The role of food in atopic excema. J Am Acad Dermatol $\underline{45}$, 57-60

Linnet J, Jemec GBE (2001): Anxiety, aggression and body ideal in adult atopic dermatitis patients. Dermatol Psychosom 2, 124-129

Löffler G, Petrides PE: Biochemie und Pathobiochemie. 7. Auflage, Springer Verlag, Berlin 2003

Lotti T, Hautmann G, Panconesi E (1995): Neuropeptides in skin.

J Am Acad Dermatol $\underline{33}, 482-496$

Madden KS, Felten DL (1995): Experimental basis for neuro-immune interactions. Physiol Rev $\underline{75}, 77-106$ 
Marx C, Ehrhart-Bornstein M, Scherbaum WA, Bornstein SR (1998): Regulation of adrenocortical function by cytokines - relevance for immune-endocrine interaction. Horm Metab Res $\underline{30}$, 416-420

Metze D (2001): Neurophysiology of the skin - functional anatomy of the skin nervous system. Exp Dermatol 10, 365-366

Morar N, Willis-Owen SA, Moffatt MF, Cookson WO (2006): The genetics of atopic dermatitis. J Allergy Clin Immunol $\underline{118}, 24-34$

Morren M-A, Przybilla B, Barmelis M, Heykants B, Reynaers A, Degreef H (1994): Atopic dermatitis: triggering factors. J Am Acad Dermatol 31, 467-473

Muthny FA: Freiburger Fragebogen zur Krankheitsverarbeitung. Beltz, Weinheim 1989

Natter S, Seiberler S, Hufnagl P (1998): Isolation of cDNA clones coding for IgE autoantigens with serum IgE from atopic dermatitis patients.

FASEB J 12, 1559-1569

Neumann RP: Der Einfluss von Katecholaminen auf die Zytokinproduktion von mononukleären Zellen des peripheren Blutes in vitro. Med. Diss. Marburg 2003

Nomura I, Goleva E, Howell MD, Hamid QA, Ong PY, Hall CF, Darst MA, Gao B, Boguniewicz M, Travers JB, Leung DYM (2003): Cytocine milieu of atopic dermatitis, as compared to psoriasis, skin prevents induction of innate immune response genes. J Immunol 171, 3262-3269

Novak N, Bieber T (2004): Pathophysiologie der atopischen Dermatitis. Dtsch Ärzteblatt 2004/3, 108-120 
Novak N, Kruse S, Kraft S, Geiger E, Klüken H, Fimmers R, Deichmann KA, Bieber T (2002): Dichotomic nature of atopic dermatitis reflected by combined analysis of monocyte immunophenotyping and single nucleotide polymorphisms of the Interleukin-4/interleukin-13 receptor gene: the dichotomy of extrinsic and intrinsic atopic dermatitis. J Invest Dermatol $\underline{119}$, 870-875

Novembre E, Cianferoni A, Lombardi E, Bernardini R, Pucci N, Vierucci A (2001): Natural history of „intrinsic“ atopic dermatitis. Allergy $\underline{56}, 452-463$

O`Connor TM, O`Halloran DJ, Shanahan F (2000): The stress response and the hypothalamic-pituitary-adrenal axis: from molecule to melancholia. Q J Med 93, 323-333

O`Kane M, Murphy EP, Kirby B (2006): The role of corticotropin-releasing hormone in immune-mediated cutaneous inflammatory disease.

Exp Dermatol 15, 143-153

O`Leary A (1990): Stress, emotion, and human immune function. Psychol Bull 108, 363-382

Ong PY, Leung DYM (2002): Atopic dermatitis. J Allergy Clin Immunol 16, 355-379

Ostrander MM, Ulrich-Lai YM, Choi DC, Richtand NM, Herman JP (2006): Hypoactivity of the hypothalamo-pituitary-adrenocortical axis during recovery from chronic variable stress. Endocrinology 147, 2008-2017

O`Sullivan R,Lipper G, Lerner E(1998): The neuro-immuno-cutaneous-endocrine network: relationship of mind and skin. Arch Dermatol 134, 1431-1435

Pallanti S, Lotti T, Urpe M (2005): Psychoneuroimmunodermatology of atopic dermatitis: from empiric data to the evolutionary hypothesis.

Dermatol Clin $\underline{23}, 695-701$ 
Palmer Lj, Burton PR, James AL, Musk AW, Cookson WO (2000): Familial aggregation and heritability of asthma-associated quantitative traits in a population-based sample of nuclear families. Eur J Hum Genet ㅎ, 853-860

Parkkinen MU, Kiistala R, Kiistala U (1992): Sweating response to moderate thermal stress in atopic dermatitis. Br J Dermatol 126, 345-350

Paus R, Schmelz M, Tamas B, Steinhoff M (2006): Frontiers in pruritus research: scratching the brain for more effective itch therapy. J Clin Invest $\underline{116}, 1174-1185$

Plytycz B, Seljelid R (1997): Rhythms of immunity.

Arch Immunol Ther Exp 4토 157-162

Proksch E, Jensen J-M, Elias PM (2003): Skin lipids and epidermal differentiation in atopic dermatitis. Clin Dermatol $\underline{21}, 134-144$

Raap U, Werfel T, Jaeger B, Schmid-Ott G (2003): Atopische Dermatitis und psychischer Stress. Hautarzt $\underline{54}, 925-929$

Reich K, Hugo S, Middel P, Blaschke V, Heine A, Gutgesell C, Williams R, Neumann C (2002): Evidence for a role of Langerhans cell-derived IL-16 in atopic dermatitis. J Allergy Clin Immunol 109, 681-687

Reitamo S, Ansel JC, Luger TA (2001): Itch in atopic dermatitis.

J Am Acad Dermatol 4도, $55-56$

Rühle H: Juckreiz-Kognitionen, Belastungen und krankheitsbezogene Erwartungen bei der atopischen Dermatitis im Kindes- und Jugendalter. Verlag Dr. Kovac, Hamburg 2000 
Rupprecht M, Hornstein OP, Schlüter D, Schäfers H-J, Koch HU, Beck G, Rupprecht R (1995): Cortisol, corticotropine, and ß-endorphin responses to corticotropin-releasing hormone in patients with atopic excema.

Psychoneuroendocrinology $\underline{20}, 543-551$

Rupprecht R, Lesch KP, Müller U, Beck G, Beckmann H, Schulte HM (1989): Blunted adrenocorticotropin but normal beta-endorphin release after human corticotropin-releasing hormone administration in depression.

J Clin Endocrinol Metab 1989 69, 600-603

Saint-Mezard P, Chavagnac C, Bosset B, Ionescu M, Peyron E, Kaiserlian D, Nicolas J-N, Berard F (2003): Psychological stress exerts and adjuvant effect on skin dendric cell functions in vivo. J Immunol 171, 4073-4080

Sampson HA (1997): Food sensitivity and the pathogenesis of atopic dermatitis. J R Soc Med $\underline{90}$, 2-8

Sapolsky RM, Romero LM, Munck AU (2000): How do glucocorticoids influence stress responses? Integrating permissive, suppressive, stimulatory, and preparative actions. Endocr Rev 21, 55-89

Schäfer T, Krämer U, Vieluf D, Abeck D, Behrendt H, Ring J (2000): The excess of atopic excema in east Germany is related to the intrinsic type. Br J Dermatol $\underline{143}, 992-998$

Schandry R: Lehrbuch Psychophysiologie. Körperliche Indikatoren psychischen Geschehens. Psychologie Verlags Union, Weinheim, 1998

Schlittgen R, Streitberg HJ: Zeitreihenanalyse. 9. Auflage, Oldenbourg Verlag, München 2001

Schmelz M (2001): A neural pathway for itch. Nat Neurosci $\underline{4}$, 9-10 
Schmid-Grendelmeier P, Simon D, Simon H-U, Akdis CA, Wüthrich B (2001): Epidemiology, clinical features, and immunology of the "intrinsic" (non-IgEmediated) type of atopic dermatitis (constitutional dermatitis).

Allergy $\underline{56}$, 841-849

Schmid-Ott G, Jaeger B, Meyer S, Stephan E, Kapp A, Werfel T (2001): Different expression of cytokine and membrane molecules by circulating lymphocytes on acute mental stress in patients with atopic dermatitis in comparison with healthy controls. J Allergy Clin Immunol $\underline{108}$, 455-462.

Schmitz B, Kruse FO, Tasche KG : Anwendung zeitreihenanalytischer Verfahren bei prozessorientierter Paardiagnostik; in: Ergebnisse einzelfallstatistischer Untersuchungen; Appelt H, Strauß B (Hrsg.); Springer Verlag, Berlin 1985, 84-113

Schneider G, Gieler U (2001): Die Haut als Spiegel der Seele:

Psychosomatische Dermatologie - aktueller Forschungsstand.

Z Psychosom Med Psychother 47, 307-331

Scholz OB, Hermanns N (1994): Krankheitsverhalten und Kognitionen beeinflussen die Juckreiz-Wahrnehmung von Patienten mit atopischer Dermatitis.

Z Klin Psychol Psychother $\underline{23}$, 127-135.

Scholzen T, Armstrong CA, Bunnett NW, Luger TA, Olerud JE, Ansel JC (1998): Neuropeptides in the skin: interactions between the neuroendocrine and the skin immune systems. Exp Dermatol $\underline{7}, 81-96$

Schubert C (2002): Inflammatory skin diseases. An assortment of clinically relevant disease conditions. Pathologe $\underline{23}$, 9-19 
Schubert C, Lampe A, Rumpold G, Fuchs D, König P, Chamson E, Schüssler G (1999): Daily psychosocial stress interfere with the dynamics of urine neopterin in a patient with systemic lupus erythematosus: an integrative single-case study. Psychosom Med $\underline{61}, 876-882$

Schubert C, Lampe A, Rumpold G, Geser W, Noisternig B, Chamson E, Schatz D, König P, Fuchs D, Schüßler G (2001): Der Einfluß von Alltagsbelastungen und assoziierten Emotionen auf den dynamischen Verlauf von Cortisol und Neopterin bei Patientinnen mit systemischem Lupus Erythematodes: Ergebnisse aus zwei "integrativen Einzelfallstudien". Z Psychosom Med Psychother 47, 58-79.

Schubert H-J: Psychosoziale Faktoren bei Hauterkrankungen. 1.Auflage Verlag für medizinische Psychologie im Verlag Vandenhoeck \& Ruprecht, Göttingen 1989

Schulz K-H, Kugler J, Schedlowski M: Psychoneuroimmunologie - Ein interdisziplinäres Forschungsfeld. Hans Huber Verlag, Bern 1997

Schwarz W, Birau N, Hornstein OP, Heubeck B, Schönberger A, Meyer C, Gottschalk J (1988): Alterations of melatonin secretion in atopic eczema. Acta Derm Venereol $\underline{68}, 224-229$

Segre JA (2006): Epidermal barrier formation and recovery in skin disorders. J Clin Invest $\underline{116}, 1150-1158$

Seiffert K, Hilbert E, Schaechinger H, Zouboulis CC, Deter HC (2005): Psychophysiological reactivity under mental stress in atopic dermatitis. Dermatology 210, 286-293

Singh LK, Boucher W, Pang X, Letourneau R, Seretakis D, Green M, Theoharides TC (1999): Potent mast cell degranulation and vascular permeability trigered by urocortin through activation of corticotropin-releasing hormone receptors. J Pharmacol Exp Ther 288, 1349-1356 
Slominski A, Wortsman J, Luger T, Paus R, Solomon S (2000): Corticotropin releasing hormone and proopiomelanocortin involvement in cutaneus response to stress. Psychological Reviews $\underline{80}$, 979-1012

Slominski A, Pisarchik A, Semak I, Sweatman T, Wortsman J, Szczesniewski A, Slugocki G, Mgnulty J, Kauser S, Tobin D (2002): Serotoninergic and melatoninergic systems are fully expressed in human skin. The FASEB Journal 16, 896-899

Smedes F, Kraak JC, Poppe H (1982): Simple and fast solvent extraction system for selective and quantitative isolation of adrenaline, noradrenaline and dopamine from plasma and urine. J Chromatogr 231, 25-39.

Sommer G, Fydrich T : F-SOZU, Fragebogen zur sozialen Unterstützung. Hofgrefe, Göttingen 1989

Sonkoly E, Muller A, Lauerma Al, Pivarcsi A, Soto H, Kemeny L, Alenius H, Dieu-Nosjean MC, Meller S, Rieker J (2006): IL-31: a new link between T cells and pruritus in atopic skin inflammation. J Allergy Clin Immunol 117, 411-417

Ständer S, Steinhoff M (2002): Pathophysiology of pruritus in atopic dermatitis: an overview. Exp Dermatol 11, 12-24

Stangier U, Ehlers A, Gieler U: Fragebogen zur Bewältigung von Hautkrankheiten (FBH). Handanweisung. Hofgrefe, Göttingen 1996

Staughton R (2001): Psychologic approach to atopic skin disease.

J Am Acad Dermatol 노, 53-54

Sugiura H, Ebise H, Tazawa T, Tanaka K, Sugiura Y, Uehara M, Kikuchi K, Kimura T (2005): Large-scale DNA microarray analysis of atopic skin lesions shows overexpression of an epidermal differentiation gene cluster in alternative pathway and lack of protective gene expression in cornified envelope.

Br J Dermatol 152, 146-149 
Szentivanyi MD (1968): The betaadrenergic theory of the atopic abnormality in bronchial asthma. In: Schulz KH, Kugler J, Schedlowski M (Hrsg.). Psychoneuroimmunolgie: ein interdisziplinäres Forschungsfeld. Hans Huber Verlag, Bern 1997, 319

Tausk F, Nousari H (2001): Stress and the Skin. Arch Dermatol 137, 78-81

Theoharides TC, Cochrane DE (2004): Critical role of mast cells in inflammatory diseases and the effect of acute stress. J Neuroimmunol $\underline{146}, 1-12$

Theoharides TC, Singh LK, Boucher W, Pang X, Letourneau R, Webster E, Chrousos G (1998): Corticotropin-realising hormone induces skin mast cell degranulation and increased vascular permeability, a possible explanation for its proinflammatory effects. Endocrinology 139, 403-413

Thepen T, Langeveld-Wildschut EG, Bihari IC, van Wichen DF, van Reijsen FC, Mudde GC, Bruijnzeel-Koomen CA (1996): Biphasic response against aeroallergen in atopic dermatitis showing a switch from initial $\mathrm{TH} 2$ response to $\mathrm{TH} 1$ response in situ: an immunocytochemical study.

J Allergy Clin Immunol $\underline{97}$, 828-837

Tovoda M, Nakamura M, Makino T, Hino T, Kagoura M, Morohashi M (2002): Nerve growth factor and substance $P$ are useful plasma markers of disease activity in atopic dermatitis. $\mathrm{Br} \mathrm{J}$ Dermatol $\underline{147}, 71-79$

Uehara M, Kimura C (1993): Descendant family history of atopic dermatitis. Acta Derm Venereol $\underline{73}, 62-63$

von Uexküll T: Psychosomatische Medizin, 5. Auflage; Hrsg. Adler RH, Hermann JM et al.; Urban Schwarzenberg, München. 1996 
Valenta R, Seiberler S, Natter S, Mahler V, Mossabeb R, Ring J, Stingl G (2000): Autoallergy: A pathogenic factor in atopic dermatitis?

J Allergy Clin Immunol $\underline{105}$, 432-437

Vanecek J (1998): Cellular mechanisms of melatonin action.

Physiol Rev $\underline{78}$, 687-721

Warschburger P, Petermann F (1996): Verhaltensmedizinische Interventionen bei atopischer Dermatitis: Ein Überblick. Verhaltensther $\underline{6}, 76-86$.

Weisshaar E, Gieler U (2002): Bericht über den "International workshop for the study of itch" in Singapur vom 5.-7.10.2001. Hautarzt $\underline{53}$, 645-646

Werfel T, Kapp A (1999): What do we know about the etiopathology of the intrinsic type of atopic dermatitis? Curr Probl Dermatol $\underline{28}, 29-36$

Werner S, Buser K, Kapp A, Werfel T (2002): The incidence of atopic dermatitis in school entrants is associated with individual life-style factors but not with local enviromental factors in Hannover, Germany. Br J Dermatol 147, 95-104

Williams HC, Burney PGJ, Hay RJ (1994a): The U.K. Working Party`s diagnostic criteria for atopic dermatitis, I: derivation of a minimum set of discriminators for atopic dermatitis. Br J Dermatol 131, 383-396

Williams HC, Burney PGJ, Strachan D, Hay RJ (1994b): The U.K. Working Party`s diagnostic criteria for atopic dermatitis, II: observer variation of clinical diagnosis and signs of atopic dermatitis. Br J Dermatol $\underline{131}, 397-405$

Williams HC, Burney PGJ, Pembroke AC, Hay RJ (1994c): The U.K. Working Party`s diagnostic criteria for atopic dermatitis, III: indipendent hospital validation. Br J Dermatol 131, 406-416 
Wilson DK, Kleiwer W, Teasly N, Plybon L, Sica DA (2002): Violence exposure, catecholamine excretion, and blood pressure nondipping status in african american male versus female adolescents. Psychosom Med 64, 906-915

Wollenberg A, Bieber T (2000): Atopic dermatitis: from the genes to skin lesions. Allergy $\underline{55}, 205-213$

Wüthrich B (1999): Clinical aspects, epidemiology, and prognosis of atopic dermatitis. Ann Allergy Asthma Immunol $\underline{83}$, 464-470

Wüthrich B, Schmid-Grendelmeier P (2003): The atopic eczema / dermatitissyndrome. Epidemiology, natural course, and immunology of the IgE-associated („Extrinsic“) and the nonallergic („Intrinsic") AEDS.

$\mathrm{J}$ Invest Allergol Clin Immunol 13, 1-5

Yosipovitch G (2003): "Pruritus". Curr Probl Dermatol 토, 135-164

Zutavern A, Hirsch T, Leupold W, Weiland S, Keil U, von Mutius E (2005): Atopic dermatitis, extrinsic atopic dermatitis and the hygiene hypothesis: results from a cross-sectional study. Clin Exp Allergy 35, 1301-1308 


\section{Danksagung}

Mein besonderer Dank gilt Herrn Prof. Dr. Hüther für die Überlassung des Dissertationsthemas sowie die gute Betreuung der Arbeit. Hervorzuheben sind seine stetige freundliche Hilfsbereitschaft sowie seine konstruktiven wertvollen Ratschläge und Ideen zur Durchführung dieser Arbeit.

Herrn Dr. Jürgen Pils danke ich für anregende Diskussionen und seine tatkräftige Unterstützung bei der Laboranalytik.

Ebenfalls bedanken möchte ich mich bei Frau U. Engelhardt und den anderen Mitarbeitern des neurobiologischen Labors für ihre Unterstützung und Zusammenarbeit.

Auch möchte ich der Paul G. Unna-Stiftung danken, deren finanzielle Unterstützung diese Arbeit überhaupt erst möglich gemacht hat. 


\section{Lebenslauf}

Am 4. Juli 1964 wurde ich als erstes Kind meiner Eltern, Erika Schmidt, geb. Bastian, und Götz Schmidt, in Hildesheim geboren.

Eingeschult wurde ich 1970 in Hildesheim. Meine Eltern zogen 1971 nach Borkum um, so dass ich dort weiter die Grundschule besuchte sowie danach von 1974 bis 1976 die Orientierungsstufe und im Anschluss von 1976-1980 die Realschule Borkum. Von 1980 bis 1983 besuchte ich das Ubbo-Emmius-Gymnasium in Leer/Ostfriesland und legte dort im Mai 1983 das Abitur ab.

Von Juni 1983 bis zum Beginn meines Biologiestudiums im Oktober 1985 war ich auf Borkum jeweils saisonal befristet erwerbstätig.

Von Oktober 1985 bis April 1989 studierte ich Biologie im Diplomstudiengang an der TU Braunschweig. Dann wechselte ich den Studienort und schloss das Biologiestudium im Oktober 1992 an der Carl von Ossietzky Universität zu Oldenburg ab. Von Oktober 1992 bis zum Beginn des Medizinstudiums arbeitete ich freiberuflich als Diplom-Biologe.

Im April 1995 begann ich dann das Studium der Humanmedizin an der GeorgAugust-Universität in Göttingen. Das Studium beendete ich mit dem Ablegen des dritten Staatsexamens im Oktober 2003.

Seit dem 1. Januar 2004 bin ich als Arzt im Evangelischen Krankenhaus in Oldenburg beschäftigt. Zunächst arbeitete ich als Arzt im Praktikum für sechs Monate in der Allgemein- und Bauchchirurgie unter der damaligen Leitung von Herrn Dr. Röhn. Zum 1. Juli 2004 wechselte ich dann in die Medizinische Klinik des Hauses, wo ich derzeit unter der Leitung von Herrn Dr. Schwarz-Eywill tätig bin.

Im Rahmen meiner Promotionsarbeit bin ich seit Februar 2000 unter der Betreuung von Herrn Prof. Dr. G. Hüther in der Abteilung für Psychiatrie und Psychotherapie im Zentrum Psychosoziale Medizin der Medizinischen Fakultät der GeorgAugust-Universität Göttingen tätig. 